This document was prepared in conjunction with work accomplished under Contract No. DE-AC09-96SR18500 with the U. S. Department of Energy.

\title{
DISCLAIMER
}

This report was prepared as an account of work sponsored by an agency of the United States Government. Neither the United States Government nor any agency thereof, nor any of their employees, nor any of their contractors, subcontractors or their employees, makes any warranty, express or implied, or assumes any legal liability or responsibility for the accuracy, completeness, or any third party's use or the results of such use of any information, apparatus, product, or process disclosed, or represents that its use would not infringe privately owned rights. Reference herein to any specific commercial product, process, or service by trade name, trademark, manufacturer, or otherwise, does not necessarily constitute or imply its endorsement, recommendation, or favoring by the United States Government or any agency thereof or its contractors or subcontractors. The views and opinions of authors expressed herein do not necessarily state or reflect those of the United States Government or any agency thereof. 


\section{MODULAR CAUSTIC SIDE SOLVENT EXTRACTION UNIT (MCU) GAMMA MONITORS SYSTEM FINAL REPORT}

by

VITO CASELLA

Westinghouse Savannah River Company

Savannah River Site

Aiken, South Carolina 29808

Additional Authors:

This paper was prepared in connection with work done under the above contract number with the U. S. Department of Energy. By acceptance of this paper, the publisher and/or recipient acknowledges the U. S. Government's right to retain a nonexclusive, royalty-free license in and to any copyright covering this paper, along with the right to reproduce and to authorize others to reproduce all or part of the copyrighted paper. 
WSRC-RP-2005-01902

Revision \#0

\section{MODULAR CAUSTIC SIDE SOLVENT EXTRACTION UNIT (MCU) GAMMA MONITORS SYSTEM FINAL REPORT}

Vito R. Casella, Timothy N. Riley, Frank S. Moore and Donald J. Pak

December 2005

Analytical Development

Savannah River National Laboratory

Aiken, SC 29808 


\section{DISCLAIMER}

This report was prepared by Westinghouse Savannah River Company (WSRC) for the United States Department of Energy under Contract No. DE-AC09-96SR18500 and is an account of work performed under that contract. Neither the United States Department of Energy, nor WSRC, nor any of their employees makes any warranty, expressed or implied, or assumes any legal liability or responsibility for the accuracy, completeness, or usefulness, of any information, apparatus, or product or process disclosed herein or represents that its use will not infringe privately owned rights. Reference herein to any specific commercial product, process, or service by trademark, name, manufacturer or otherwise does not necessarily constitute or imply endorsement, recommendation, or favoring of same by WSRC or by the United States Government or any agency thereof. The views and opinions of the authors expressed herein do not necessarily state or reflect those of the United States Government or any agency thereof.

\section{Printed in the United States of America \\ Prepared For U.S. Department of Energy}


WSRC-RP-2005-01902

Revision \#0

Key Words: gamma monitors, solvent extraction, waste disposal

Retention: permanent

\section{CAUSTIC SIDE SOLVENT EXTRACTION MONITOR SYSTEM FINAL REPORT}

Vito R. Casella, Timothy N. Riley, Frank S. Moore and Donald J. Pak

December 2005

Analytical Development

Savannah River National Laboratory

Aiken, SC 29808

Prepared for the U.S. Department of Energy Under Contract Number DEAC09-96SR18500

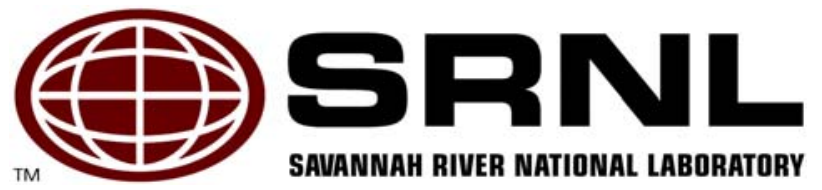


WSRC-RP-2005-01902

Revision \#0

REVIEWS AND APPROVALS

AUTHOR(S):

$\frac{\text { Wt R Canella }}{\text { V. R. Canella, Analytical Development Section, Lead Author }} \frac{12 / 8 / 05}{\text { Date }}$

TECHNICAL REVIEWERS:

\begin{tabular}{lr} 
Radefyer & $12 / 8 / 05$ \\
\hline R. A. Sign, Analytical Development Section & Date
\end{tabular}

Darrell tejalkes iz/8/05

D. D. Walker, Process Engineering Research

Date

APPROVER

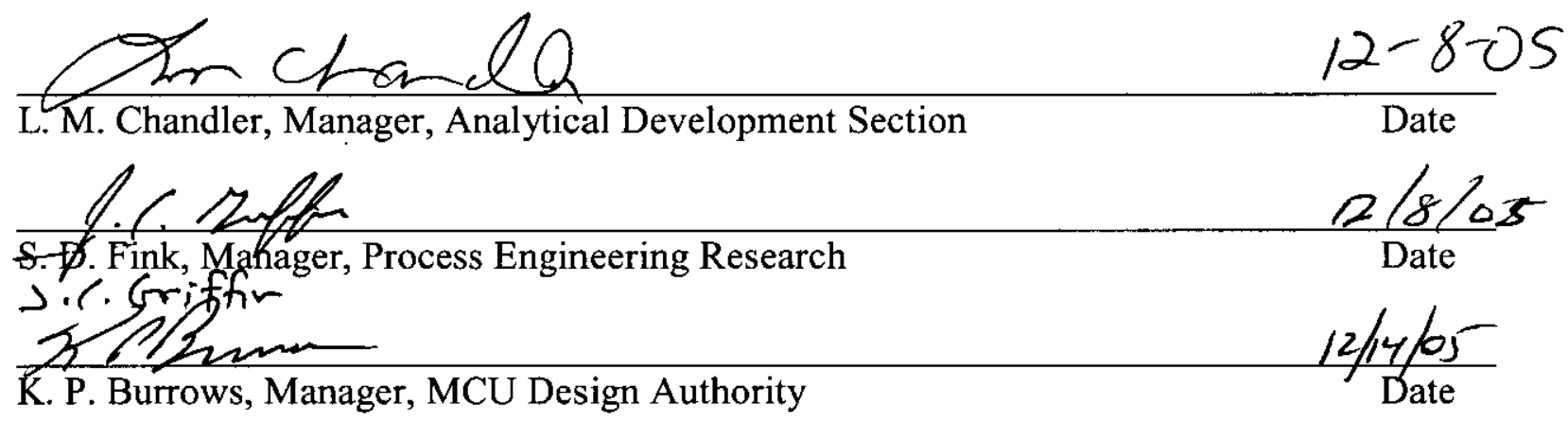




\section{EXECUTIVE SUMMARY}

The Department of Energy (DOE) selected Caustic-Side Solvent Extraction (CSSX) as the preferred technology for the removal of radioactive cesium from High-Level Waste (HLW) at the Savannah River Site (SRS). Before the full-scale Salt Waste Processing Facility (SWPF) becomes operational, the Closure Business Unit (CBU) plans to process a portion of dissolved saltcake waste through a Modular CSSX Unit (MCU).

This work was derived from Technical Task Request SP-TTR-2004-00013, "Gamma Monitor for MCU.” The deliverables for this task are the hardware and software for the gamma monitors and a report summarizing the testing and acceptance of this equipment for use in the MCU.

Gamma-ray monitors are required to:

- Measure the Cs-137 concentration in the decontaminated salt solution before entering the DSS (Decontaminated Salt Solution) Hold Tank,

- Measure the Cs-137 concentration in the strip effluent before entering the Strip Effluent Hold Tank,

- Verify proper operation of the solvent extraction system by verifying material balance within the process (The DSS Hold Tank Cs-137 concentration will be very low and the Cs-137 concentration in the Strip Effluent Hold Tank will be fifteen times higher than the Cs-137 concentration in the Feed Tank.)

Sodium iodide monitors are used to measure the Cs-137 concentration in the piping before the DSS Hold tank, while GM monitors are used for Cs-137 measurements before the Strip Effluent Hold Tank. Tungsten shields were designed using Monte Carlo calculations and fabricated to reduce the process background radiation at the detector positions. These monitors were calibrated with NIST traceable standards that were specially made to be the same as the piping being monitored.

Since this gamma ray monitoring system is unique, specially designed software was written and acceptance tested by Savannah River National Laboratory personnel. The software is a LabView-based application that serves as a unified interface for controlling the monitor hardware and communicating with the host Distributed Control System (DCS). In order to provide user friendly software for the process personnel, the software was broken down into just a few software modules. These software modules are the Application Window, Detector Selection, Detector Configuration Settings, Background Counting, and Routine Data Acquisition. Instructions for using the software have been included in a user's manual that is appended to this report.

The work presented in this report meets all of the requirements set forth in the project task plan to design and implement gamma ray monitors for the MCU. Additional setup and testing of the system will be required when it implemented in the process. 


\section{TABLE OF CONTENTS}

EXECUTIVE SUMMARY

LIST OF FIGURES

LIST OF TABLES

LIST OF ACRONYMS

1.0 INTRODUCTION AND BACKGROUND

2.0 APPROACH

2.1 Sodium lodide Monitors

2.1.1 Detector Description

2.1.2 Data Acquisition Electronics

2.1.3 Performance Checks

2.2 Geiger-Mueller Monitors

2.2.1 Detector Description

2.2 System Software 12

3.0 RESULTS

3.1 GM Shield Design

3.2 NaI Shield Design

3.3 Detector Installation

3.4 Hardware Description

3.5 MCU-GRM Software Description

3.5.1 Application Window

3.5.2 Detector Selection

3.5.3 Detector Configuration Settings 24

3.5.4 Routine Data Acquisition . . 26

3.5.5 Background Counting 27

3.6 Detector Efficiencies and Other Operation Parameters 30

3.6.1 NaI Detector Efficiencies 30

3.6.2 NaI Cable Length 31

3.6.3 GM Detector Efficiencies 31

3.6.4 GM Linear Detection Range 32

3.6.5 GM Detection Versus Angular Position 33

$\begin{array}{ll}\text { 3.6.6 GM Shielding Effect } & 34\end{array}$

4.0 CONCLUSIONS

5.0 REFERENCES

6.0 ACKNOWLEDGEMENTS 37

APPENDIX A. DESIGN DOCUMENT FOR MCU-GRM 39

APPENDIX B. SOFTWARE QUALITY ASSURANCE PLAN FOR MCU-GRM 54

APPENDIX C. SOFTWARE TEST PLAN FOR MCU-GRM 73

APPENDIX D. SOFTWARE USER'S MAUAL FOR MCU-GRM 92

APPENDIX E. CALIBRATION CERTICICATES FOR CS-137 STANDARDS 114 


\section{LIST OF FIGURES}

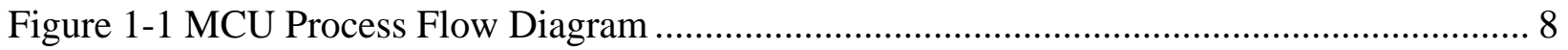

Figure 3-1 Dose Rate as a Function Of Distance Above Tank................................................ 13

Figure 3-2 Dose Rate Attenuation of Tungsten as a Function of Tungsten Thickness ................ 14

Figure 3-3 Tank Model Used for Dose Rate Calculations.................................................... 15

Figure 3-4 Model to Determine Dose Rate at $16.5 \mathrm{Ci} /$ Gallon .................................................. 16

Figure 3-5 Final GM Shield Design............................................................................... 16

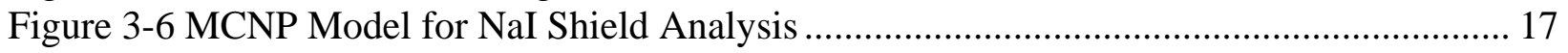

Figure 3-7 Typical NaI Spectrum Calculated by MCNP ....................................................... 18

Figure 3-8 Collimator Aperature Versus c/sec @ 0.1 Ci/gal................................................... 19

Figure 3-9 Final NaI Shield Design (top view, side view and with detector) ........................... 20

Figure 3-10 Detector Arrangement Within the Process........................................................ 21

Figure 3-11 MCU-GRM Electronics Rack ..................................................................... 21

Figure 3-12 MCU-GRM Hardware Block Diagram ........................................................... 22

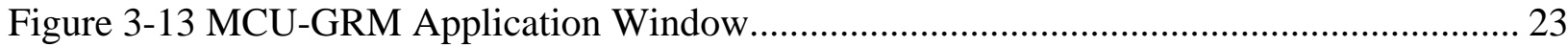

Figure 3-14 Detector Configuration Settings Password Screne .............................................. 24

Figure 3-15 Detector Configuration Screne.......................................................................... 25

Figure 3-16 Am Peak Channel Error State ..................................................................... 27

Figure 3-17 Start Background Count Screen ..................................................................... 28

Figure 3-18 Background Count Complete Screen ................................................................ 29

Figure 3-19 Spectrum from NaI Detector with Am-241 Pulser ............................................. 29

Figure 3-20 Detecor Calibration Standards ............................................................................ 31

Figure 3-21 SRS Cs-137 Gamma Source and Positioning System........................................... 32

Figure 3-22 Relationship of GM Detector Response Versus Activity Measured........................ 33

\section{LIST OF TABLES}

Table 3-1. Tank Distance Versus Dose Rate ......................................................................... 15

Table 3-2 Shielding Thickness Versus Dose Rate ................................................................. 16

Table 3-3 Collimator Aperature Versus C/Sec ....................................................................... 18

Table 3-4 Count Rate Versus Aperature .............................................................................. 20

Table 3-5 Calibration Results for the NaI Detectors SAM333 and SAM334 ............................ 30

Table 3-6 Determination of Cs-137 Efficiencies for the GM Detectors.................................. 32

Table 3-7 Detector Response Versus Measured Dose ........................................................... 32

Table 3-8 Angular Position Versus Detector Response...................................................... 34

Table 3.9 Evaluation of GM Shielding Versus Count Rate ...................................................... 34 


\section{LIST OF ACRONYMS}

\begin{tabular}{|c|c|}
\hline MCU-GRM & Modular Caustic Side Solvent Extraction Unit - Gamma Ray Monitor \\
\hline SRNL & Savannah River National Laboratory \\
\hline DCS & Distributed Control System \\
\hline NIM & Nuclear Instrumentation Module \\
\hline MCA & Multi-channel Analyzer \\
\hline GM & Geiger-Mueller \\
\hline $\mathrm{NaI}$ & Sodium Iodide \\
\hline FFB & Foundation Fieldbus \\
\hline MCNP & Monte Carlo N Particle \\
\hline DOE & Department of Energy \\
\hline CSSX & Caustic Side Solvent Extraction \\
\hline CBU & Closure Business Unit \\
\hline ARP & Actinide Removal Process \\
\hline WCP & Waste Compliance Plans \\
\hline WAC & Waste Acceptance Criteria \\
\hline DSS & Decontaminated Salt Solution \\
\hline SEHT & Strip Effluent Hold Tank \\
\hline DSSHT & DSS Hod Tank \\
\hline DWPF & Defense Waste Processing Facility \\
\hline NIST & National Institute of Standards Technology \\
\hline SRNL & Savannah River National Laboratory \\
\hline
\end{tabular}




\subsection{INTRODUCTION AND BACKGROUND}

The Department of Energy (DOE) selected Caustic-Side Solvent Extraction (CSSX) as the preferred technology for the removal of radioactive cesium from High-Level Waste (HLW) at the Savannah River Site (SRS). Before the full-scale Salt Waste Processing Facility (SWPF) becomes operational, the Closure Business Unit (CBU) plans to process a portion of dissolved saltcake waste through a Modular CSSX Unit (MCU).

The MCU provides cesium removal for the clarified salt solution after the Actinide Removal Process (ARP). The MCU employs the CSSX process, a continuous process that uses a novel solvent to extract cesium from waste and concentrate it in dilute nitric acid. The MCU provides this function without impeding ARP operations. Since all Savannah River Site (SRS) inter-area and intra-area transfers are batch transfers, the MCU has product and receipt tanks sufficient to facilitate accepting and transferring solutions.

A larger-scale facility that also utilizes the CSSX process is scheduled to begin operations at a later date. At such time, the MCU will no longer be needed; therefore, the operating window for the MCU is two to three years. The MCU is scheduled to be ready for radiological operations by June 2007. The accelerated development/design schedule, combined with constraints placed on the facility, necessitate that Waste Compliance Plans (WCP) for downstream facilities rely on a combination of targeted sampling, instrumentation, and process knowledge.

Typically, once a facility completes a product batch, a sample is taken and the batch is held while the sample is transported for analysis. Once the sample results confirm the batch is within the Waste Acceptance Criteria (WAC) of the downstream facility, the product is transferred. The MCU does not have the capacity to wait for sample results while continuing to operate. The Waste Acceptance Strategy is to demonstrate compliance to downstream facility WACs prior to final design and development of WCPs.

The CSSX process, which is the basis for the MCU, removes cesium from alkaline salt solutions. Of primary concern is Cs-137 which makes the solution highly radioactive. A process flow diagram can be seen in Figure 1-1. Removal of cesium from the alkaline salt solution is accomplished by contacting an immiscible organic solvent with the waste, then separating the phases again using centrifugal contactors. The contactors are arranged in banks of multiple contactors.

The process is broken down into four sections; extraction, scrub, strip and wash. The extraction section is a bank of 7 contactors where the cesium is extracted from the alkaline waste into the solvent. Once the waste exits the extraction bank, it has been decontaminated of cesium. The waste is then considered Decontaminated Salt Solution (DSS).

The solvent flows to the scrub section next. This bank of 2 contactors neutralizes any alkaline carryover from the extraction section and returns any sodium or potassium to the aqueous waste feed stream. The aqueous phase for the scrub section is dilute nitric acid, which is combined with the waste feed of the extraction section as it exits the scrub section.

The solvent then flows to the strip section, which is another bank of 7 contactors. The strip section strips the solvent of the cesium and concentrates it in a very dilute nitric acid stream. The nitric 
acid stream exiting the strip section contains the cesium and is called strip effluent. Finally, with the cesium removed, the solvent flows to the wash section. The solvent is washed with caustic solution to prevent the buildup of unwanted organics in a bank of 2 contactors. Once the solvent exits the wash section, it is ready to be reused in the process.

Both the strip effluent and DSS are sent to decanters to remove any solvent carryover before being collected for transfer in the Strip Effluent Hold Tank (SEHT) and the DSS Hold Tank (DSSHT) respectively. The DSS is transferred to Tank 50, which is the feed tank to the Saltstone Production Facility (SPF) for solidification in grout. Streams destined for Tank 50 must meet the SPF WAC. The strip effluent in the SEHT is sent to the Defense Waste Processing Facility (DWPF) for vitrification.

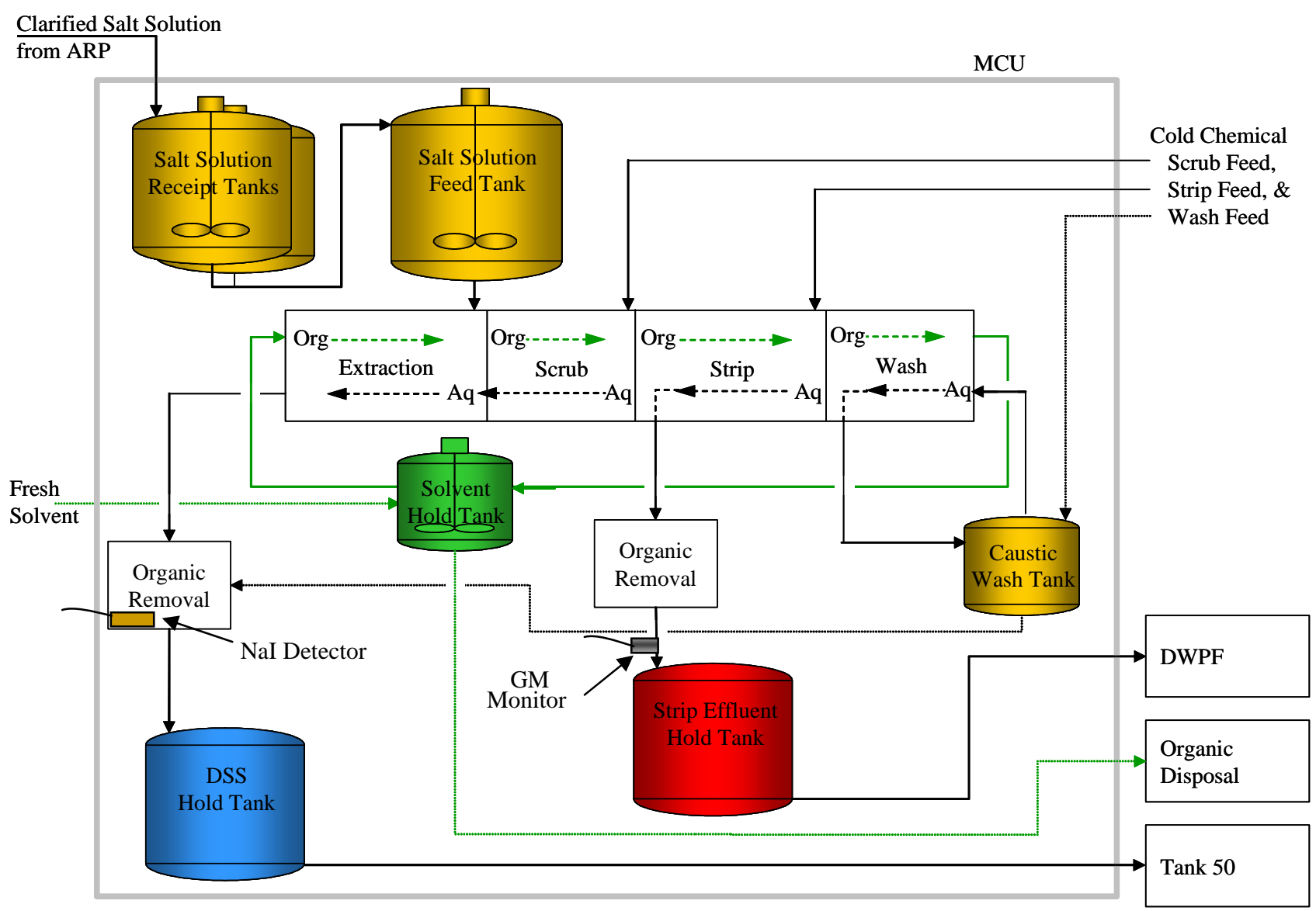

Figure 1-1: MCU Process flow diagram.

This work was derived from Technical Task Request SP-TTR-2004-00013, "Gamma Monitor for MCU." The deliverables for this task will be the hardware and software for the gamma monitors and a report summarizing the testing and acceptance of this equipment for use in the MCU.

Gamma-ray monitors are required to:

- Measure the Cs-137 concentration in the decontaminated salt solution before entering the DSS Hold Tank,

- Measure the Cs-137 concentration in the strip effluent before entering the Strip Effluent Hold Tank, 
- Verify proper operation of the solvent extraction system by verifying material balance within the process (The DSS Hold Tank Cs-137 concentration will be very low and the Cs137 concentration in the Strip Effluent Hold Tank will be fifteen times higher than the Cs137 concentration in the Feed Tank.)

The only observable gamma-ray for Cs-137 decay is from its short-lived Ba-137m daughter. Chemical processes, such as the CSSX, will disrupt the secular equilibrium between this parentdaughter pair since Ba- $137 \mathrm{~m}$ is not extracted by the solvent; meaning that, measurement of Ba$137 \mathrm{~m}$ will not necessarily yield information about Cs-137 content. While this is a complicating factor that can not be ignored, it is also controllable by either: 1) allowing sufficient time for equilibrium to be reestablished (about 25 minutes), or 2) by making multiple measurements with sufficient statistical precision to determine the extent of disequilibrium. For the CSSX process, there will be sufficient time after extraction and before Cs-137 measurements ( $>25$ minutes) such that Cs-137 / Ba-137m equilibrium will be reestablished.

The following monitor criteria are required:

- Accuracy of the NaI monitor will be $\pm 10 \%$ or better,

- Accuracy of the GM monitor will be $\pm 20 \%$ or better,

- Output signals from the monitors will be provided to the Distributed Control System,

- NaI monitor output will be used to control a diversion valve to divert flow for recycling in the event of a high reading (diversion valve and programming for diversion valve will not be provided by SRNL),

- Monitor shielding sufficient to reduce radiation backgrounds to the levels needed to meet measurement requirements,

- Monitor collimators having fields of view both to yield adequate gamma-ray flux at the detector and to control the signal rate to acceptable dead-time levels.

- Monitors must be able to measure cesium activities for the concentrations ranges given below.

Expected (best estimates) environmental conditions, concentration ranges and flow rates at the monitor locations are:

- Atmospheric pressure,

- Total integrated exposure of 1.5E08 Rad over 5 years for the process, but this is not the background level and this exposure may not apply to the monitors. The monitors must be in a relatively low radiation background area or proper shielding must be employed to ensure that the detectors can provide accurate measurements. The Cs-137 background level should be at least a factor of ten below the lowest Cs-137 concentration detected.

- Temperature range of 21 to 104 degrees Fahrenheit. (At temperatures below 45 degrees Fahrenheit, the electronics may not provide reliable results, and above 85 degrees Fahrenheit the useful life of the electronics is greatly shortened. Therefore, the preferred temperature range is 45 to 85 degrees Fahrenheit.)

- Relative humidity range of 5 to $100 \%$. (Electronic equipment is very sensitive to environmental conditions with high humidity, and this will adversely affect measurement capabilities. In general, if the non-condensing humidity gets above $80 \%$, there is an adverse effect on the electronics per the manufacturer's manual.)

- $\quad$ Cs-137 concentration ranges are: $\mathrm{MCU}$ feed $\leq 1.1 \mathrm{Ci} /$ gal; solvent $\leq 4.7 \mathrm{Ci} /$ gal; DSS $\leq 0.1$ $\mathrm{Ci} /$ gal; and strip effluent $\leq 16.5 \mathrm{Ci} / \mathrm{gal}$. (MCU design will achieve a minimum decontamination factor of 12 with a concentration factor of 15 . Therefore, the original feed Cs-137 concentration $(1.1 \mathrm{Ci} / \mathrm{gal})$ will be reduced to less than $0.1 \mathrm{Ci} / \mathrm{gal}$.) 
WSRC-RP-2005-01902

Revision \#0

- DSS waste stream flow rate between DSS decanter and DSS hold tank is estimated to be 10 gpm.

- $\quad$ Strip effluent to Strip Effluent Hold Tank is estimated to be 0.5 gpm. 


\subsection{APPROACH}

Gamma-ray monitors will be provided at two MCU locations for the purpose of measuring Cs-137 and for monitoring normal transfers of radioactive materials. These include:

- Two sodium iodide spectrometers as the DSS monitor.

- Two Geiger-Mueller strip effluent monitors.

\subsection{Sodium Iodide Monitors}

\subsubsection{Detector Description}

A thallium-doped sodium iodide, $\mathrm{NaI}(\mathrm{Tl})$, gamma-ray spectrometer will provide quantitative Cs137 concentration data. In the event that the system fails, spare parts will be available per project needs. A redundant detector will be able to provide equivalent data. In this case, when one of the two detectors is operational, the other will operate in a flow-through mode. Results from either detector can be obtained by designating through the software which detector is being used. The two $\mathrm{NaI}$ systems are automated to switch data-acquisition modes (isolated or flow-through) in order to detect any changes in monitor performance between check-source performance validations.

Tests at Savannah River National Laboratory (SRNL) showed that short-duration counts provide the anticipated required detection limits using a 1 inch by 1 inch $\mathrm{NaI}(\mathrm{Tl})$ detector viewing a few milliliters of effluent. The detector and its preamplifier are contained in a hermetically sealed chamber. The detector housing is a 1.2-inch diameter by 1-inch long steel pipe, containing the detector, which is connected to a 2.3 inch diameter by 10 inch long steel pipe containing the photomultiplier tube (PMT) /preamplifier assembly.

The shield provides a collimated beam from the piping to impinge on the side of the detector so that the photomultiplier tube is not directly exposed to the beam. To assure that the detector signal is representative of the sample rather than other MCU components, the detector and PMT are shielded to reduce the background from materials other than sample to less than $0.5 \mathrm{mrem} / \mathrm{hour}$. This background requirement applies during normal operations.

The detector assembly must be removable from the process system in order to permit maintenance or replacement, if necessary. The shield assembly allows precise repositioning of the detector relative to the collimator and the piping in order to maintain calibration. The detector should only view a vertical section of the piping and flush lines (containing no radioactivity), and the region of pipe being assayed must always be filled (no void volume).

\subsubsection{Data Acquisition Electronics}

Personal-computer-based data-acquisition electronics must be located nearby (within 150 feet to the detectors). Electronics for the $\mathrm{NaI}(\mathrm{Tl})$ detectors include high voltage bias supplies, amplifiers and multichannel analyzers. Photopeak areas and continuum backgrounds are analyzed using the PC. The analyses will apply calibration data that will be determined using traceable standards. Photopeak areas are also corrected for photopeak background data that will be acquired.

Note that the detector dimensions assume that preamplifier power, high voltage bias and analog signal cables can be run from the detector positions to the data-acquisition electronics. 


\subsubsection{Performance Checks}

Backgrounds and low-level check source measurements can be obtained by isolating the piping at the monitors and flushing with water.

Therefore, the piping containing the detector must include a capability for occasional flushing with a nonradioactive solution. After flushing, the nonradioactive solution must be held statically in the loop while detector background data are acquired. This test is needed to measure and compensate for any changes in full-energy peak backgrounds that may result, for example, from accumulation of cesium on piping. Solid deposits or radionuclides that have plated on the pipe walls are not removed by this occasional flushing operation.

\subsection{Geiger-Mueller Monitors}

\subsubsection{Detector Description}

The Geiger-Mueller monitor measures the gross count rate per the radiation field. This count rate can then be converted to Cs-137 activity in curies per gallon. Shielding is also necessary because of its proximity to radiation sources other than the piping being measured. It is calibrated and tested with a standard pipe source.

Before the Strip Effluent Hold Tank, a high range Geiger-Mueller (GM) tube is used to measure the Ba-137m (in equilibrium with Cs-137) in the piping.

\subsubsection{Data Acquisition Electronics}

GM Tube signals will be used to generate Transistor-Transistor-Logic (TTL) pulses that will be summed in PC-based counter-scalers. Each of the GM tubes is 1 inch diameter by 3.5 inch long with a 0.65 inch overall length electrical connector on it.

\subsubsection{Performance Checks}

GM tubes are adequate at each of these strip effluent monitoring points. The GM tubes must be 1) installed such that exposure from other process components is less than $100 \mathrm{mrem} / \mathrm{hr}, 2$ ) removable to allow maintenance if needed, 3) view a vertical or horizontal section of full pipe, and 4) provide the ability to flush the line to re-evaluate pipe background levels. The tube viewing the strip effluent line must be mounted to allow precise repositioning of the sensor. The detector shields have a cavity area for insertion of a check source.

\subsection{System Software}

Software, meeting WSRC E7 Manual requirements, has been written to process the instrument output and obtain the Cs-137 concentrations. Background radiation must be subtracted from the results, and calibration data are used to derive the reported Cs-137 concentrations.

Software has been developed to provide real-time concurrent data from multiple gamma-ray spectrometers and from multiple gross gamma counters. The software will:

- Account for the specific models of multichannel analyzers,

- Provide calibration capabilities,

- Provide background measurement and subtraction,

- Provide graphical (strip-chart) representation of data with time. 


\section{RESULTS}

\subsection{GM Shield Design}

A GM (Geiger-Muller) detector gives a pulse for each gamma photon interacting within the sensitive volume of the detector. There is no energy information in the output of the detector and therefore the calibration is simply the total count rate as a function of the gamma field seen by the detector.

The gamma field seen by the GM detector is composed of two parts, the general background in the area in which the detector is located, and the field from the pipe which it is intended to measure. Shielding must be supplied to ensure that the detector sees the gamma rays coming from the pipe, not those from the area background. When the analyses were performed, it was not known where the detector would be located, other than somewhere on the inlet pipe to the strip effluent hold tank. The strip effluent hold tank can have a solution with up to $16.5 \mathrm{Ci} /$ gallon Cs-137. Therefore analyses were obtained with this worst case scenario. For this case the dose rate as a function of distance above the tank is given in Figure 3-1.

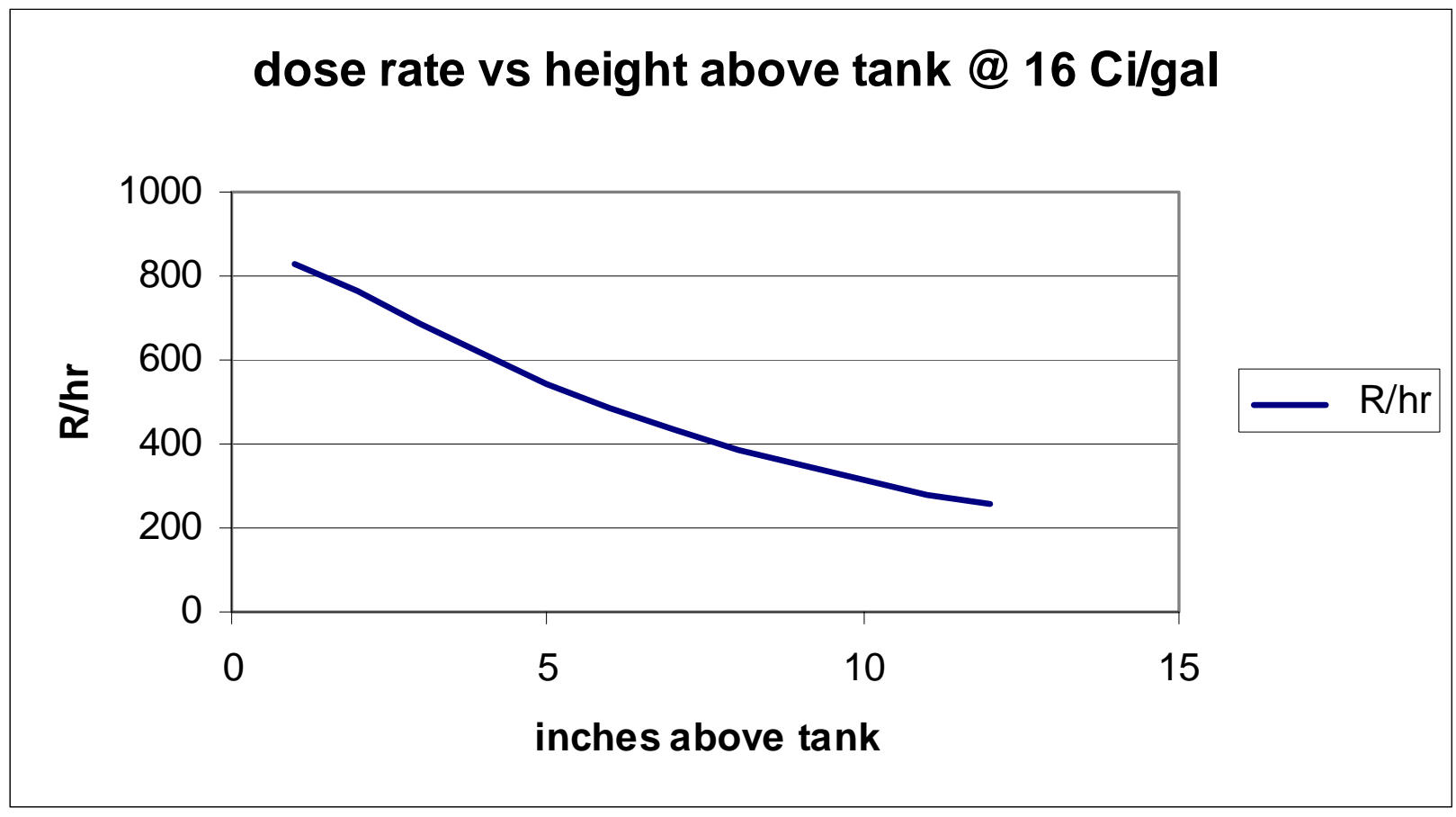

Figure 3-1. Dose rate as function of distance above tank.

Analyses of the dose rate from the pipe were performed. Assuming the pipe to be 1 " schedule 40 pipe, at the same $16 \mathrm{Ci} /$ gallon concentration, the dose rate at the detector was calculated to be less than $6 \mathrm{R} / \mathrm{hr}$. The contribution from the pipe would be completely masked by the much larger dose rate from the tank. Hence shielding must be supplied to reduce the contribution from the tank.

One must assume a dose rate to calculate the amount of shielding necessary. Therefore, it was assumed that the detector would be 12 inches above the top of the tank, at which point the 16.5 $\mathrm{Ci} /$ gallon dose rate was computed to be $256 \mathrm{R} / \mathrm{hr}$. Shields of both lead and tungsten were studied. 
Lead is less expensive to purchase than tungsten, however it is a hazardous material. This makes fabrication more difficult and means that eventual disposition is expensive, especially if it should become contaminated. Also, lead, being a soft material, is difficult to machine and drill and tap, adding to the cost of fabrication. Tungsten is approximately $20 \%$ more efficient as a shield than lead. Therefore a tungsten shield is somewhat smaller for the same attenuation. Tungsten is not a hazardous material and, when purchased in the machinable form, machines essentially like stainless steel, thus simplifying fabrication. Therefore, even though it is more expensive to purchase, the total cost over the life of the project is similar or lower. For these reasons tungsten was selected. Figure 3-2 shows the dose rate attenuation of tungsten as a function of the thickness of tungsten. An unattenuated dose rate of $250 \mathrm{R} / \mathrm{hr}$, corresponding to an elevation of 12 inches above the tank was used.

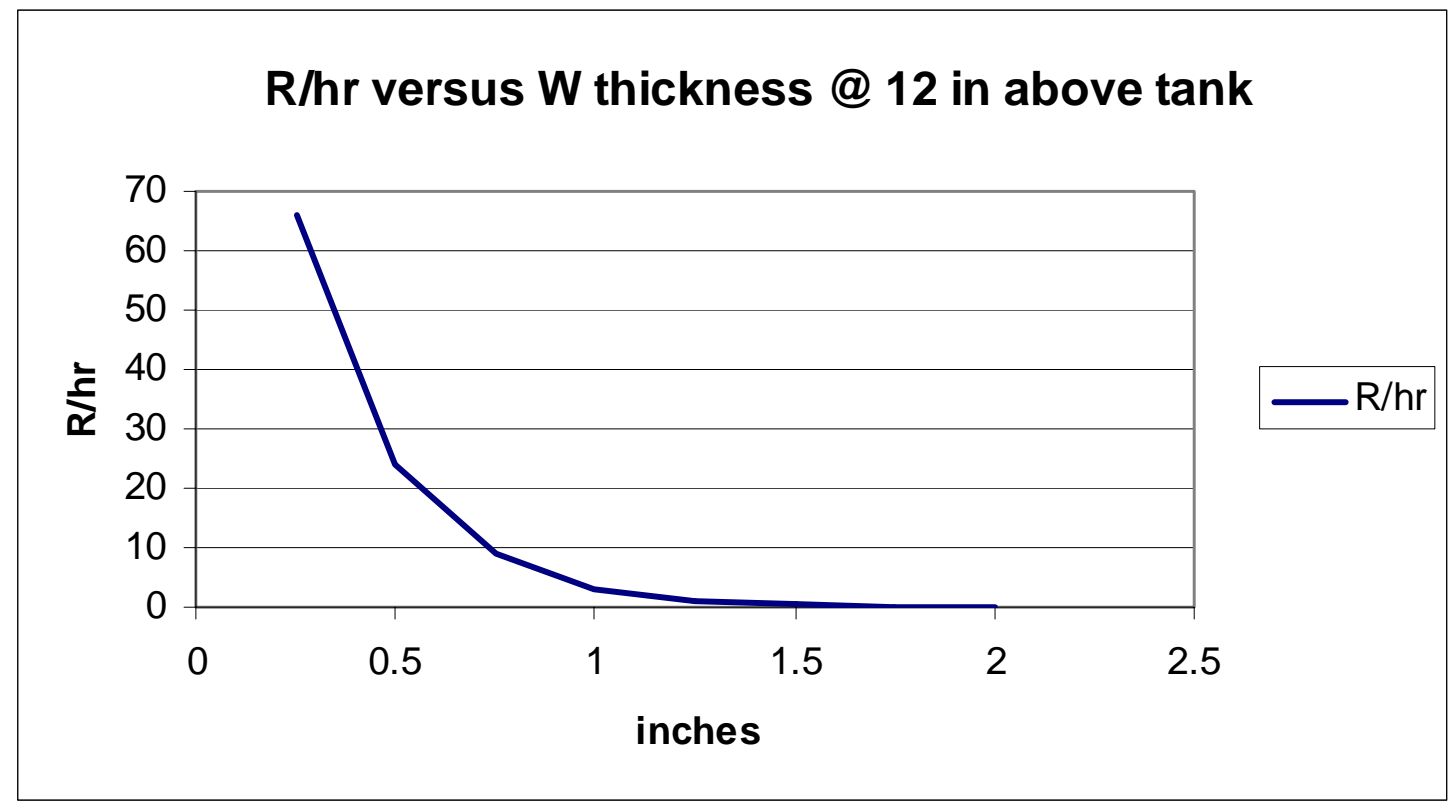

Figure 3-2. Dose rate attenuation of tungsten as a function of tungsten thickness.

A Ludlum model 133-6 GM detector was chosen for this application. This detector has a linear range of from $4 \mathrm{mR} / \mathrm{hr}$ to $6 \mathrm{R} / \mathrm{hr}$ with no deadtime correction. The maximum dose rate at 16.5 $\mathrm{Ci} /$ gallon is expected to be less than $6 \mathrm{R} / \mathrm{hr}$, so there is sufficient overrange to allow for any contingency. The nominal detector size is 1 ” in diameter by 4 ” long.

The shield is a cylinder, 3-in diameter by 6.25 inch long. One inch of tungsten surrounds the GM tube on all sides to allow maximum flexibility in locating the detector. One side is flattened to permit attaching the pipe clamp to hold it in place. Since the actual detector position varies within the housing, there is a 3-in long slot in this side to permit the detector to view the pipe. There is also one inch of tungsten shielding the top of the detector and tungsten shielding with a clamp attached that holds the electrical feed on the bottom of the detector in place. The bottom of the shield assembly with the electrical feed should be positioned away from the most intense radiation source.

The GM detector will be located on the inlet pipe to the Strip Effluent Hold Tank, where the Cs-137 concentration may be as great as $16.5 \mathrm{Ci} /$ gallon. Analyses using the shielding code Microshield 5.0 have been made to estimate dose rates and resulting shielding requirements. For this purpose, the tank was assumed to be 2 feet in diameter and 1 foot tall. The top of the tank was assumed to be 
0.25-inch thick steel. The dose rate at various distances above the top of the tank from one inch to twelve inches was computed using the model shown in Figure 3-3. The red dot in Figure 3-3 represents the distance above the tank.

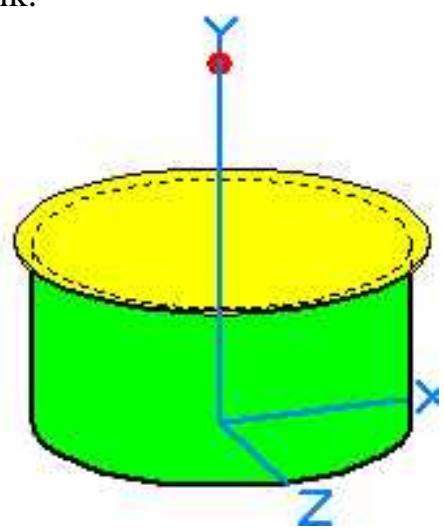

Figure 3-3 Tank model used for dose rate calculations.

The results are given in Table 3-1. These results show that when the tank is filled with 16.5 $\mathrm{Ci} /$ gallon Cs-137 solution, the dose rates will vary from $256 \mathrm{R} / \mathrm{hr} 12$ inches above the tank to more than $800 \mathrm{R} / \mathrm{hr}$ at one inch above the tank top.

$\begin{array}{cc}\begin{array}{c}\text { Table 3-1 Tank distance versus dose rate } \\ \text { Distance above tank } \\ \text { inches }\end{array} & \begin{array}{c}\text { Dose rate } \\ \text { R/hr }\end{array} \\ 1 & 829 \\ 2 & 763 \\ 3 & 687 \\ 4 & 614 \\ 5 & 546 \\ 6 & 487 \\ 7 & 434 \\ 8 & 388 \\ 9 & 348 \\ 10 & 313 \\ 11 & 282 \\ 12 & 256\end{array}$

Therefore, the dose rate to the GM detector will depend upon how close it is to the tank. The gamma dose rate to a GM detector attached to the pipe, with the pipe containing $16 \mathrm{Ci} /$ gallon of Cs137 was obtained using the model in Figure 3-4. The red dot in Figures 3-4 represents the average distance of the material in the process piping. 


\section{Figure 3-4. Model to determine dose rate at $16.5 \mathrm{Ci} /$ gallon.}

The analysis gave a dose rate at $16.5 \mathrm{Ci} /$ gallon of $68 \mathrm{R} / \mathrm{hr}$.

This demonstrates that the dose rate from the pipe (68 R/hr) will be completely masked by the dose rate from the tank (256 R/hr at 12 inches elevation above the tank) unless shielding is supplied. Calculations were made using tungsten and lead as the shielding material. For the purpose of the analyses, the GM detector was assumed to be 12 inches above the tank top. The results are shown in Table 3-2.

$\begin{array}{ccc}\begin{array}{c}\text { Table 3-2 Shielding thickness versus do } \\ \text { thickness }\end{array} & \text { shielding } & \text { shielding } \\ \text { inches } & \mathrm{Pb} \mathrm{R} / \mathrm{hr} & \mathrm{W} \mathrm{R} / \mathrm{hr} \\ 0.25 & 79 & 66 \\ 0.5 & 38 & 24 \\ 0.75 & 17 & 9 \\ 1 & 8 & 3 \\ 1.25 & 4 & 1 \\ 1.5 & 2 & 0.4 \\ 1.75 & 0.9 & 0.15 \\ 2 & 0.4 & 0.05\end{array}$

In this case, the shielding required to reduce the gamma dose rate to the GM tube would be one inch of Tungsten or 1.25 inches of lead. As previously discussed, since lead is a hazardous material and more difficult to machine, tungsten was used.

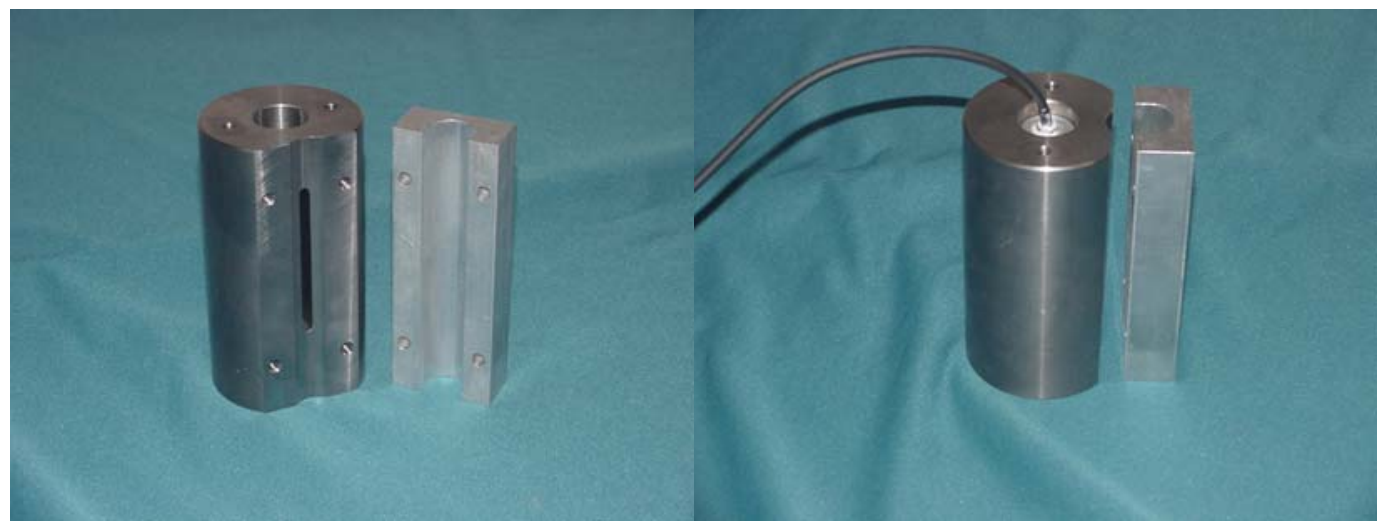

Figure 3-5. Final GM shield design. 
The final GM shield design is shown in Figure 3-5. It is nominally one-inch thick tungsten with a 3-inch long collimator. This length of the collimator provides insurance that the detector will be exposed to the Cs-137 gamma rays, regardless of where the actual detector is located within the four-inch casing.

\subsection{NaI Shield Design}

The Monte Carlo N Particle (MCNP) model for the NaI shield analyses is shown in Figure 3-6. It is a cutaway of the shield design showing the tungsten portion in white, the NaI detector in red, and air or vacuum areas in green. The 1" schedule 40 pipe and the liquid inside it may also be seen, the pipe in black and the liquid in blue. The green volume between the pipe and the NaI detector is the air filled collimator.
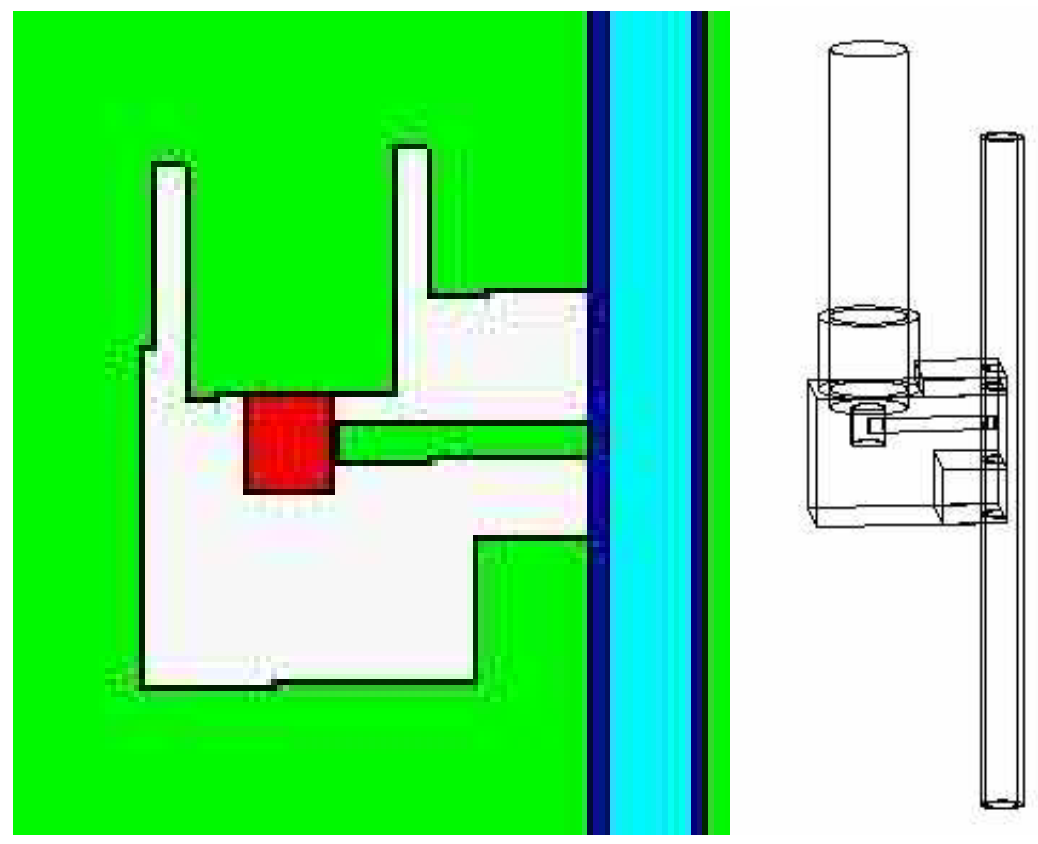

Figure 3-6 MCNP model for the NaI shield analyses.

A series of MCNP calculations were made, with a $0.1 \mathrm{Ci} /$ gallon source in the pipe interior (blue). To optimize the size of the collimator aperture, the source was centered on the hole and extended 1" above and below the center of the collimator. MCNP calculations were made for collimator diameters of $3 / 8$ inch, $1 / 2$ inch, 5/8 inch and 3/4 inch keeping the Cs- 137 content of the pipe constant at $0.1 \mathrm{Ci} /$ gallon. A typical spectrum calculated by MCNP is shown in Figure 3-7. 
WSRC-RP-2005-01902

Revision \#0

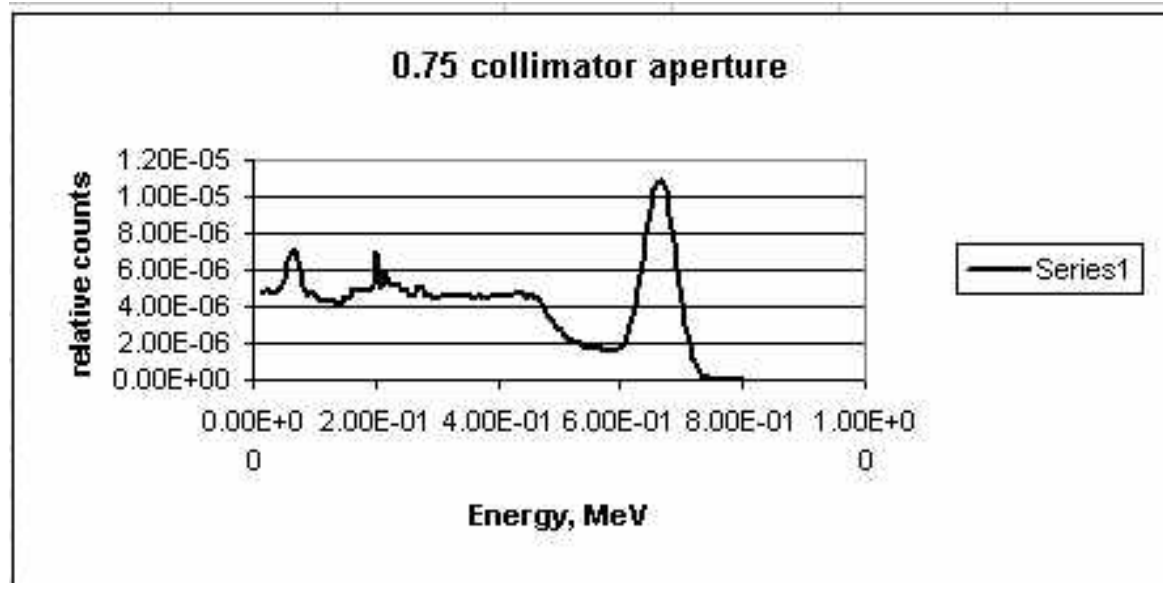

Figure 3-7 Typical NaI spectrum calculated by MCNP

In Figure 3-7, the region between 0.6 and $0.7 \mathrm{MeV}$ is the Cesium photopeak. This region is be counted for the measurement. The region below $0.6 \mathrm{MeV}$ contains scattered gamma rays which have been detected by the NaI crystal. They are not counted to determine the Cs concentration, but are important because they enter the detector and contribute to what is called the "dead time" of the counting system. Hence, to obtain accurate results one must balance increasing the counts in the photopeak against increasing the total counts in the detector too much, producing excessive dead time. The results of this analysis, given in terms of estimated count rates, are given in Table 3-3 and graphically displayed in Figure 3-8.

Table 3-3 Collimator aperture (inches) versus c/sec

$\begin{array}{ccc}\begin{array}{c}\text { aperture } \\ \text { (inches) }\end{array} & \begin{array}{c}\text { photopeak } \\ (\mathrm{c} / \mathrm{s})\end{array} & \begin{array}{c}\text { total } \\ (\mathrm{c} / \mathrm{s})\end{array} \\ 0.375 & 2.67 \mathrm{E}+02 & 1.01 \mathrm{E}+03 \\ 0.5 & 7.40 \mathrm{E}+02 & 2.91 \mathrm{E}+03 \\ 0.625 & 1.54 \mathrm{E}+03 & 6.24 \mathrm{E}+03\end{array}$




\section{C/R vs collimator aperture}

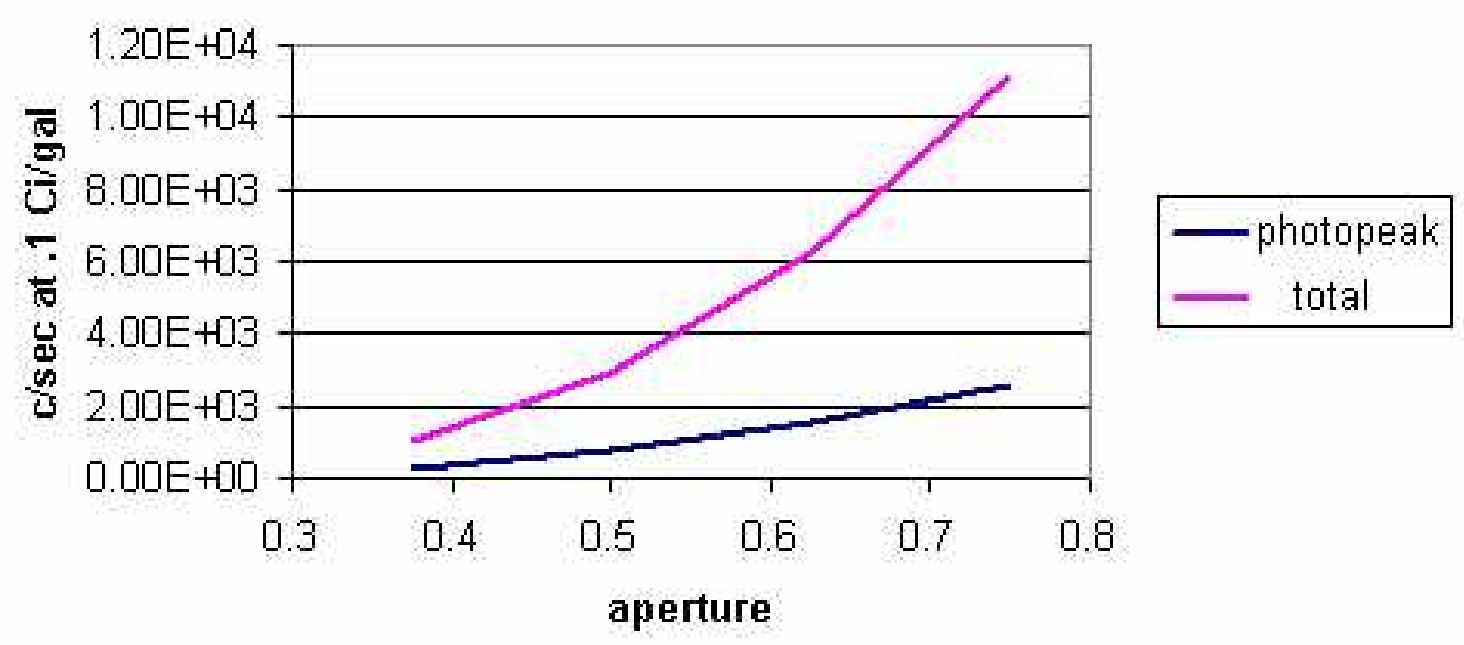

Figure 3-8 Collimator apertures versus c/sec @ 0.1 Ci/gal

It can be seen that as the collimator aperture increases, the total count rate increases faster than the photopeak count rate. The collimator diameter can be set at 0.625 inches or 0.311 inches, giving a photopeak count rates of $6,000 \mathrm{c} / \mathrm{s}$ or $400 \mathrm{c} / \mathrm{s}$ that provide a count rate range producing good counting statistics for the photopeak. The collimator diameter used for the process will give a photopeak with good counting statistics while having a dead time correction of less than $20 \%$. The Am pulser contained in the detector produces a dead time of about 6\%; therefore, dead time considerations must also be considered for collimator selection.

Once this had been done, MCNP analyses were run for two cases in which the source was above the shield, one two inches long and the other 6 inches long. In both cases the lower end of the source was level with the top of the shield. This was done to assess the effect of Cs-137 in the pipe above the shield on the count rate seen by the NaI detector. It is obvious from observation (and verified by calculations) that Cs-137 in piping below the detector will have no effect due to the thickness of the Tungsten shield. Count rates obtained from the above shield studies are given in Table 3.4 with the Table 3-3 data included. 
Table 3-4 Count rate versus aperature.

$\begin{array}{ccc}\text { Aperture (in) } & \text { Photopeak (c/s) } & \text { Total }(\mathrm{c} / \mathrm{s}) \\ 0.375 & 2.67 \mathrm{E}+02 & 1.01 \mathrm{E}+03 \\ 0.5 & 7.40 \mathrm{E}+02 & 2.91 \mathrm{E}+03 \\ 0.625 & 1.54 \mathrm{E}+03 & 6.24 \mathrm{E}+03 \\ 0.75 & 2.61 \mathrm{E}+03 & 1.11 \mathrm{E}+04 \\ 2 \text { in above } & 4.15 \mathrm{E}+01 & 5.11 \mathrm{E}+02 \\ 6 \text { in above } & 5.15 \mathrm{E}+02 & 2.98 \mathrm{E}+03\end{array}$

What can be seen from this Table 3-4 is that for the first two inches of pipe extending above the shield, the effects on the measurement are small. However, for the six inch case, for the chosen 5/8 inch aperture, the extraneous photopeak counts resulting from the pipe above the source would provide $1 / 3$ as many as those produced by the Cs- 137 gamma rays coming through the collimator.

Therefore, it is essential that the piping be bent away from the shield in the first two inches of piping above the shield.

The final shield design is shown in Figure 3-9. The shield is made of tungsten and has two apertures of either 0.313 -inch or 0.616 -inch diameter. A tungsten tube insert provides a means to change the aperture. A clamp, also made of tungsten, is used to hold the shield to the piping. This clamp has a cavity for insertion of a pipe calibration standard if desired.

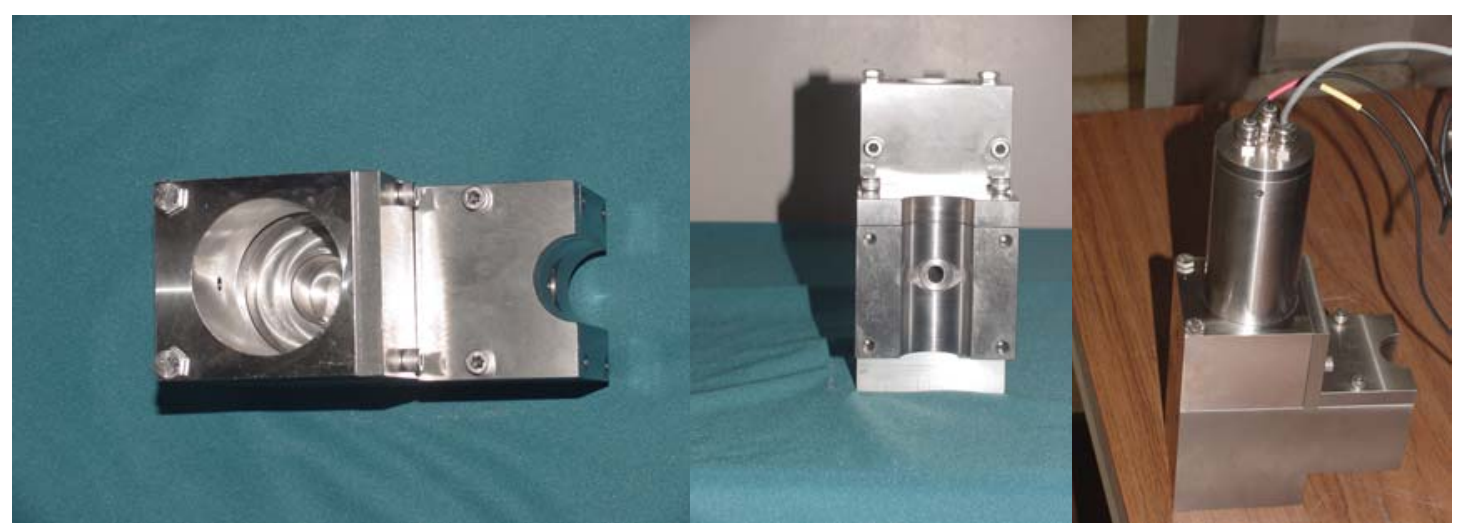

Figure 3-9 Final NaI shield design (top view, side view, and with detector).

\subsection{Detector Installation}

Figure 3-10 shows a detector arrangement within the process. The detectors will be positioned onto a trap of the process piping such that the pipe is full of liquid. A horizontal arrangement is shown but a vertical arrangement will probably be used since it would be better for detector replacement if needed. 


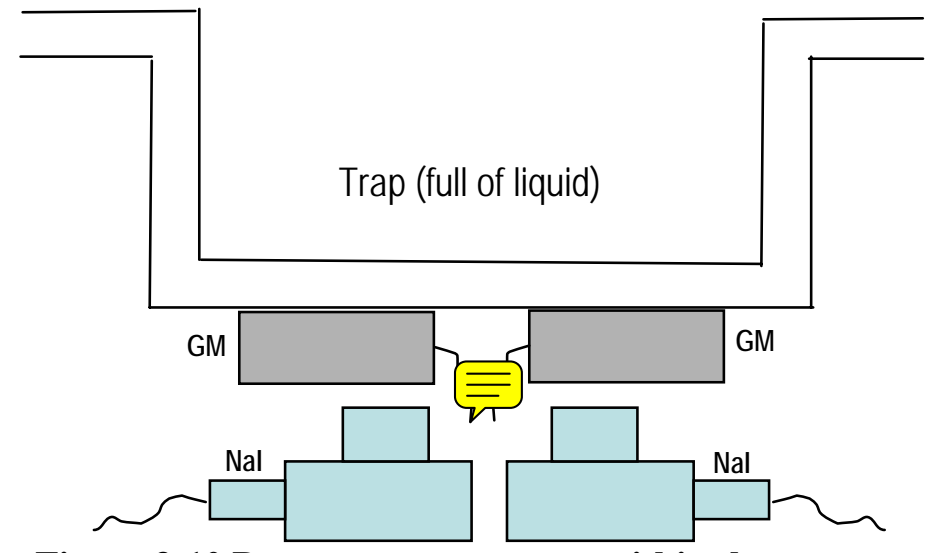

Figure 3-10 Detector arrangement within the process.

\subsection{Hardware Description}

The MCU-GRM hardware consists of two redundant systems. Each sodium iodide system consists of a detector (NaI) and photomultiplier tube, a spectroscopy amplifier, a high voltage power supply and a MCA card, while each GM system consists of a GM tube, a power supply and pulse conversion module, and a counter/scalar card. These detector systems electronics are mounted in a modular Nuclear Instrumentation Module (NIM) bin and power supply with a computer, keyboard, a Foundation Field Bus card, and the associated connection hardware. A materials and equipment listing for the MCU-GRM hardware is included in Appendix D - Software User's Manual for the MCU-GRM and the electronics rack is shown in Figure 3-11.

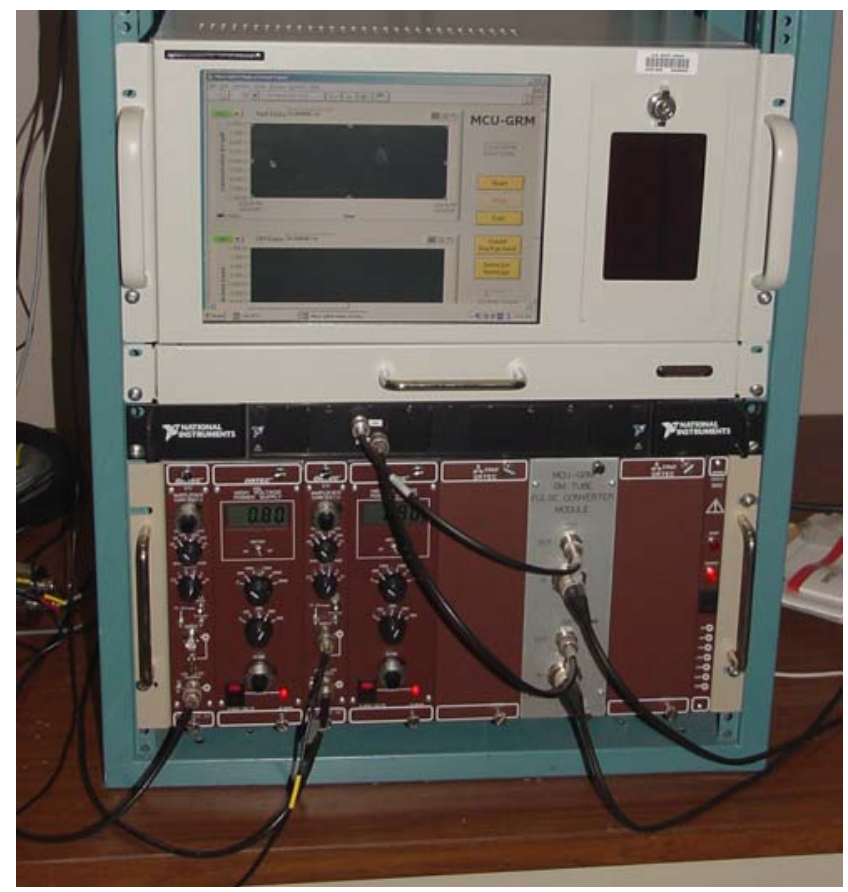

Figure 3-11 MCU-GRM Electronics Rack

Two NaI spectrometers (one online and one backup) are used for measuring the Cs-137 concentration in the decontaminated salt solution entering the DSS Hold Tank. High voltage and 
preamp power are provided to the detectors through Nuclear Instrumentation Module (NIM) based modular electronics. The amplified and scaled output signals from each detector are connected to an ORTEC Trump-PCI card located inside the MCU-GRM computer housing. The Trump-PCI card is a computer controlled Multi-Channel Analyzer (MCA) geared specifically towards nuclear spectroscopy applications.

Two GM tubes (one online and one backup) are used for measuring the Cs-137 concentration in the strip effluent before entering the Strip Effluent Hold Tank. These detectors are connected by a single coaxial cable to an Aware Electronics PMI30 instrument module. The Aware module is a self contained radiation detection system that provides detector High Voltage, as well as pulse scaling and amplification. The Aware modules are mounted inside a blank double width NIM module along with a custom circuit board designed to convert the Aware module pulse output to TTL compatible signal levels. This scaled output signal is applied to a National Instruments 6602 counter/scalar card for gross activity counting.

The two Trump-PCI cards and the NI 6602 counter card are installed in spare PCI slots in the MCUGRM computer, along with a National Instruments PCI-FBUS/2 Foundation FieldBus card which is required for communication between the MCU-GRM and the Distributed Control System (DCS). A block diagram of the MCU-GRM hardware is shown in Figure 3-12 below.

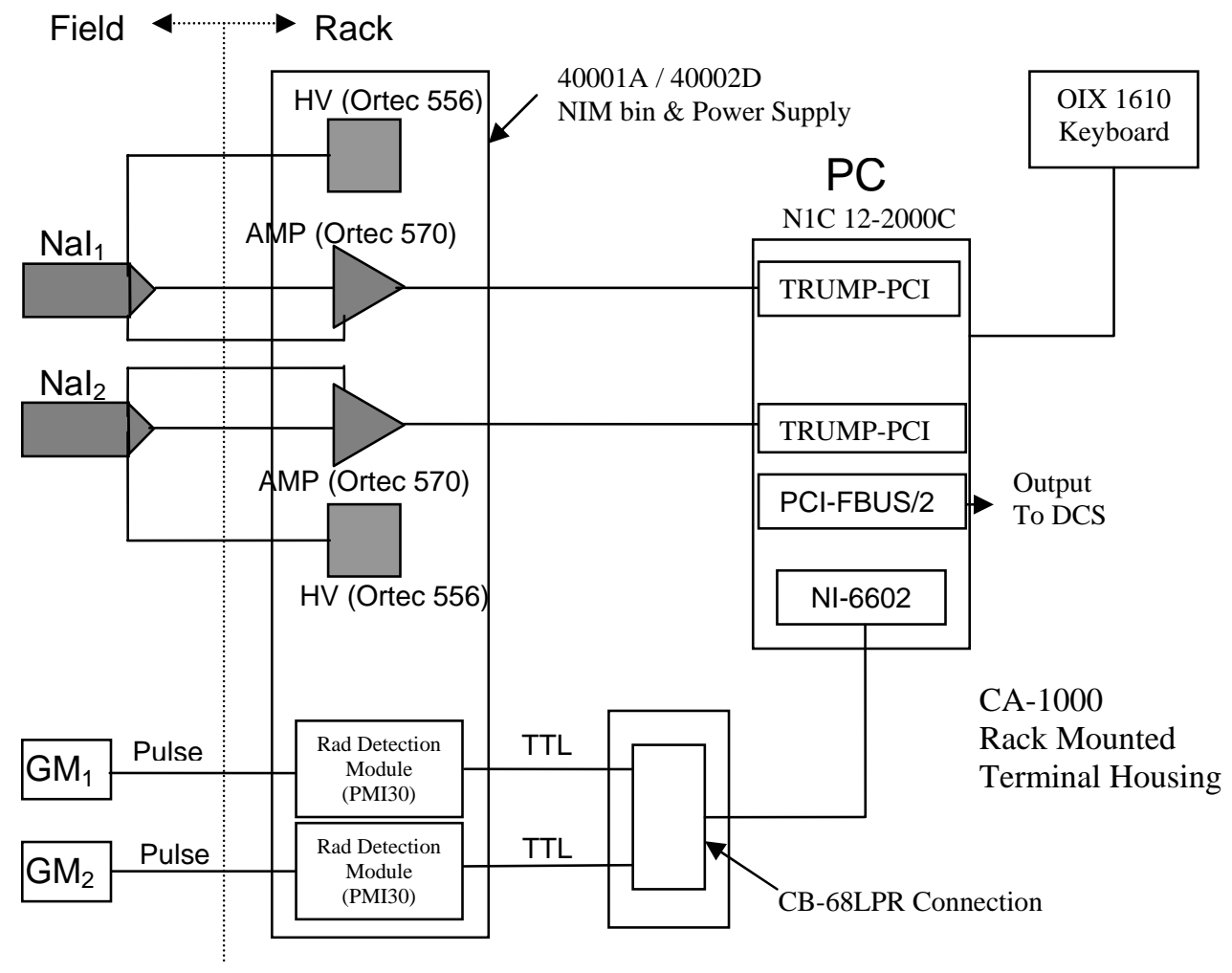

Figure 3-12 MCU-GRM Hardware Block Diagram 


\subsection{MCU-GRM Software Description}

The MCU-GRM production software is a LabView based application that serves as a unified interface for controlling the MCU-GRM hardware and communicating with the host Distribution Control System (DCS). These activities are accomplished through five basic software modules that are described in detail in J-DD-H-00001 "MCU-GRM Design Document for Software”. The MCUGRM software source code number is L814-J-002v Version 1.0.

From the User's point of view, the MCU-GRM software can be broken down into just a few software modules that will be described in this section. These software modules are the MCU-GRM Application Window, Detector Selection, Detector Configuration Settings, Background Counting, and Routine Data Acquisition.

\subsubsection{Application Window}

The major component of the MCU-GRM software is the application window, shown in Figure 3-13. Besides serving as the primary user interface, this window provides a means for selecting the appropriate $\mathrm{NaI}$ or GM detector, performing routine MCU-GRM measurement activities, performing a background measurement, or gaining access to the detector configuration settings screen. All actions associated with the MCU-GRM software originate from this screen. The system time is displayed in the upper right hand corner of the screen and is updated every second to indicate that the system is active.

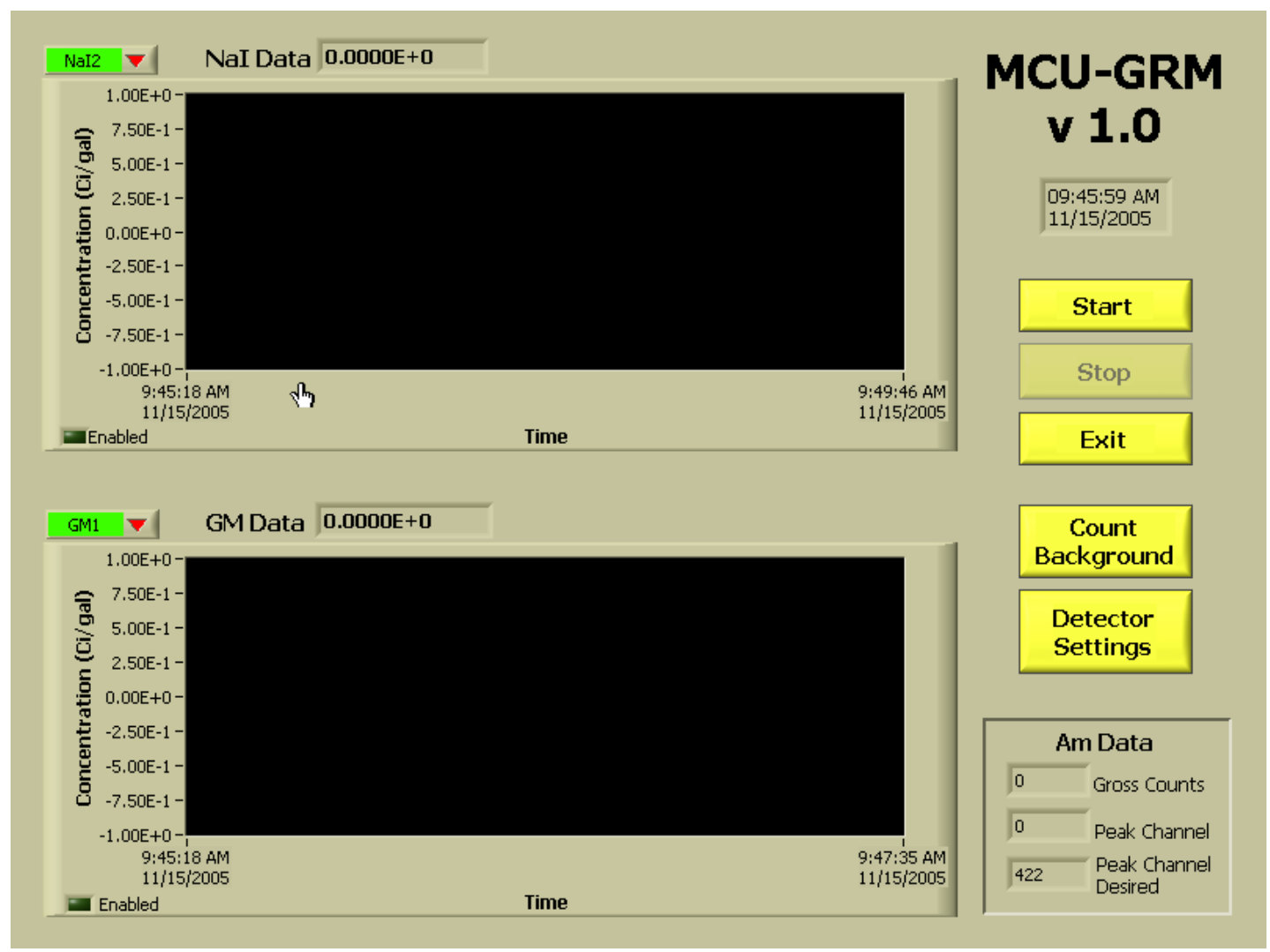

Figure 3-13 MCU-GRM Application Window

The most prominent features on the application window are the measurement history graphs. The two graphs display the 50 most recent data points collected during routine measurement activities. This serves as a visual reference of the measurement trend over the past 50 cycles. Additionally, the 
data display at the top center of each graph shows the most recently acquired data point for the selected detector.

\subsubsection{Detector Selection}

Selection of the desired NaI or GM detector is performed from the MCU-GRM Main screen, as shown in Figure 3-13, by clicking on the red arrow selector located beside both detector selection menus. This action brings up a pull-down menu from which the user can select the desired detector. Only one detector of each type may be selected at any given time. When NaI1 is on, NaI2 is off and vice versa. The same rules apply to the GM detectors. The detector selection function is disabled if either the MCU-GRM routine data collection or background counting options have been started.

\subsubsection{Detector Configuration Settings}

As is the case with any gamma monitoring system, the user must know certain detector operating parameters such as the detector efficiency and measured background count in order to make compensations to the measured activity for variations in the detector internals and for the amount of activity entrained within the system. Without these values, accurate determination of the solution activity is impossible. The MCU-GRM stores these values in a configuration file (MCU_GRM_CONFIG.ini). The format of this file is shown in Appendix D - Software User's Manual for MCU-GRM.

The user is granted access to these parameters only through the detector configuration utility. The user can access this utility, by clicking the Detector Settings button on the MCU-GRM main screen (Figure 3-13). Because these values are crucial to the operation of the system and its ability to produce reliable output data, a password is required for access. The Password Utility Screen is shown in Figure 3-14.

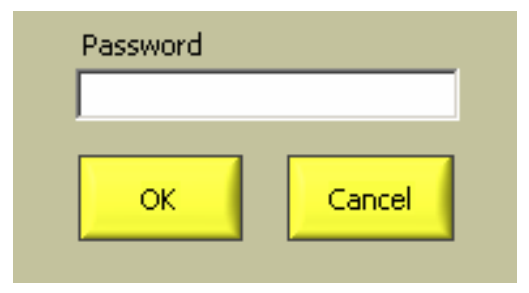

Figure 3-14 Detector Configuration Settings Password Screen

The password utility is case sensitive. Upon entering the correct password, the user will be able to access data on the Detector Configuration screen as illustrated in Figure 3-15. The user can change the password by changing the password character string in the password file. The filename is not included in this document. NOTE: The password will be changed by the User after the project turnover.

The Detector Configuration Screen is divided into 5 sections. Four identical sections, two for the $\mathrm{NaI}$ detectors and two for the GM detectors, are used for setting the detector operating parameters. This allows for independent parameter settings that are specific to each detector in the system. The single section at the bottom of the screen is used for setting the cycle times for routine data collection.

Within each of the detector sections, the user can set values for the detector Efficiency, measured Background, and Background Count Time. Changes can be made by either clicking the yellow up or down arrows next to each of the fields, or by typing a value directly into the text box. Each field 
performs automatic range checking on the entered data to allow only numerical entries within a predetermined range of values. The final range will be determined empirically when the system functional testing is performed.

If changes are made to either the detector Efficiency or measured Background settings, the associated Last Update fields are automatically imprinted with the current date. This is to help keep track of the last entries made for the critical detector operating parameters. Changes to the Last Update fields are done programmatically and are not accessible to the user. The user can select the Background Count Time for each detector. Optimal values will be determined empirically during system functional testing. Once changed, the new values are stored in the configuration file (MCU_GRM_CONFIG.ini) and are used for all future computations.
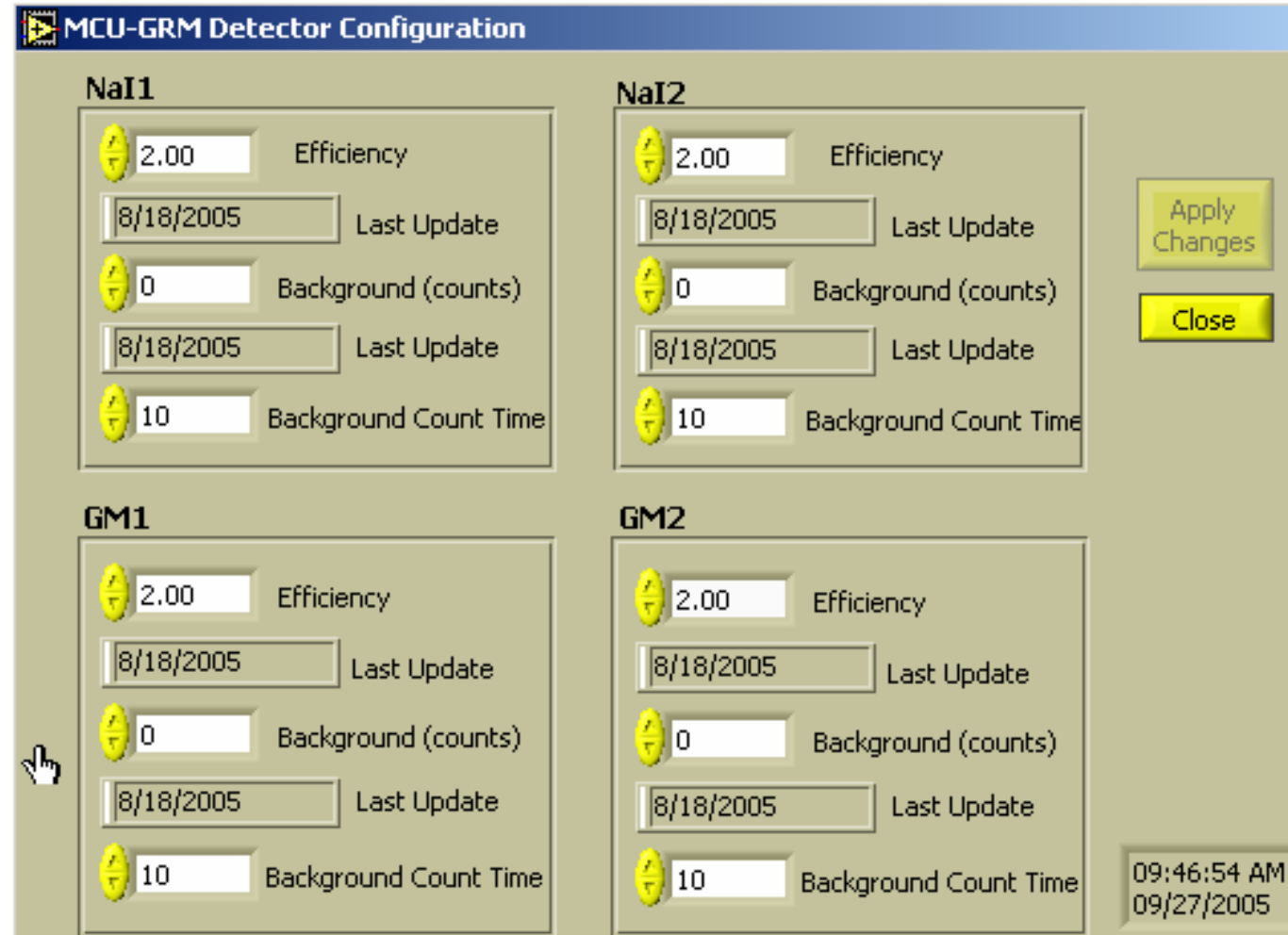

Cycle Times (seconds)

t) $\sqrt{10 \quad \text { NaI }}$ GM

Figure 3-15 Detector Configuration Screen

\subsubsection{Routine Data Acquisition}

The Routine Data Acquisition mode is the primary mode of operation for the MCU-GRM software. In order to start the routine monitoring application, the user should verify that the desired detector pair has been selected (one GM and one NaI detector) and then click the Start button on the MCUGRM application window (Figure 3-13). 
At this point, the application changes to the running state as indicated on the screen. In the running mode, the time remaining for each detector's acquisition cycle is displayed in the corresponding Next Update counter along the top of each graph. The Next Update counter is updated once a second to show the time remaining until the end of the current acquisition cycle. By default, the data acquisition cycle for both detectors is set for 60 seconds.

At the start of Run cycle, the program reads the GM and NaI detector configuration data as set previously using the Detector Configuration Utility. The system starts the first count by writing the live time preset to the Trump Card to start the spectrum collection. The Trump card performs all the required spectrum collection functions as instructed without further interaction from the MCUGRM software. The system also initializes and starts the NI-6602 counter to monitor the pulse output of the GM signal train.

After the NaI time interval has elapsed, the program polls the Trump card to determine if the required live time spectrum collection has completed. If the live time interval has not completed the program waits for its completion. (NOTE: These two times should be about equal, unless a significant amount of dead time is encountered.) At completion of the counting cycle, the program queries the Trump card to get the raw counts in the Cesium photo-peak, along with other Cesium Region-of-Interest (ROI) statistical information. The program also reads the raw counts from the Americium photo-peak as well as the Am peak centroid channel number within the Am peak ROI. The ROIs in question are those established by the user during the initial system setup and calibration and should be the one containing the Cs and Am photo-peaks respectively. The program then issues commands to the Trump card to clear the current spectrum and restart the NaI data acquisition cycle. After the Trump card is restarted, the MCU-GRM software calculates the net counts in the Cesium photo-peak. At this point, the program has enough information to calculate the Cesium Concentration (Ci/gal) in the decontaminated salt solution. This is done by subtracting the measured background value from the net counts and dividing the result by the detector efficiency.

To wrap up the processing of the NaI data, the program calculates the net counts in the Americium peak as well as the location (spectrum channel number) of the Am peak centroid. The actual Am peak centroid channel number is compared against its desired location to determine if adjustments need to be made in the detector HV supply or the amplifier gain. If the Am peak channel is outside of an acceptable band, the system will flag the user with an error message similar to that shown in Figure 3-16. The NaI detector system will not perform its monitoring function until this condition is corrected. If the system electronics fail and do not provide an Am peak, this error message will also appear and will be an indication of a system hardware problem. These adjustments are covered in Appendix D, Software User's Manual for the MCU-GRM. 


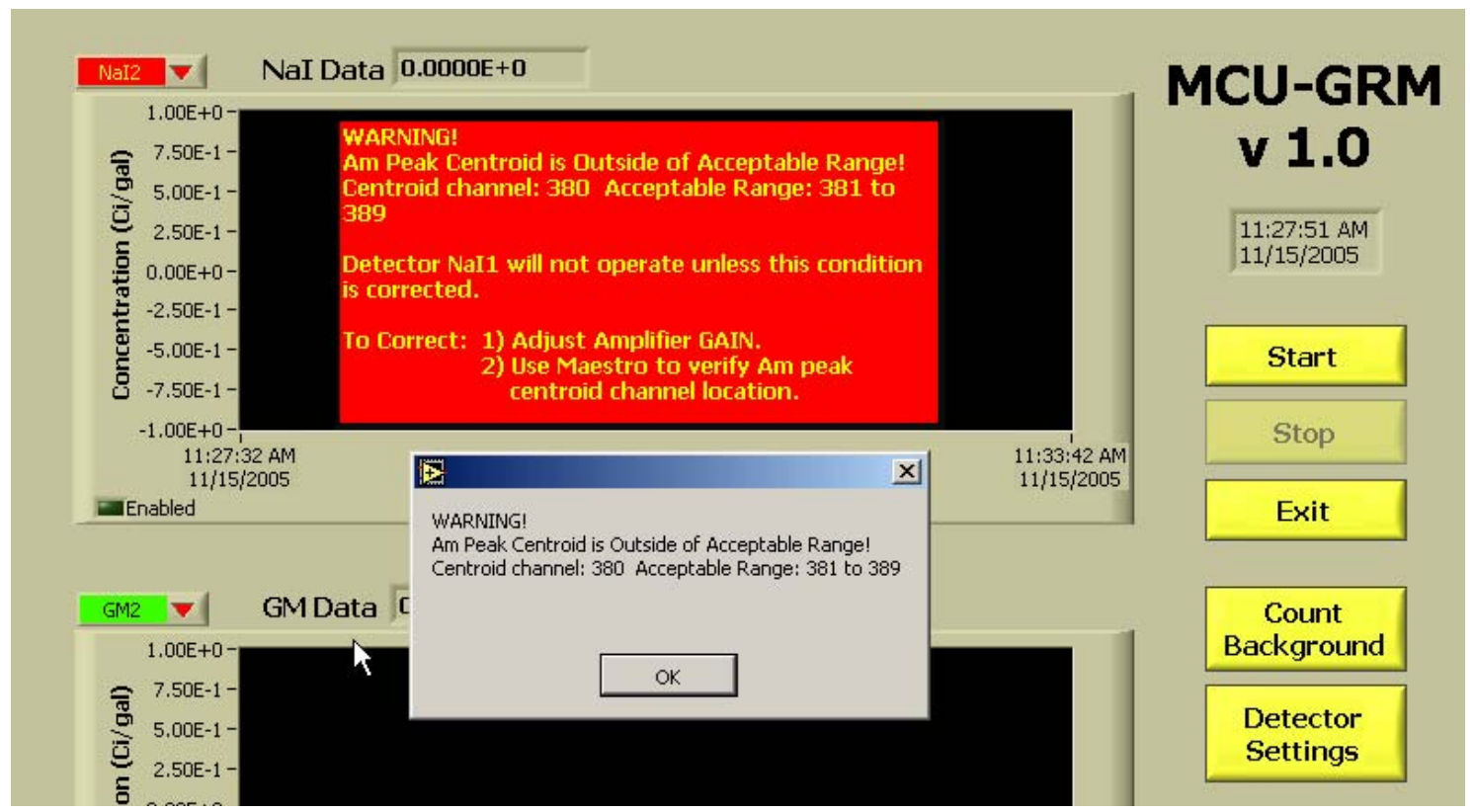

Figure 3-16. Am Peak Channel Error State

Like the NaI detector cycle, the MCU-GRM software issues commands to stop the NI-6602 counter and to read the total count collected during the GM data acquisition cycle. When this is completed, the program issues commands to clear and restart the count for the next cycle. Similar to the NaI data, the GM net counts are calculated using the GM detector measured background and the detector efficiency.

At the completion of the acquisition cycle, the two new data points are written to their corresponding graphs and any linked digital displays. Each new data point is also passed along to the DCS through the Foundation FieldBus interface. The new data and a selected subset of system and detector parameters are written to a log file (See Appendix D - NaI and GM DataLog file Format). Both acquisition cycles continue until the user clicks the Stop button on the application window.

\subsubsection{Background Counting}

In order to gain an accurate picture of the activity of the solution moving through the system the system must be able to separate out that portion of the measured activity that is contributed by the salt solution from the portion that is due to the entrained particles within the system and its surroundings. In order to do this, the software must be able to null out the contribution of the system components to the overall measured activity. The MCU-GRM software accomplishes this through background subtraction. In order to perform the background subtraction and report only the activity of the solution moving through the system, periodic background measurements must be performed. Frequency will depend on the measured background variations during processing. This task must necessarily be performed in-situ, as this is the only method for accurate determination of the ambient activity levels.

The performance of this measurement requires coordination between the MCU-GRM and the DCS because a thorough flushing is required for all components within the detectors field of view. Since the detector is shielded, the field of view only consists of the piping section where the detectors are located. The system setup for this operation will be procedurally controlled within the facility and is 
outside the scope of this document. What is covered here is the performance of a background measurement as related to the MCU-GRM.

From the MCU-GRM point of view, the user will initiate a background count by first selecting the desired detector pair (one GM and one NaI detector) and then clicking the Count Background button on the MCU-GRM application window (Figure 3-13). The Start Background dialog box will be displayed as shown in Figure 3-17.

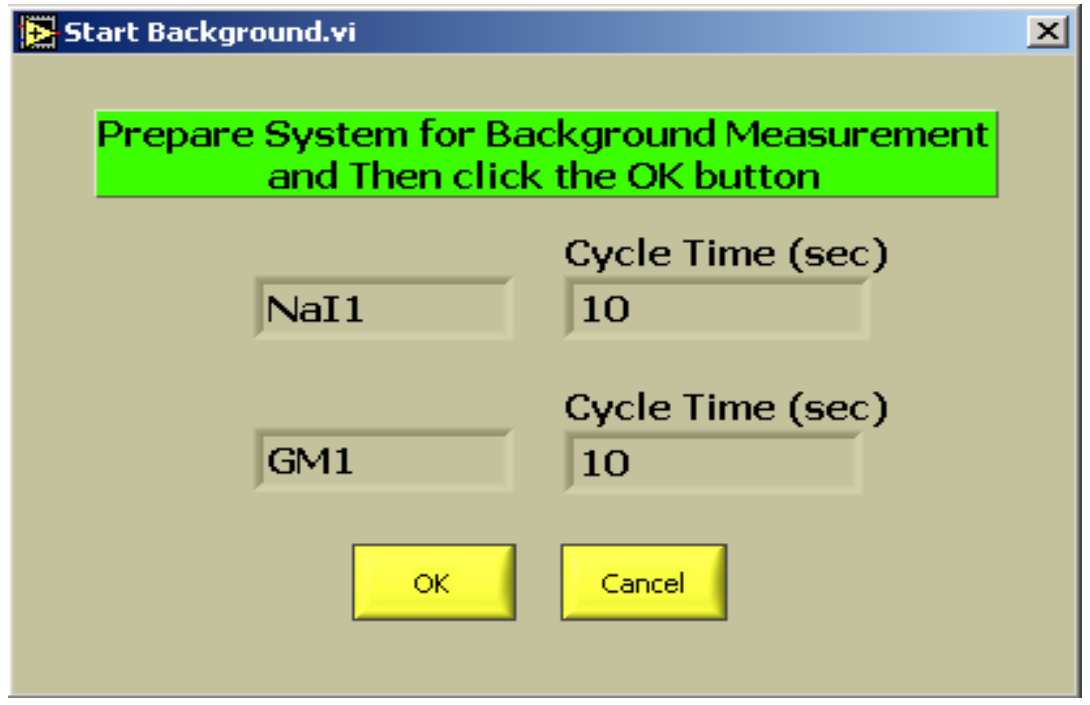

Figure 3-17 Start Background Count Screen

The Start Background screen shows the detectors currently selected for the background counting operation, as well as the background count time for each detector. The screen also contains a message to remind the user the system preparation should be completed prior to performing the background measurement. The MCU-GRM software only reminds the user that these activities should be performed, but has no method to enforce the requirement. Inadequate system preparation may result in inaccurate readings for the measured background values.

To proceed beyond the initial screen, the user must either accept or cancel the activity. If cancelled, the Start Background screen will disappear and the MCU-GRM application window will be displayed. If accepted, the Background count will commence. The count will be performed for the length of time specified in the window for each detector. During the count, the Next Update field on the MCU-GRM main screen (Figure 3-13) will count down to indicate the time remaining in the current counting cycle. At the completion of the background counting cycle for each detector a Background Count Complete dialog box will appear. This screen is shown in Figure 3-18. 
Detector Background Counts

NaI1 1324

OK

Cancel

\section{Click "OK" to save new Background Reading} "Cancel" to discard

Figure 3-18 Background Count Complete Screen

The Background Complete screen displays the newly acquired background data point for the indicated detector and prompts the user to decide whether to keep or discard the new data. If the user decides to keep the new data point, the data are written to the detector configuration file (MCU_GRM_CONFIG.ini) and used for all subsequent calculations requiring background correction. This would also cause the Last Update field to be changed to reflect the new data point change. (Refer to Figure 3-15.) Otherwise the data are discarded and the current settings retained. When the background counts for both detectors have completed, the system returns to the standby mode awaiting further instructions from the user.

To summarize, the Background Counting mode performs a count for the two detectors that are currently selected, one GM and one NaI detector. Each count is performed for a preset period of time as determined by the setting in the Detector Configuration Window for the specified detector. At the completion of the count the new measured background data point may either be discarded, or written to the detector configuration settings file to be used on all subsequent calculations. Neither of the data points is written to the graph or to the digital display on the MCU-GRM application window. The procedure for routine startup and operation of the MCU-GRM software is given in Appendix D.

A typical spectrum collected using the Ortec Corporation spectral stripping program Maestro is shown in Figure 3-19. The Cs-137 peak and Am-241 pulser peak are evident.

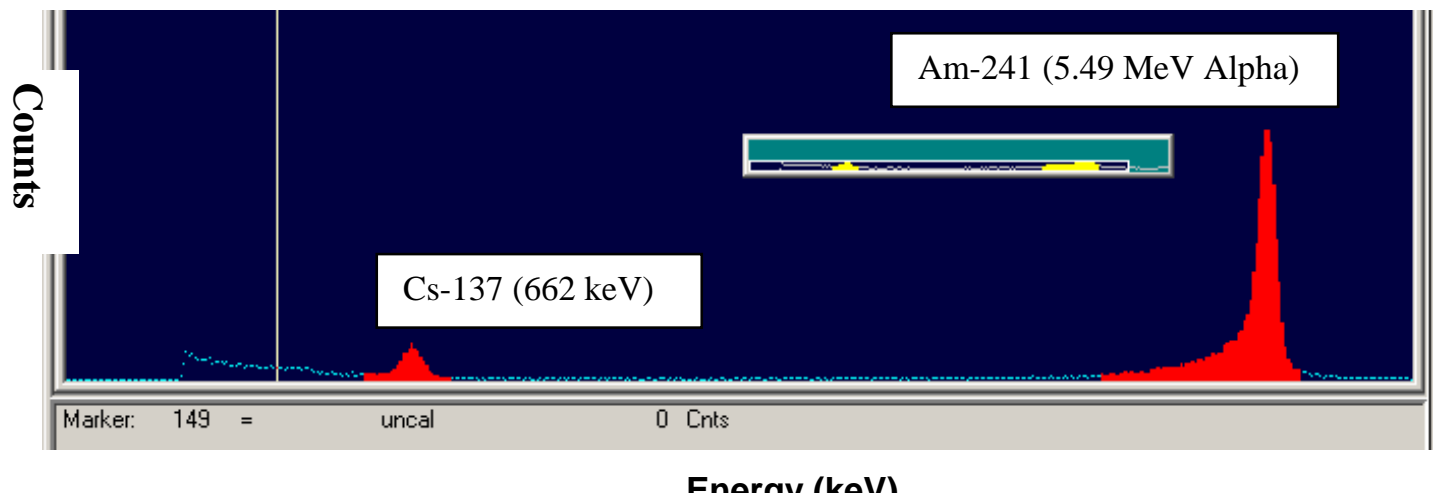

Energy (keV)

Figure 3-19 Spectrum from Na(Tl) detector with Am-241 Pulser 


\subsection{Detector Efficiencies and Operations}

\subsubsection{NaI Detector Efficiencies}

In order to calibrate the detectors, NIST traceable standard sources were purchased from Analytics Corporation, Atlanta, GA. These consisted of Cs-137 activity in a polymeric matrix that were contained in one-inch schedule 40 pipe for $\mathrm{NaI}$ monitor calibrations and half-inch schedule 40 pipe for GM calibrations. These standards are shown in Figure 3-20, and the NaI calibration results are shown in Table 3-5. The source certificates of calibration are given in Appendix F.

Table 3.5 Calibration results for the NaI detectors SAM 333 and SAM334.

\begin{tabular}{|c|c|c|c|c|c|c|c|c|c|c|c|}
\hline $\begin{array}{l}\text { Nal } \\
\text { SAM }\end{array}$ & Volts & $\begin{array}{l}\text { Col. } \\
\text { Dia. }\end{array}$ & $\begin{array}{l}\text { Std. } \\
\mu \mathrm{Ci}\end{array}$ & $\begin{array}{l}\text { Cs137 } \\
\text { Counts }\end{array}$ & Integral & $\begin{array}{c}\text { Am } 241 \\
\text { Counts } \\
226368 \pm\end{array}$ & Integral & $\begin{array}{c}\% \\
\text { DT }\end{array}$ & $\begin{array}{c}\text { Cs137 } \\
\text { cps }\end{array}$ & $\begin{array}{l}\text { Cs137 } \\
\text { dps }\end{array}$ & EFF \\
\hline $\begin{array}{l}333 \\
\text { SAM }\end{array}$ & 520 & 0.313 & 0 & $\begin{array}{c}39 \pm 96 \\
23587\end{array}$ & 3155 & $\begin{array}{c}960 \\
218799 \pm\end{array}$ & 271804 & 6.8 & 0.07 & 0 & \\
\hline $\begin{array}{l}333 \\
\text { SAM }\end{array}$ & 520 & 0.313 & 226 & $\begin{array}{l} \pm 236 \\
49160\end{array}$ & 34315 & $\begin{array}{c}596 \\
213429+\end{array}$ & 272911 & 7.7 & 39.3 & $8.36 E+6$ & 4.70E-6 \\
\hline 333 & 520 & 0.313 & 511 & \pm 344 & 72272 & 1061 & 273029 & 8.9 & 81.9 & $1.89 E+7$ & 4.34E-6 \\
\hline $\begin{array}{l}\text { SAM } \\
333 \\
\text { SAM }\end{array}$ & 520 & 0.616 & 0 & $\begin{array}{c}240 \pm \\
94 \\
181519\end{array}$ & 3168 & $\begin{array}{c}225417 \pm \\
962 \\
183298 \pm\end{array}$ & 271167 & 6.8 & 0.40 & 0 & \\
\hline $\begin{array}{l}333 \\
\text { SAM }\end{array}$ & 520 & 0.616 & 226 & $\begin{array}{c} \pm 776 \\
305695\end{array}$ & 322235 & $\begin{array}{c}1281 \\
124728 \pm\end{array}$ & 278505 & 16.8 & 303 & $8.36 \mathrm{E}+6$ & $3.62 E-5$ \\
\hline 333 & 520 & 0.616 & 511 & \pm 1248 & 723703 & 1618 & 287408 & 30.7 & 509 & $1.89 \mathrm{E}+7$ & $2.70 E-5$ \\
\hline $\begin{array}{l}\text { SAM } \\
334 \\
\text { SAM }\end{array}$ & 520 & 0.313 & 0 & $\begin{array}{c}43 \pm 86 \\
20832\end{array}$ & 2507 & $\begin{array}{c}244402 \pm \\
671 \\
242142+\end{array}$ & 273914 & 7.8 & 0.07 & 0 & \\
\hline $\begin{array}{l}334 \\
\text { SAM }\end{array}$ & 520 & 0.313 & 226 & $\begin{array}{l} \pm 231 \\
45765\end{array}$ & 31744 & $\begin{array}{c}692 \\
237942 \pm\end{array}$ & 276118 & 8.8 & 34.7 & $8.36 \mathrm{E}+6$ & 4.15E-6 \\
\hline 334 & 520 & 0.313 & 511 & \pm 335 & 67945 & 710 & 276046 & 10.2 & 76.3 & $1.89 E+7$ & $4.04 \mathrm{E}-6$ \\
\hline $\begin{array}{l}\text { SAM } \\
334 \\
\text { SAM }\end{array}$ & 520 & 0.616 & 0 & $\begin{array}{l}91+89 \\
170166\end{array}$ & 2593 & $\begin{array}{c}243814 \pm \\
676 \\
216940 \pm\end{array}$ & 274270 & 7.8 & 0.15 & 0 & \\
\hline $\begin{array}{l}334 \\
\text { SAM }\end{array}$ & 520 & 0.616 & 226 & $\begin{array}{c} \pm 729 \\
293842\end{array}$ & 290670 & $\begin{array}{c}830 \\
183755 \pm\end{array}$ & 284388 & 18.5 & 284 & 8.36E+06 & $3.39 E-5$ \\
\hline 334 & 520 & 0.616 & 511 & +1187 & 666082 & $99-$ & 299451 & 33.8 & 490 & $1.89 \mathrm{E}+07$ & $2.59 \mathrm{E}-5$ \\
\hline
\end{tabular}




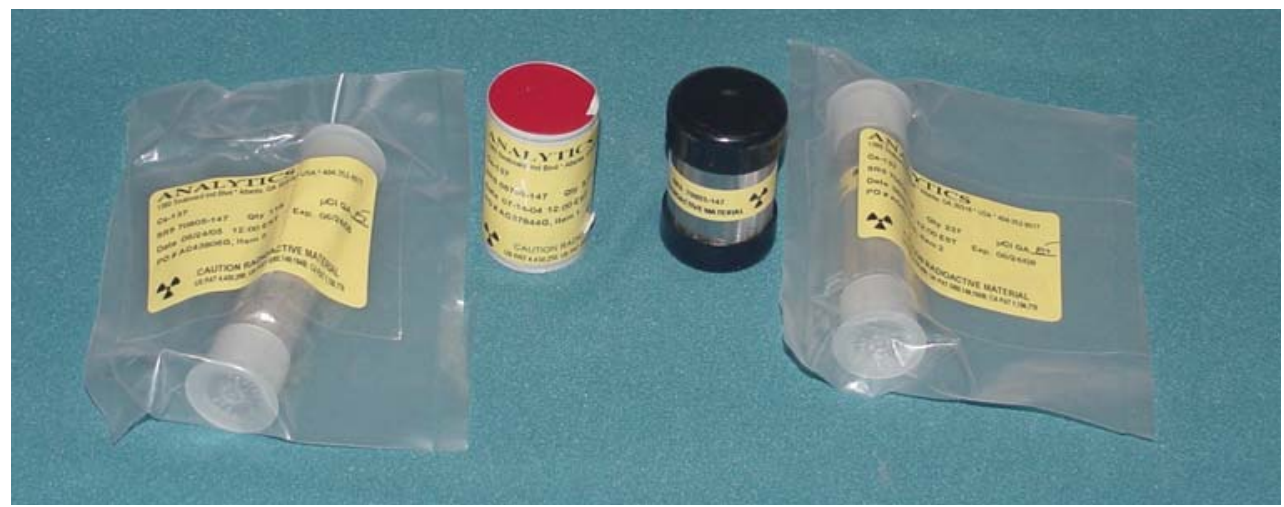

Figure 3.20 Detector calibration standards.

The average Cs-137 efficiencies for SAM 333 are 4.52E-6 for the 0.313 -in collimator aperture and $3.62 \mathrm{E}-5$ for the 0.616 -in collimator aperture, while these values are $4.10 \mathrm{E}-6$ and $3.39 \mathrm{E}-5$ for SAM334, respectively. Efficiencies for both $\mathrm{NaI}$ detectors are very similar as expected. The efficiency data for the $511 \mu \mathrm{Ci}$ standard using the 0.616 -in collimator aperture were not considered to be accurate because the MCA dead time was over $30 \%$ for these measurements. A dead time of $20 \%$ is considered a good upper limit for these measurements.

\subsubsection{NaI Cable Length}

Since the detector came with 100 feet of cable and since the process required the use of 150 feet of cable, a study was done to ensure that the NaI system would function properly with the longer cables. A $226 \mu \mathrm{Ci}$ standard was counted in a fixed geometry with 100 -foot cables, and then a 50 foot extension was added to the end of the cables and the standard was counted again. The 100 -foot cable results were $9737 \pm 170$ counts (detector SAM333) and $9947 \pm 224$ (detector SAM 334), while the 150-foot cable result was $9858 \pm 164$ (detector SAM333) and $9982 \pm 223$ (detector SAM 334). Obviously, the additional cable length had essentially no effect on the results.

\subsubsection{GM Detector Efficiencies}

The Cs-137 measurement efficiencies for the GM detectors were also determined and this data are presented in Table 3-6.

Table 3-6 Determination of Cs-137 efficiencies for the GM detectors.

\begin{tabular}{|c|c|c|c|c|c|c|c|}
\hline Detector & Volts & Count Time (s) & Source & Counts & cps CS-137 & dps Cs-137 & EFF (cps/dps) \\
\hline GM1 & 550 & 600 & none & 1 & & & \\
GM1 & 550 & 6000 & $118 \mu \mathrm{Ci}$ & 5847 & 0.975 & 4366000 & $2.23 \mathrm{E}-07$ \\
GM1 & 550 & 6000 & $237 \mu \mathrm{Ci}$ & 11560 & 1.927 & 8769000 & $2.20 \mathrm{E}-07$ \\
& & & & & & & \\
GM2 & 550 & 600 & none & 0 & & & \\
GM2 & 550 & 6000 & $118 \mu \mathrm{Ci}$ & 7938 & 1.323 & 4366000 & $3.03 \mathrm{E}-07$ \\
GM2 & 550 & 6000 & $237 \mu \mathrm{Ci}$ & 16353 & 2.726 & 8769000 & $3.11 \mathrm{E}-07$
\end{tabular}

The measured efficiencies for two standards were in excellent agreement; however, there was a large variation in the efficiencies of GM1 versus GM2. Therefore, the efficiencies must be determined for each detector. 


\subsubsection{GM Linear Detection Range}

Since the standards used to determine the efficiencies are much lower than the activities that will be measured in the process, it was necessary to determine how the response of the detectors varies with increased activity. In order to accomplish this task, the GM detectors were exposed to high levels of radiation at the SRS health physics instrument calibration facility (Figure 3-21). The GM count rates were measured for Cs-137 exposures from 0.01 to $7 \mathrm{R} / \mathrm{hr}$ and this data are presented in Table 3-7.

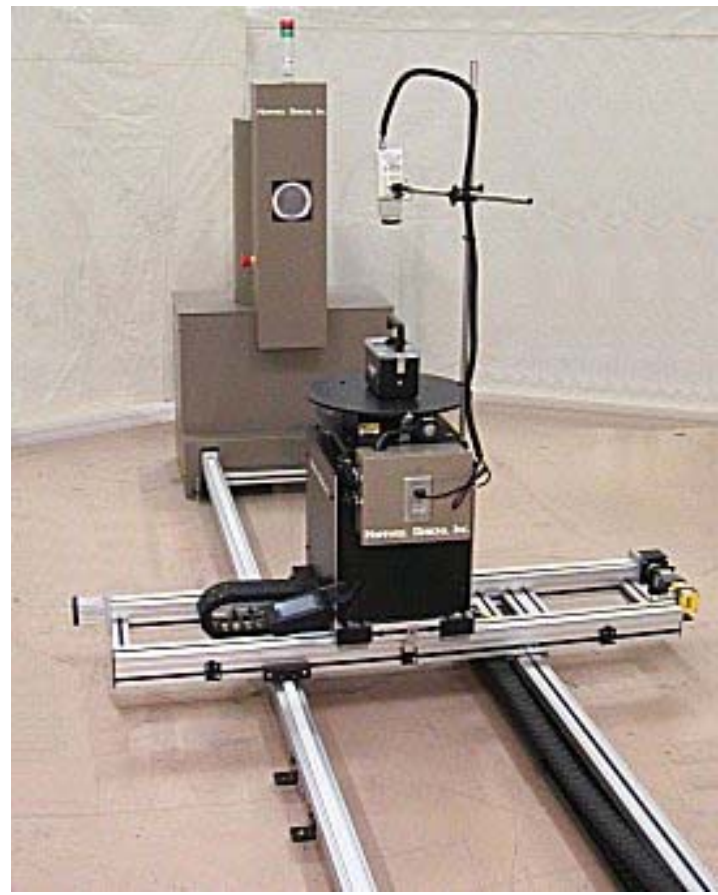

Figure 3-21 SRS Cs-137 gamma source and positioning system.

Table 3-7 Detector response versus measured dose.

\begin{tabular}{|c|c|c|c|c|}
\hline Detector & Dose $(\mathrm{R} / \mathrm{hr})$ & $\mathrm{c} / \mathrm{s}(60 \mathrm{sec})$ & $\mathrm{cps} /(\mathrm{Ci} / \mathrm{gal})$ & $\mathrm{Ci} / \mathrm{gal}$ \\
\hline $\mathrm{GM} 1$ & 0.010 & 2.80 & 42.8 & 0.065 \\
$\mathrm{GM} 1$ & 0.10 & 26.9 & 42.8 & 0.63 \\
$\mathrm{GM} 1$ & 1.0 & 265 & 42.8 & 6.19 \\
$\mathrm{GM} 1$ & 5.0 & 1301 & 42.8 & 30.4 \\
$\mathrm{GM} 1$ & 6.0 & 1557 & 42.8 & 36.4 \\
$\mathrm{GM} 1$ & 7.0 & 1795 & 42.8 & 41.9 \\
& & & & \\
$\mathrm{GM} 2$ & $10 \mathrm{mR} / \mathrm{hr}$ & 2.28 & 42.8 & 0.053 \\
$\mathrm{GM} 2$ & $100 \mathrm{mR} / \mathrm{hr}$ & 24.3 & 42.8 & 0.57 \\
$\mathrm{GM} 2$ & $1 \mathrm{R} / \mathrm{hr}$ & 240 & 42.8 & 5.61 \\
$\mathrm{GM} 2$ & $5 \mathrm{R} / \mathrm{hr}$ & 1183 & 42.8 & 27.6 \\
$\mathrm{GM} 2$ & $6 \mathrm{R} / \mathrm{hr}$ & 1414 & 42.8 & 33.0 \\
$\mathrm{GM} 2$ & $7 \mathrm{R} / \mathrm{hr}$ & 1645 & 42.8 & 38.4
\end{tabular}

Ludlum Inc., the vendor that makes the GM detectors (Model 133-6), provides a linear range without dead time correction for these detectors to be 0.004 to $6 \mathrm{R} / \mathrm{hr}$. Therefore, this study should 
verify the linearity in this range which corresponds to a pipe activities in the range of about 0.05 to $40 \mathrm{Ci} / g a l$. Figure 3-22 provides this plot.

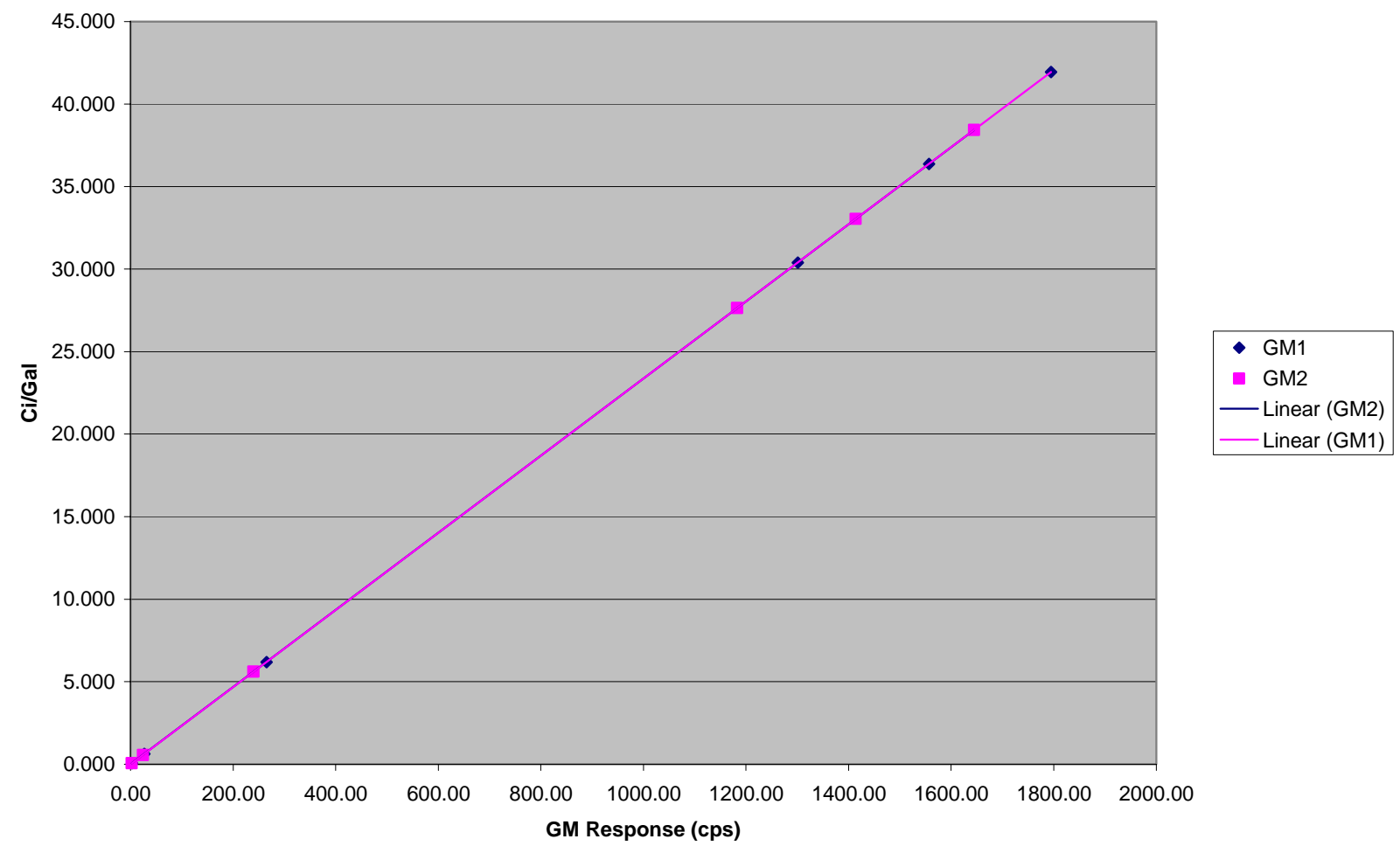

Figure 3-22 Relationship of GM detector Response versus activity measured.

This graph clearly shows that the detector response varies linearly as the Cs-137 dose increases over the CSSX measurement range ( 0.1 to $16.5 \mathrm{Ci} / \mathrm{gal})$. Therefore, calibrating the GM detectors with low-level standards and knowing that the detector response is linear in this range provides the basis for detector calibration.

\subsubsection{GM Detection versus angular position}

Another important consideration when using GM detectors is how the measurement varies if the detector is rotated within the shield. If the very small ion chamber is centered within the detector housing, there would be no variation in detector positioning in the shield. However, the vendor makes little effort to ensure that the ion chamber is centered in the chamber housing. Table 3-8 shows how rotational positioning of the detector affects the detector response. 
WSRC-RP-2005-01902

Revision \#0

Table 3-8 Angular position versus detector reponse.

\begin{tabular}{ccc|c|c|c|c|}
\hline Detector & Voltage & Count Time (s) & Source & Angle (degrees) & Counts \\
\hline GM1 & 550 & 600 & $237 \mu \mathrm{Ci}$ & 0 & 1118 \\
GM1 & 550 & 600 & $237 \mu \mathrm{Ci}$ & 45 & 1144 \\
GM1 & 550 & 600 & $237 \mu \mathrm{Ci}$ & 90 & 1169 \\
GM1 & 550 & 600 & $237 \mu \mathrm{Ci}$ & 135 & 1296 \\
GM1 & 550 & 600 & $237 \mu \mathrm{Ci}$ & 180 & 1421 \\
Average & & & & & 1230 \\
STDEV & & & & & 127 \\
& & & & 0 & 1607 \\
GM2 & 550 & 600 & $237 \mu \mathrm{Ci}$ & 45 & 1622 \\
GM2 & 550 & 600 & $237 \mu \mathrm{Ci}$ & 90 & 1485 \\
GM2 & 550 & 600 & $237 \mu \mathrm{Ci}$ & 135 & 1448 \\
GM2 & 550 & 600 & $237 \mu \mathrm{Ci}$ & 180 & 1486 \\
GM2 & 550 & 600 & $237 \mu \mathrm{Ci}$ & & 1530 \\
Average & & & & &
\end{tabular}

The data in Table 3-8 show that the angular positioning of the detector has an appreciable effect on the detector response. For GM1 the counts from the same calibration source varied from 1421 to 1118, about 25\% variation compared to the average value, and GM2 counts varied from 1622 to 1448, about an $11 \%$ variation compared to the average value. Therefore, it is imperative to ensure that the angular position of the detector is the same during calibration and for the measurements.

\subsubsection{GM Shielding Effect}

Another interesting aspect of the GM detector arrangement is how much the collimated shield reduces the radiation seen by the detector. In order to determine this shielding effect, a pipe standard was positioned as a process pipe would be positioned and a count was performed, then the same standard was counted touching the detector with no shielding. Table 3-9 shows the results for the shielding effect.

Table 3-9 Evaluation of GM shielding versus count rate.

\begin{tabular}{ccccccc|}
\hline Detector & Dose $(\mathrm{R} / \mathrm{hr})$ & counts (shield) & counts (no shield) & shield/no shield \\
\hline $\mathrm{GM} 1$ & $118 \mu \mathrm{Ci}$ & 5847 & 16830 & 0.35 \\
$\mathrm{GM} 2$ & $118 \mu \mathrm{Ci}$ & 7938 & 21232 & 0.37
\end{tabular}

Based on the data given in Table 3-9, the shield reduced the detector exposure by about $64 \%$ when compared to using an unshielded detector. 


\section{CONCLUSIONS}

Sodium iodide monitors are used to measure Cs-137 concentration in the MCU product streams (DSS and strip effluent). Sodium iodide monitors have been developed for use at the piping before the DSS Hold tank, while GM monitors have been developed for Cs-137 measurements before the Strip Effluent Hold Tank. Tungsten shields were designed using Monte Carlo calculations and fabricated to reduce the process background radiation at the detector positions. These monitors were calibrated with NIST traceable standards that were specially made to be the same size as the piping being monitored.

Since this gamma ray monitoring system is unique, specially designed software was written and acceptance tested by Savannah River National Laboratory personnel. The software is a LabView-based application that serves as a unified interface for controlling the monitor hardware and communicating with the host Distributed Control System (DCS). In order to provide relatively simple software for the process personnel, the software can be broken down into just a few software modules. These software modules are the Application Window, Detector Selection, Detector Configuration Settings, Background Counting, and Routine Data Acquisition. Instructions for using the software have been included in a user's manual that is appended to this report.

The work presented in this report meets all of the requirements set forth in the project task plan to design and implement gamma ray monitors for the MCU. Additional setup and testing of the system will be required when it is implemented in the process. 


\section{REFERENCES}

1. J-SQP-H-00013, Rev. 0, "Modular Caustic Side Solvent Extraction Unit Gamma Ray Monitors Software Quality Assurance Plan”

2. L814-J-002v Version 1.0, "Modular Caustic Side Solvent Extraction Unit Gamma Ray Monitors Software User’s Manual, Rev. 0”

3. U-FCD-H-00008, Rev. 0, "Modular CSSX Unit (MCU) Software Classification - a portion of the DISTRIBUTED CONTROL SYSTEM (DCS) network”

4. WSRC-RP-2004-00875, Rev 0, “Task Technical and Quality Assurance Plan for Caustic Side Solvent Extraction Gamma-Ray Monitors”

5. U-MT-H-00085, Rev 1, “Cesium Removal Implementation Using Caustic Side Solvent Extraction Technology”

6. G-TC-H-00041, Rev 5, "Task Requirements and Criteria - Modular Caustic Side Solvent Extraction Unit (MCU)”

7. G-ESR-H-00072, Rev 1, "Interface Control Document Modular Caustic Side Solvent Extraction (CSSX) Unit (MCU)”

8. Technical Task Request, SP-TTR-2004-00013, Rev 1

9. WSRC 1Q Manual QAP 20-1, "Software Quality Assurance"

10. WSRC E7 Manual Procedure 5.20 “Software Design and Implementation”

11. IEEE Standard 1016-1998, “IEEE Recommended Practice for Software Design Descriptions” 


\section{ACKNOWLEDGEMENTS}

The authors would like to acknowledge Fred Ogden of the SRS Health Physics Instrument Calibration Facility for his assistance in the GM detector dose calibration measurements. We would also like to thank CSSX project personnel for their assistance throughout this project. 
WSRC-RP-2005-01902

Revision \#0

This page intentionally left blank. 


\section{Modular Caustic Side Solvent Extraction Unit Gamma Ray Monitors (MCU-GRM)}

L814-J-002v Version 1.0.

\section{Design Document for Software (U)}

Document Number: J-DD-H-00001 Rev 0

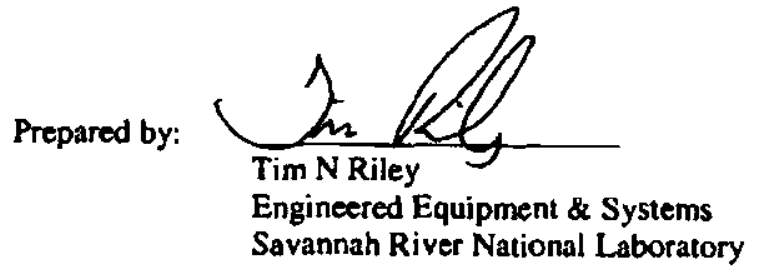

Date:

October 3, 2005

' ENGINEERING DOC. CONTAOL - SAS

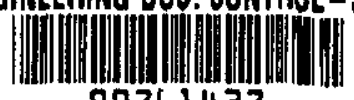


WSRC-RP-2005-01902

$\therefore \quad \because$

Revision \#0

Modular Caustic Side Solvent Extraction Unit Gamma Ray Monitors Design Document for Software
J-DD-H-0000I

Revision 0

Page 2 of 13
Approvals:

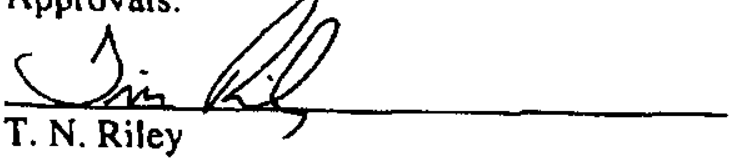

Design Agency

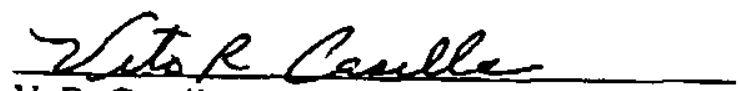

V. R. Canella

IR- independent Reviewer

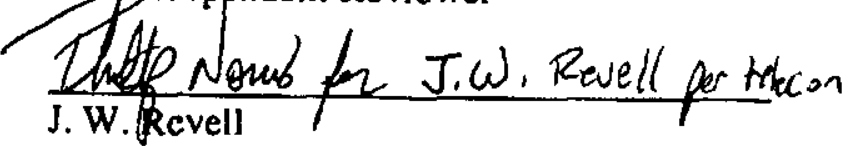

Design Authority

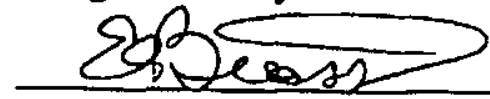

E. A. Brass

MCU Design Authority Manager

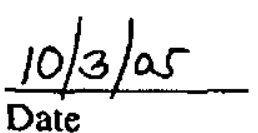

$11 / 05$

Date

$\frac{11 / 1 / 05}{\text { Date }}$

$\frac{14 / 4 / 5}{\text { Date }}$

- $\circ:=$. 
WSRC-RP-2005-01902

Revision \#0

\section{SUMMARY OF CHANGES}

\begin{tabular}{|l|l|l|}
\hline Revision: & Date: & Description: \\
\hline A & $8 / 5 / 05$ & Initial routing for review and comments \\
\hline 0 & $10 / 3 / 05$ & Approval \\
\hline & & \\
\hline
\end{tabular}




\section{TABLE OF CONTENTS}

Summary of Changes $\quad 41$

Table of Contents $\quad 42$

Table of Figures $\quad 42$

1. Introduction $\quad 43$

1.1. Purpose 43

1.2. Scope 43

1.3. Definitions and Acronyms 43

2. References 43

3. General System Description 45

3.1. MCU-GRM Software Module Descriptions $\quad 45$

3.1.1. MCU-GRM Main.vi 45

3.1.2. MCU-GRM Config.vi 46

3.1.3. Login.vi 46

3.1.4. Start Background.vi 46

3.1.5. Background Complete.vi 46

3.2. Data Description 46

3.3. File Creation 46

3.4. $\quad$ Configuration Programs 47

4. Detailed Design $\quad 47$

4.1. Initialization $\quad 48$

4.2. Detector Configuration Mode $\quad 49$

4.3. $\quad$ Run Mode 51

4.4. Background Counting Mode $\quad 52$

\section{TABLE OF FIGURES}

Figure 1: Initialization State Diagram ........................................................................... 49

Figure 2: Detector Configuration State Diagram .............................................................. 50

Figure 3: Run Mode State Diagram ........................................................................................ 52

Figure 4: Background Counting Mode State Diagram .................................................... 53 


\section{Introduction}

\subsection{Purpose}

This document describes the software developed for operation of the Modular Caustic Side Solvent Extraction Unit - Gamma Ray Monitor (MCU-GRM). A brief description of the system hardware is included as necessary for clarification of its interaction with the MCU-GRM software.

\subsection{Scope}

Provisions of this document apply to software developed by SRNL for the Modular Caustic Side Solvent Extraction Unit Gamma Ray Monitors (MCU-GRM). The MCU-GRM software source code number is L814-J-002v Version 1.0. This document does not cover the design or development of the supervisory distributed control system (DCS).

\subsection{Definitions and Acronyms}

MCU-GRM Modular Caustic Side Solvent Extraction Unit - Gamma Ray Monitor

SRNL Savannah River National Laboratory

DCS Distributed Control System

NIM Nuclear Instrumentation Module

MCA Multi-channel Analyzer

GM Geiger-Mueller

NaI Sodium Iodide

FFB Foundation Fieldbus

\section{References}

- J-SQP-H-00013, Rev. 0, “Modular Caustic Side Solvent Extraction Unit Gamma Ray Monitors Software Quality Assurance Plan”

- L814-J-002v Version 1.0, "Modular Caustic Side Solvent Extraction Unit Gamma Ray Monitors Software User’s Manual, Rev. 0”

- U-FCD-H-00008, Rev. 0, "Modular CSSX Unit (MCU) Software Classification - a portion of the DISTRIBUTED CONTROL SYSTEM (DCS) network” 
- WSRC-RP-2004-00875, Rev 0, “Task Technical and Quality Assurance Plan for Caustic Side Solvent Extraction Gamma-Ray Monitors”

- U-MT-H-00085, Rev 1, “Cesium Removal Implementation Using Caustic Side Solvent Extraction Technology"

- G-TC-H-00041, Rev 4, “Task Requirements and Criteria - Modular Caustic Side Solvent Extraction Unit (MCU)”

- G-ESR-H-00072, Rev 0, "Interface Control Document Modular Caustic Side Solvent Extraction (CSSX) Unit (MCU)”

- Technical Task Request, SP-TTR-2004-00013

- WSRC 1Q Manual QAP 20-1, "Software Quality Assurance"

- WSRC E7 Manual Procedure 5.20 "Software Design and Implementation”

- IEEE Standard 1016-1998, “IEEE Recommended Practice for Software Design Descriptions”. 


\section{General System Description}

The Modular Caustic-Side Solvent Extraction Unit - Gamma Ray Monitor (MCUGRM) provides monitoring of the cesium removal process from the clarified salt solution after the Actinide Removal Process. The MCU employs the CSSX process, a continuous process that uses a novel solvent to extract cesium from waste and concentrate it in dilute nitric acid.

The MCU-GRM hardware is comprised of the following items.

Two NaI spectrometers (one online and one backup) are used for measuring the Cs-137 concentration in the decontaminated salt solution entering the DSS Hold Tank. High voltage and preamp power are provided to the detectors through NIM based modules. The amplified and scaled output signal from each detector is connected to an ORTEC Trump-PCI MCA card.

Two GM tubes (one online and one backup) are used for measuring the Cs-137 concentration in the strip effluent before entering the Strip Effluent Hold Tank. High voltage is supplied to these detectors through an Aware Electronics instrument module. The Aware module also provides pulse scaling and amplification. The scaled signal is applied to a National Instruments 6602 counter/scalar card for gross activity counting

The two Trump-PCI cards and the NI 6602 counter card are installed in spare PCI slots on the MCU-GRM computer, along with a National Instruments NI PCI-FBUS/2 Foundation Fieldbus card for communication between the MCU-GRM and the DCS.

The MCU-GRM production software serves as a platform for the integration of these devices into a unified interface. From this interface, the user can view the most current data points, change the detector selection for both the GM and NaI detectors, change any of the detector configuration settings, perform a detector background measurement, control the operation of the measurement cycle, and view a historical trend of the measured values.

\subsection{MCU-GRM Software Module Descriptions}

\subsubsection{MCU-GRM Main.vi}

The MCU-GRM Main.vi is the primary module for controlling the activities and events in the MCU-GRM production software environment. This module contains the primary user interface from which the user can initiate all the functions needed to perform all normal measurement activities, perform a detector background measurement, or gain access to the detector configuration settings screen. 


\subsubsection{MCU-GRM Config.vi}

The MCU-GRM Config.vi allows the user to change or review the configuration settings, the measurement cycle times, and background counting times for each of the four detectors connected to the MCU-GRM.

\subsubsection{Login.vi}

The Login.vi controls access to the MCU-GRM Config.vi settings screen through password verification. This is to limit unwarranted access to the detector configuration file.

\subsubsection{Start Background.vi}

The Start Background module is a dialog box that is displayed at the beginning of the background counting cycle. This module shows the detectors currently selected for the background counting operation, as well as the background count time for each detector. The screen also contains a message to remind the user to prepare the system for background measurement. System preparation may involve flushing the piping and components and other activities that are procedurally controlled by the facility and are outside the scope of the MCU-GRM software. The software only reminds the user that these activities should be performed, but has no method to enforce the requirement. Inadequate system preparation may result in inaccurate readings for the measured background values.

\subsubsection{Background Complete.vi}

The Background Complete module is a dialog box that is displayed at the end of the background counting cycle. The module displays the newly acquired background data point and prompts the user to decide whether to keep or discard the new data. If the user decides to keep the new data point, the data are written to the detector configuration file and used for all subsequent calculations requiring background correction. Otherwise the data are discarded and the current settings retained.

\subsection{Data Description}

During the normal operation mode, the most recent data point collected for each of the selected detectors is displayed on the MCU-GRM user interface. The 50 most recent points are graphically displayed in a strip chart format on the MCU-GRM Main.vi main screen to provide a visual historical trend of the data.

Each new data point is also passed to the DCS through the Foundation Fieldbus interface. The data type for these values are double-precision, floating-point numbers. These follow the 64-bit IEEE double-precision format.

\subsection{File Creation}

Three files are created as a result of the MCU-GRM application software. They are MCU-GRM-CONFIG.ini, MCU_GRM NaI Data_mmyyyy.txt, and MCU_GRM 
GM Data_mmyyyy.txt. The format of these files is listed in the MCU-GRM Software Users Manual.

\section{MCU-GRM-CONFIG.ini}

At startup, the MCU-GRM software reads the detector configuration values from the configuration file (MCU_GRM_CONFIG.INI). Data in this file can only be changed from the detector configuration window or after completion of a background measurement.

MCU_GRM NaI Data_mmyyyy.txt \& MCU_GRM GM Data_mmyyyy.txt The MCU-GRM creates two DataLog files, one for NaI data and the other for GM data. At the end of each measurement cycle, the new data points and selected detector and system parameters are appended to the end of the appropriate file for each detector. A new file is created at the beginning of each month to keep the log file to a manageable size. The old log files are stored on the MCU-GRM computer hard drive for future access if needed. The month and year are embedded within each file name as follows: ( $\mathrm{mm}$ is the 2 digit month and yyyy is the 4 digit year for the month in which the file was first created.)

\subsection{Configuration Programs}

There are four configuration programs that must be run to set up the MCU-GRM hardware before starting the MCU-GRM application software for the first time. This operation is only required to be performed prior to the initial startup.

The first operation is to run the ORTEC “MCB Config” program to setup the communication channels with MCA1 and MCA2. At the completion of this step, the user must run the ORTEC “Maestro" program to properly establish the two regions of interest (ROIs) needed for the data collection process. Similarly, the user must run the NI-FBUS Interface Configuration Utility to set up the Foundation Fieldbus card, and the Measurement and Automation Explorer to set up the NI6602 Counter/Timer card.

The MCU-GRM initialization sequence verifies that these operations have been completed. The MCU-GRM application program will be unable to initialize or communicate with the hardware devices and will generate an appropriate error should any of these steps fail to be performed. The procedures for performing all the above actions are listed in the appropriate manufacturer's literature for each device and will not be included in the MCU-GRM documentation.

\section{DETAILED DESIGN}

The MCU-GRM software can be broken down into four basic sequences: Initialization, Detector Configuration, Run Mode, and Background Counting Mode. Each of these sequences is described in detail below. 


\subsection{Initialization}

The initialization sequence is illustrated in the Initialization State Diagram shown in Figure 1. The process begins at program startup by reading the detector configuration settings file (MCU_GRM_CONFIG.ini) to obtain the latest values. After this is completed, the two multi-channel analyzers, MCA1 and MCA2, are initialized. This is a multi-step process in which the MCA hardware, configuration, and communications are tested to verify the correct hardware is installed, functional, and the proper MCA setup has been performed. Similar initialization protocols are followed for the National Instruments Foundation Fieldbus card and the NI-6602 counter/scalar card. The initialization sequence is completed by establishing some programmatic control elements and setting up the user interface.

Failure of any of the initialization steps puts the program in an ERROR state. Since the elements of the initialization process are critical to the operation of the MCUGRM, the event causing the ERROR state must be corrected before the program can be made operational. If no errors are encountered, the system enters the IDLE state awaiting commands from the user.

There are some preliminary setup operations that must be performed prior to starting the MCU-GRM application for the first time. These operations are only required to be performed prior to the initial startup. The first operation is to run the ORTEC "MCB Config” program to setup the communication channels with MCA1 and MCA2. At the completion of this step, the user must run the ORTEC

"Maestro" program to properly establish the two regions of interest (ROIs) needed for the data collection process. Similarly, the user must run the NI-FBUS Interface Configuration Utility to set up the Foundation Fieldbus card, and the Measurement and Automation Explorer to set up the NI-6602 Counter/Timer card. The MCUGRM initialization sequence verifies that these operations have been completed. However, failure to perform any of these steps will result in an error condition as previously stated. 


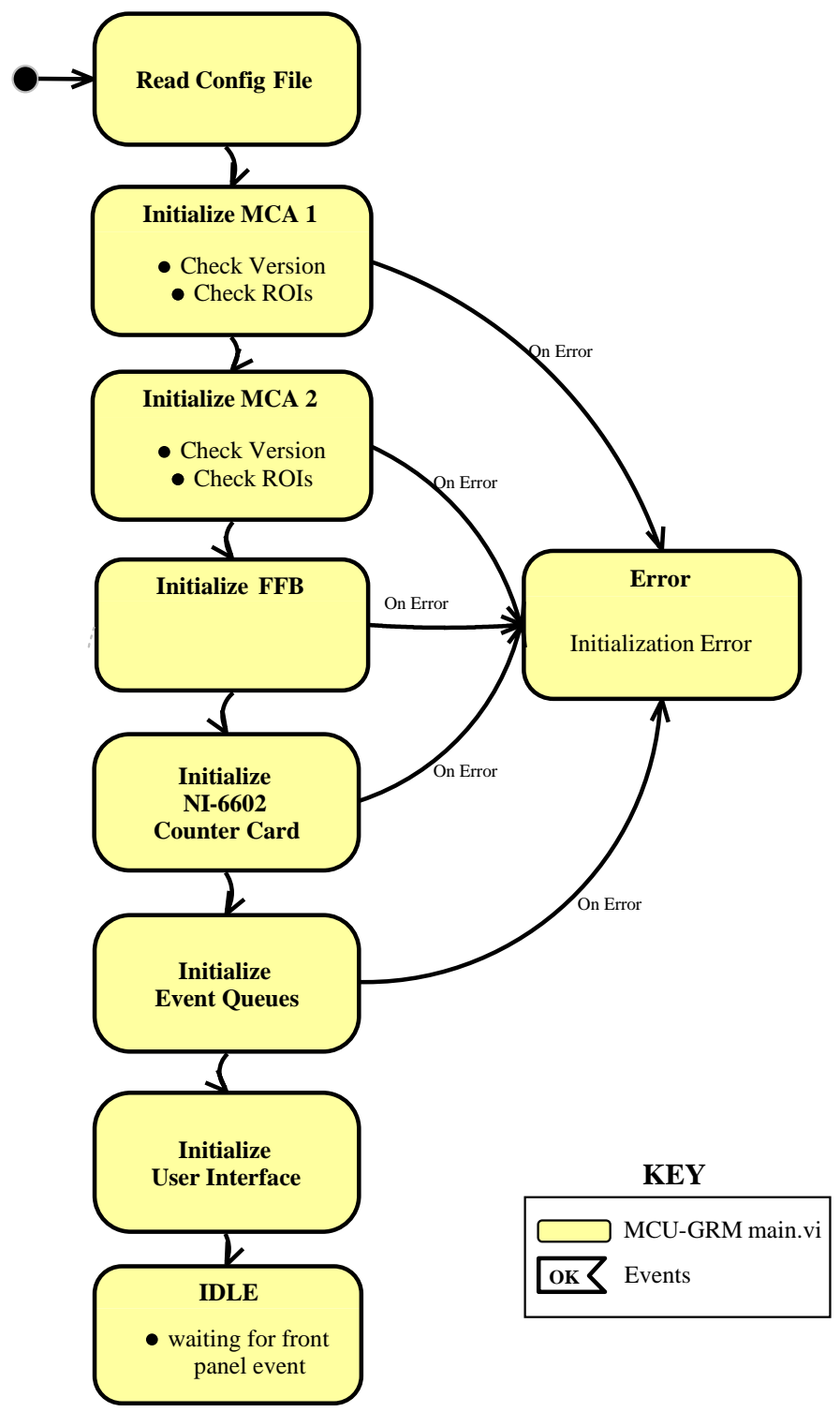

Figure 1: Initialization State Diagram

\subsection{Detector Configuration Mode}

One of the user actions that can be initiated from the IDLE state is the Detector Configuration Mode. The basic steps in this sequence are illustrated in the Detector Configuration State Diagram shown in Figure 2.

The process begins when the user initiates the CONFIGURE DETECTORS event from the user interface screen. When this event is received, the program displays a Login dialog box prompting the user for a password. If the password is correctly entered the user is granted access to the Detector Configuration screen. From this screen, the user can change any of a number of parameters associated with the four 
detectors. If accepted, changes are written to the detector configuration settings file (MCU_GRM_CONFIG.ini) where they replace the current values for the corresponding parameter. At the completion of this process, the system then returns to the IDLE state awaiting further user commands.

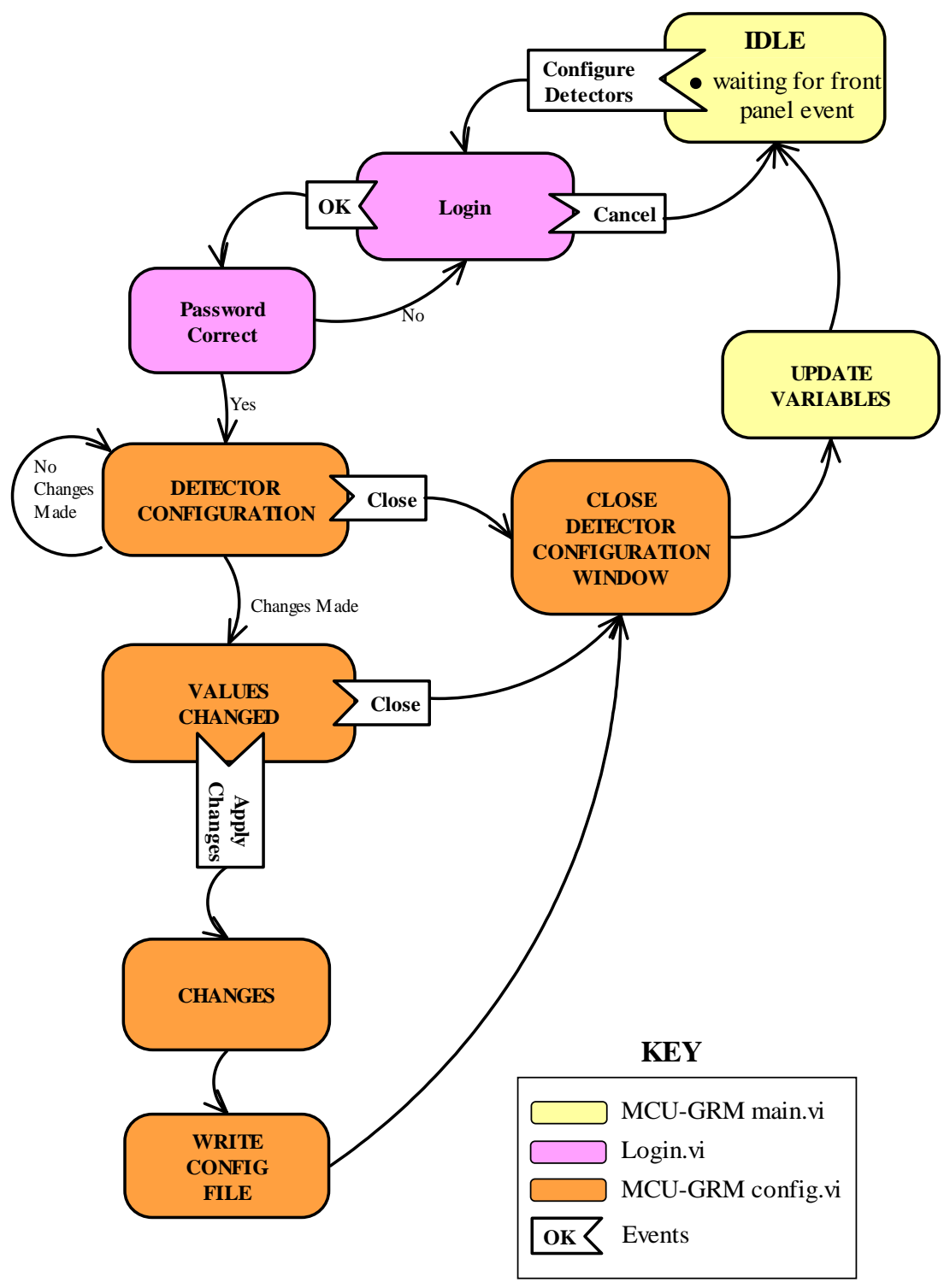

Figure 2: Detector Configuration State Diagram 


\subsection{Run Mode}

Another user action that can be initiated from the IDLE state is the Run Mode. The basic steps in this sequence are illustrated in the Run Mode State Diagram shown in Figure 3. The process begins when the user initiates the START event from the user interface screen.

When the START event is received, the program initiates a data acquisition cycle from the selected MCA and counter channel. The program then enters the RUNNING state, awaiting either a TIMEOUT event or a STOP command from the user. If a STOP command is issued, all data acquisition activities are halted and the program returns to the IDLE state awaiting further user interaction.

TIMEOUT events are generated at periodic intervals (1/second) for the purpose of updating the on-screen clock and cycle timers and for polling the MCA and Counter acquisition timers for completion. When an MCA acquisition has completed, the event handler reads the MCA data, restarts the MCA acquisition cycle, performs background and efficiency correction of the new data point, evaluates the Am peak centroid channel location, and writes the new data point to the screen and to the data log file. The data point is also passed to the DCS through the FFB interface. A similar sequence of events is performed for the Counter cycle. ERROR events are generated when communication cannot be established between either the MCA or Counter. The ERROR event states are not shown in the diagram for clarity. The system will remain in the RUNNING state until the user initiates a STOP event as described earlier. 
WSRC-RP-2005-01902

Revision \#0

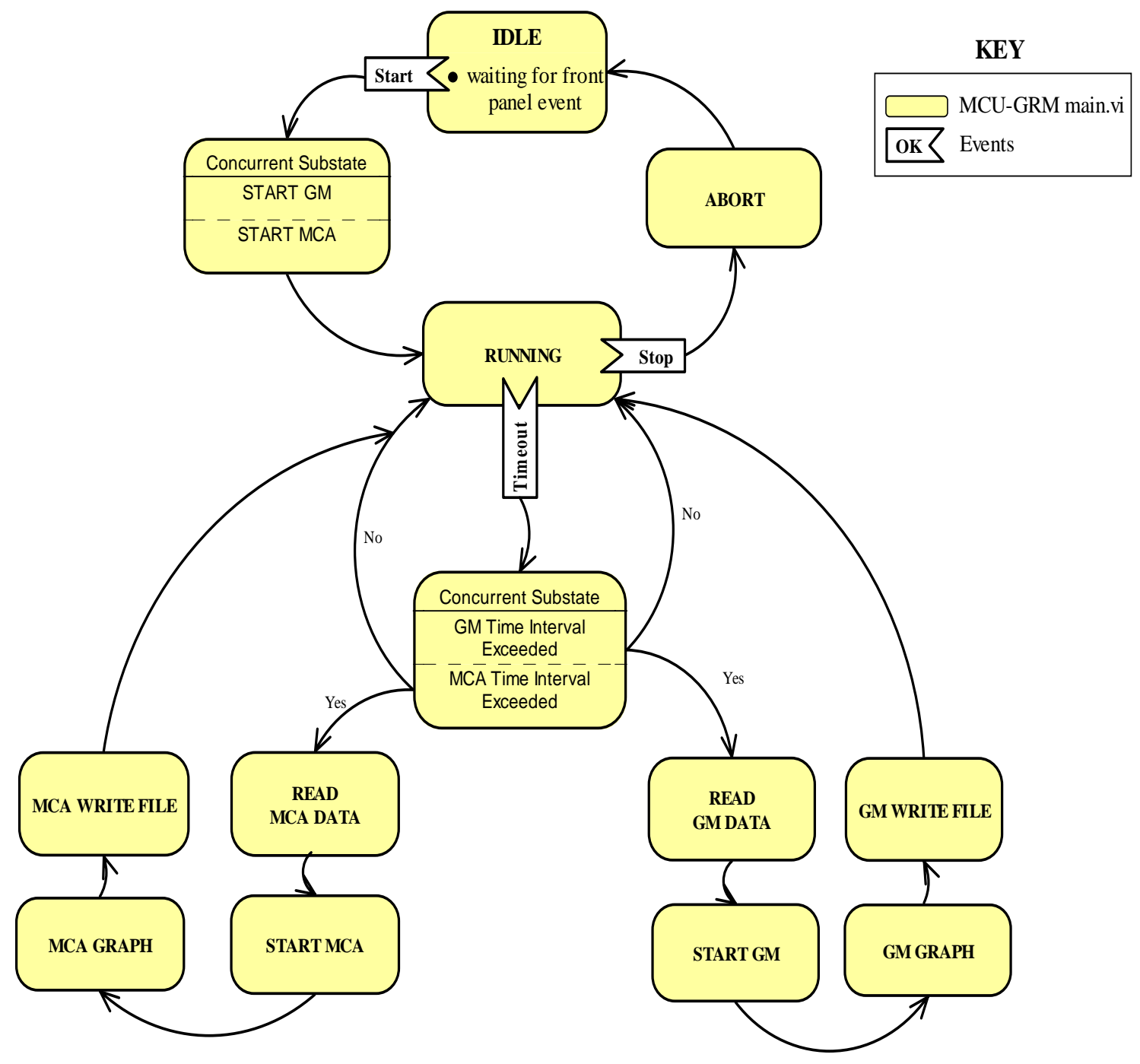

Figure 3: Run Mode State Diagram

\subsection{Background Counting Mode}

The basic sequence for the Background Counting Mode is illustrated in Figure 4. The process begins when the user initiates the COUNT BACKGROUND event from the user interface screen. This causes the Start Background.vi module to be displayed. From this screen, the user can verify the selected detectors and background count times. The screen also contains a message to remind the user to prepare the system for background measurement. If the user selects CANCEL from this screen, the program returns to the IDLE state awaiting further user interaction. If the operation is accepted, the program initiates a data acquisition cycle from the selected MCA and counter channel. The program then enters the COUNTING BACKGROUND state, awaiting either a timeout event or a STOP command from the user. If a STOP command is issued, all data acquisition activities are halted and the program returns to the IDLE state awaiting further user interaction. 
Similar to the Run Mode, TIMEOUT events are generated at periodic intervals (1/second) for the purpose of updating the on-screen clock and cycle timers and for polling the MCA and Counter acquisition timers for completion. When an MCA acquisition has completed, the event handler reads the MCA data, and passes the data point on the Background Complete.vi. The Background Complete module displays the newly acquired background data point and prompts the user to decide whether to keep or discard the new data. If the user decides to keep the new data point, the data are written to the detector configuration file and used for all subsequent calculations requiring background correction. Otherwise the data are discarded and the current settings retained. A similar sequence of events is performed for the Counter cycle. When both counting cycles have completed, program control is returned to the IDLE state.

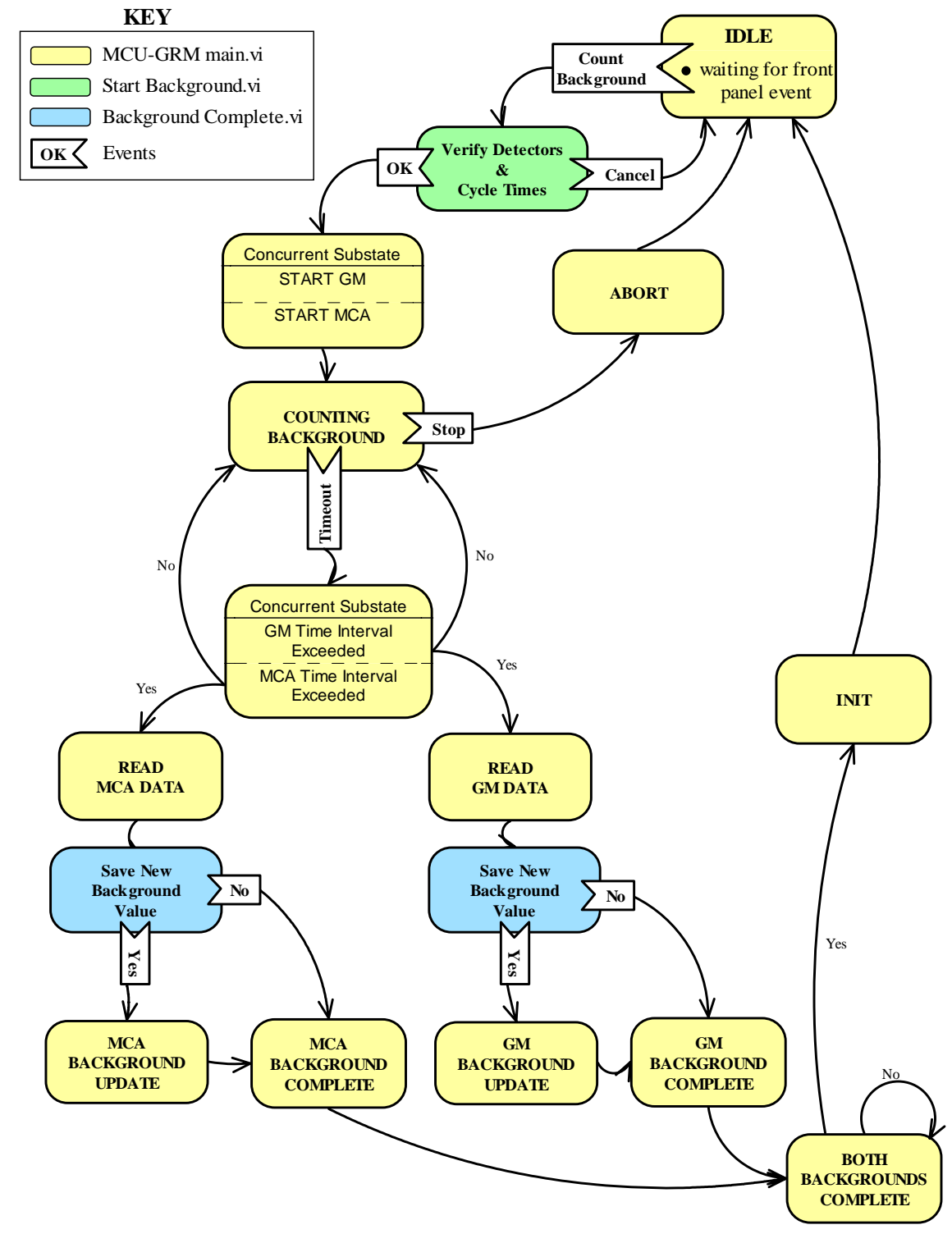

Figure 4: Background Counting Mode State Diagram 
Modular Caustic Side Solvent Extraction Unit Gamma Ray Monitors (MCU-GRM)

Software Quality Assurance Plan (U)

Document Number: J-SQP-H-00013 Rev 0

Date: $\quad$ May 24, 2005

ENGINEERING DOC. CONTROL - SAS

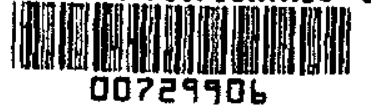


WSRC-RP-2005-01902

Revision \#0

Modular Caustic Side Solvent Extraction Unit Gamma Ray Monitors

Software Quality Assurance Plan
J-SQP-H-00013

Revision 0

Page 2 of 14
Approvals:

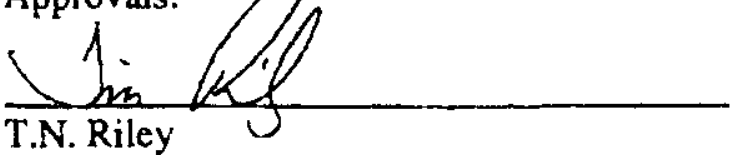

Design Agency

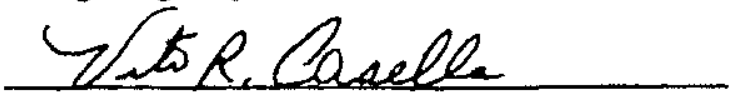

V.R. Canella

IR-1 Independent Reviewer

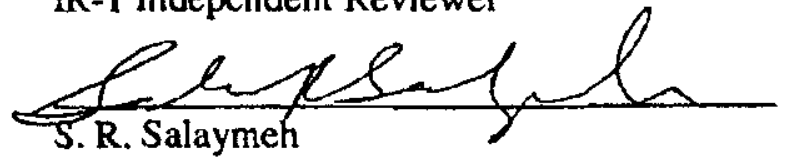

Manager, Sensor and Analyzer Technology

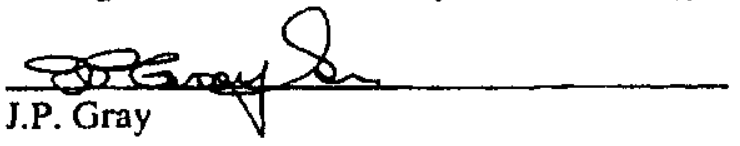

CQF

G. A. Hill

Software Owner

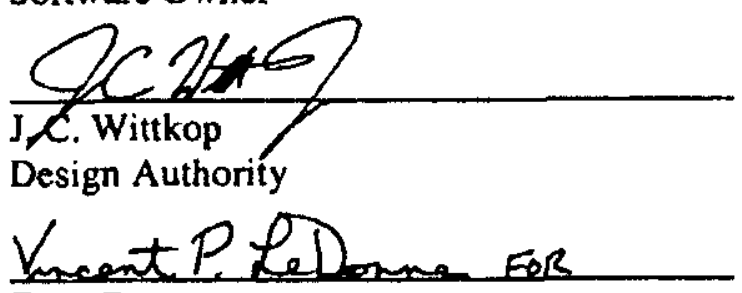

E. A. Brass

MCU Design Authority Manager

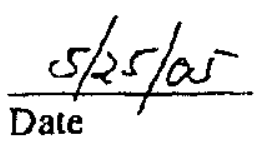

$5 / 26 / 05$

Date

$6 / 30105$

Date

$\frac{6 / 2 / 05}{\text { Date }^{2}}$

$\frac{6 / 20 / 05}{\text { Date }}$

$6 / 8 / 2005$

Date

$\frac{6 / 7 / 05}{\text { Date }}$

55

1. 
WSRC-RP-2005-01902

Revision \#0

\section{SUMMARY OF CHANGES}

\begin{tabular}{|l|l|l|}
\hline Revision: & Date: & Description: \\
\hline A & $4 / 14 / 05$ & Initial routing for review and comments \\
\hline 0 & $5 / 24 / 05$ & Approval \\
\hline & & \\
\hline
\end{tabular}




\section{TABLE OF CONTENTS}

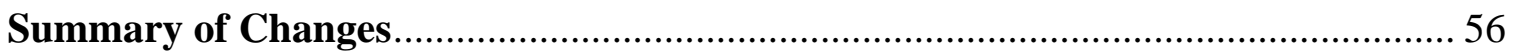

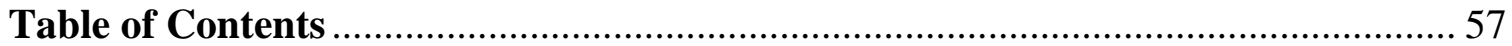

1. Scope. Error! Bookmark not defined.

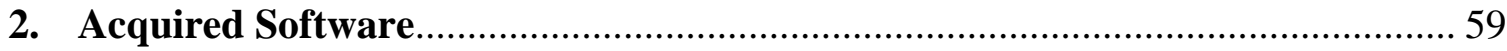

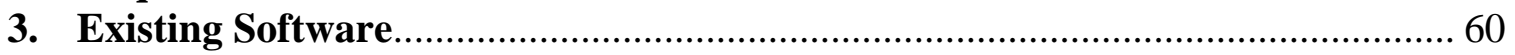

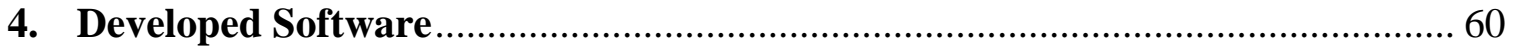

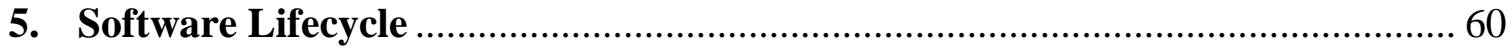

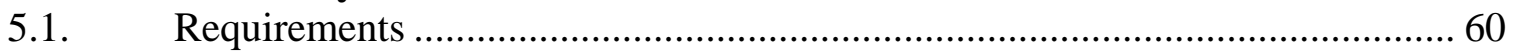

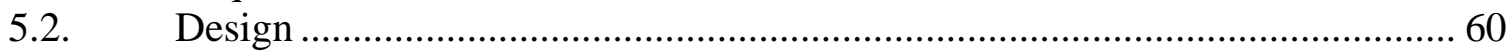

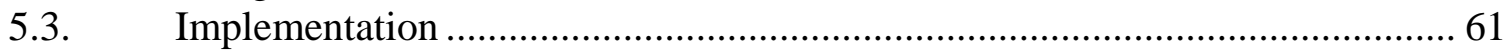

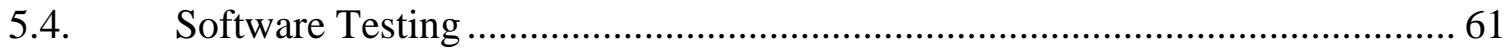

5.5. Software Installation and Acceptance Testing................................................... 61

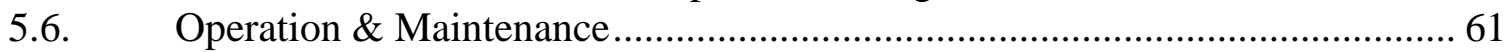

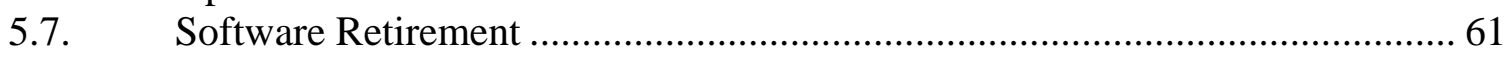

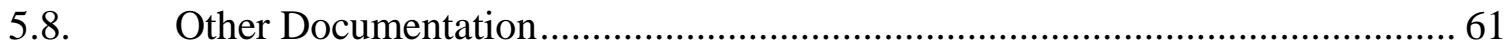

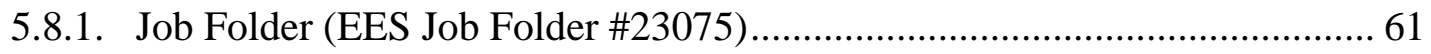

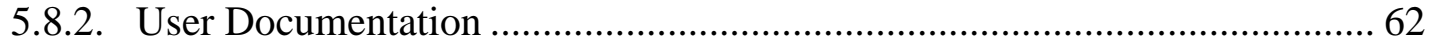

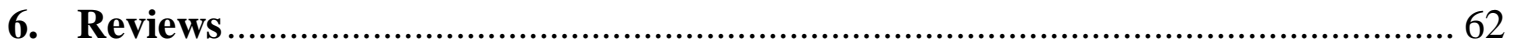

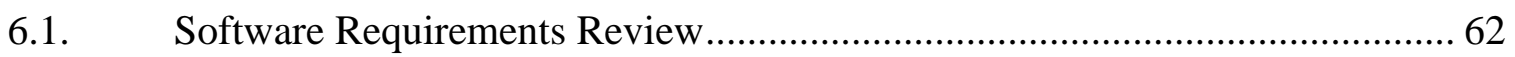

6.2. Requirements Traceability Matrix ……………............................................. 62

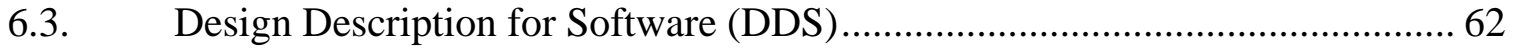

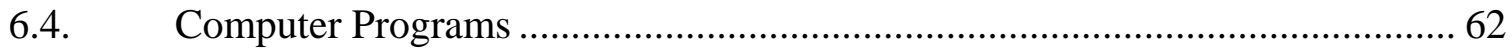

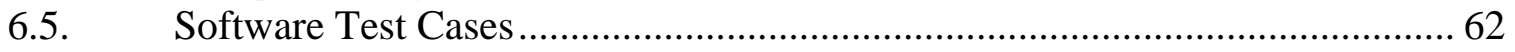

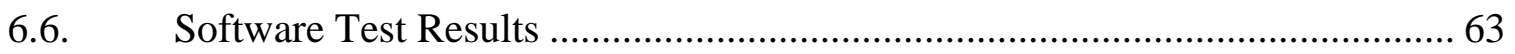

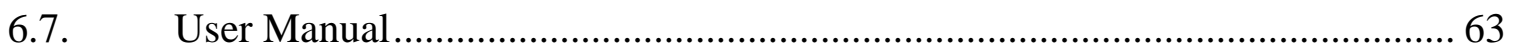

6.8. Installation and Acceptance Test Results ......................................................... 63

7. Configuration Management / Baseline Control.......................................................6 63

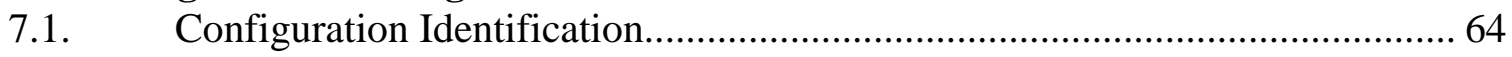

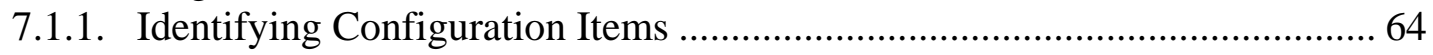

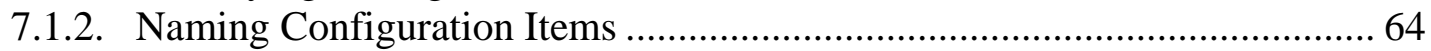

7.1.3. Removable Media Requirements ................................................................. 64

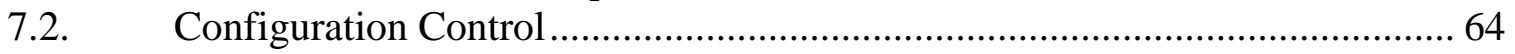

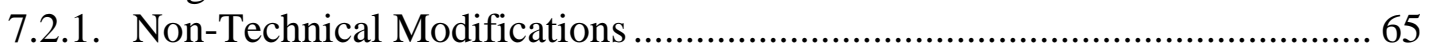

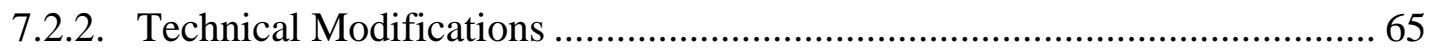

8. Problem Reporting and Corrective Action ........................................................... 65

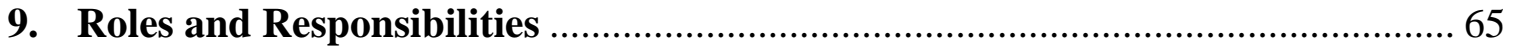

9.1. Customer and Software Owner: HTF Operations.............................................. 65

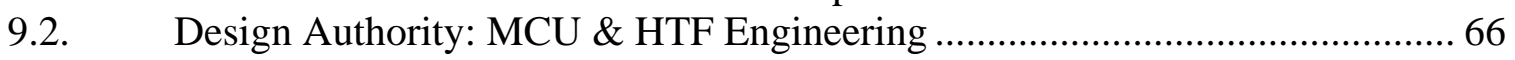

9.3. Design Agency: SRNL-Engineered Equipment \& Systems (EES) .................... 66

9.4. Software Cognizant Quality Function: SRNL-Quality Engineering ................. 67

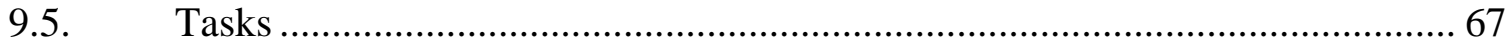

10. Tools, Techniques, Methods, Standards, Practices, and Conventions........... 67

11. Quality Assurance Records / Documentation …………………....................... 68

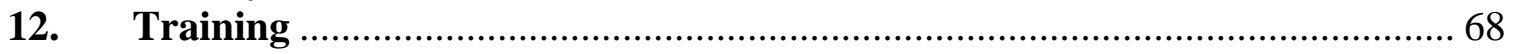


WSRC-RP-2005-01902

Revision \#0

13. Reference Documents

68

Attachment 1: MCU-GRM Software Requirements.

69 


\section{Scope}

This Software Quality Assurance Plan (SQAP) applies to the development of software for the Modular Caustic Side Solvent Extraction Unit Gamma Ray Monitors (MCUGRM). This SQAP follows guidelines set forth in Manual E7 procedure 5.03 “Software Quality Assurance Plan”, WSRC Manual 1Q QAP 20-1 “Software Quality Assurance” and IEEE Standard 730 "Software Quality Assurance Plans”. The software engineering approach used to produce this software is a combination of the acquisition of Commercial, Off-The-Shelf (COTS) software elements and the development of MCU-GRM process specific application software elements. The MCU-GRM software has been classified as Production Support (PS) per U-FCD-H-00008. These elements are separated into two distinct software units, development and production. The makeup of each system as related to COTS and developed software applications is depicted below:

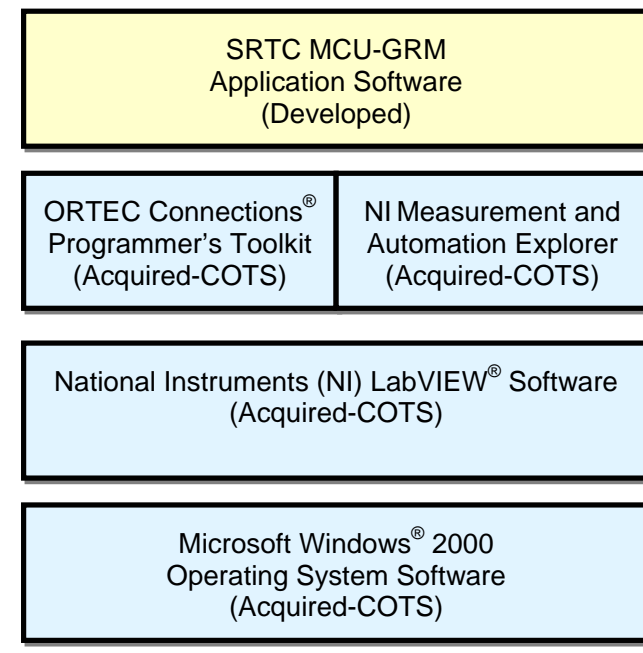

DeVelopment SySteM
SRTC MCU-GRM Application Software (Developed)

Microsoft Windows ${ }^{\circledR} 2000$

Operating System Software (Acquired-COTS)

Use of the Development System software will be limited to the development and maintenance of the MCU-GRM production software. The MCU-GRM production software is an integration of both developed and acquired elements. The intended use of the MCU-GRM production software is for monitoring and control of the MCU-GRM hardware.

\section{Acquired Software}

The MCU-GRM production software will be developed using the following products: Microsoft Windows 2000 Operating System, National Instruments LabVIEW software, 
National Instruments Measurement \& Automation Explorer software, and the ORTEC Connections Programmer's Toolkit. All software products for this task shall be purchased in accordance with requirements for PS or Level C components. Evaluation/ dedication of acquired software will be in accordance with the requirements of Manual E-7, Procedure 5.07.

\section{Existing Software}

All new software will be acquired or developed per Sections 2 and 4 of this SQAP. Software products previously purchased and intended for use with this task shall be evaluated to determine adequacy for their intended purpose through the completion of a Software Evaluation Package (SEP) per Manual E7 Procedure 5.07.

\section{Developed Software}

All software developed or modified as part of this project shall comply with the task requirements for the following lifecycle activities:

- Requirements

- Design

- Implementation

- Test, Installation \& Acceptance

\section{Software Lifecycle}

The following documentation will be developed / used per this SQAP. These documents shall be maintained and updated as necessary throughout the software life cycle. Technical baseline documents will be managed per the E7 manual.

\subsection{Requirements}

Requirements for the MCU-GRM software are listed in attachment 1 . These requirements shall be used to form the basis for software design, testing and validation. Neither a separate requirements specification for software (RSS) nor a requirements traceability matrix (RTM) will be required for the MCU-GRM system.

\subsection{Design}

The Design Agency shall develop a Design Description for Software (DDS) for the MCU-GRM based on the requirements defined in Attachment 1. The DDS shall follow the format in the Manual E7 Procedure 5.20, where possible. Design Descriptions of other formats may be used as necessary to convey the correct information. If any of these documents should become classified as part of the facility technical baseline, then they shall become documents of record, otherwise, departmental storage with the design agency shall be adequate. 


\subsection{Implementation}

The design agency shall produce source code and a software test plan (STP) with test cases traceable to the required elements specified in Attachment 1. MCU-GRM software shall be developed and implemented per the approved design documentation as described in Sections 5.1 and 5.2 of this document in accordance with manual E7 Procedure 5.20. The extent of testing and verification will be detailed in the software test plan per Manual E7 Procedure 5.40. Resolution of problems and deficiencies noted during testing shall be addressed in the software test plan.

\subsection{Software Testing}

The design agency shall perform off-line testing of the MCU-GRM production software per the STP. The testing is to be conducted on an offline system with a successful demonstration of software functionality to be demonstrated to the design authority and software owner prior to deployment to the field.

\subsection{Software Installation and Acceptance Testing}

The following will be required prior to placing the MCU-GRM production software in service:

- Completion of all software design and implementation activities.

- Successful completion of all offline testing and acceptance by the Design Authority.

- Successful completion of the Software Acceptance Test

- Software owner approval.

NOTE: The Test Lead Engineer shall develop a Software Acceptance Test Plan for the MCU-GRM software for testing the system after installation in the facility.

\subsection{Operation \& Maintenance}

The MCU-GRM software will be operated using approved operational procedures. Changes to the software configuration are covered in section 7 of this procedure.

\subsection{Software Retirement}

The Design Authority and the Software Owner will determine when the software is to be retired. Removal of the MCU-GRM software from service shall be documented on a CMT per Manual E7 procedure 5.62.

\subsection{Other Documentation}

Documents that relate to the lifecycle of this software include:

5.8.1 Job Folder (EES Job Folder \#23075)

A job folder has been established in the 730-A Document Control Facility for collecting all MCU-GRM related documentation. The job folder shall 
contain a software index, the SQAP, DDS, and STP, etc., as well as any other user documentation developed as part of this project.

\subsubsection{User Documentation}

SRNL will keep vendor manuals as appropriate for use as reference during the software lifecycle. A User Manual will be developed by SRNL for use by the customer.

\section{Reviews}

In order to ensure the technical adequacy and acceptance of the software and its conformance to system requirements, reviews shall be required for the MCU-GRM production software as specified in this section. Type 1 or Type 2 Independent Reviews of some elements of the MCU-GRM software shall be performed as required by Manual E7 Procedure 5.03. A Type 1 Independent Review (IR-1) is the review of a document performed by an individual knowledgeable in the area of review to ensure that the assumptions, methodology and resulting product reflect sound engineering judgment. An individual other than the individual that did the work being reviewed conducts the IR-1 Review. A Type 2 Independent Review (IR-2) is similar to an IR-1 with the added requirement that it be conducted by an individual subject to a different technical direction (i.e., not assigned to the same project or task).

\subsection{Software Requirements Review}

The software requirements are included as part of this document and will be reviewed during the normal review and approval cycle. This review shall also include a Type 1 (IR-1) review. A separate Requirements Specification for Software (RSS) is not required for this project.

\subsection{Requirements Traceability Matrix}

Not required for this project.

\subsection{Design Description for Software (DDS)}

The Design Description for Software (DDS) and other software design documents may be reviewed and if necessary revised as required during the development phase of the project. A Type 1 (IR-1) review of the DDS will be performed internally by SRNL. The Design Authority will approve the final software design.

\subsection{Computer Programs}

A Type 1 Independent Review (IR-1) shall be performed on all Acquired Software to ensure that the programs meet the design constraints of the MCU-GRM production software.

\subsection{Software Test Cases}

Test cases selected for software testing must be subjected to a Type 1 Independent Review, with the results documented, including identification of the reviewer. The test cases shall be reviewed against the design criteria as specified in Attachment 1 
to ensure all design requirements are being tested. The Design Authority will approve the final Software Test Plan (STP).

\subsection{Software Test Results}

All test results must be followed by a Type 1 Independent Review to ensure the test requirements as specified in Section 6.5 have been satisfied. IR-1 results must be documented, including identification of the reviewer. This review must be completed prior to use of the software.

\subsection{User Manual}

The MCU-GRM Software User's Manual shall be subjected to a Type 1 Independent Review, with the results documented, including identification of the reviewer. The Design Authority and Software Owner will approve the final manual.

\subsection{Installation and Acceptance Test Results}

A Type 2 Independent Review shall be performed on all Installation and Acceptance Test Results prior to placing the MCU-GRM system in service. This review shall include verification of the deliverables for each lifecycle phase. It will also determine the acceptability of the detailed software design as depicted in the software design description in satisfying the requirements of the software requirement specifications. The Design Authority and Software Owner shall approve the Installation and Acceptance Test Results.

\section{Configuration Management / Baseline Control}

Software for the MCU-GRM shall be placed under Configuration Management (CM). All Configuration Items (CIs) shall become part of the software baseline and placed in the Configuration Management System (CMS). All items in the CMS shall be uniquely identified, indexed, and tracked by generation / revision throughout the software lifecycle. Configuration change control shall be governed through the CMT process outlined in Manual E7 Procedure 5.62, and tested / accepted by an approved STP per Manual E7 Procedure 5.40.

After the Test and Installation phase and prior to the Operation and Maintenance phase of the lifecycle, the software shall be re-baselined as necessary. At this time a unique identifier, with version number, will be placed on the software main screen. Additionally, the LabVIEW version and serial number will be recorded.

Changes to the configuration shall occur only through approval of the Design Authority and the Software Owner. Changes shall be documented, tested and the software revision number sequentially increased. LabVIEW updates, service packs, etc. shall be reviewed by the Software Owner and Design Authority before incorporation. If incorporated, the software shall be re-baselined and regression testing completed as necessary. 
An electronic baseline of the software source code, and all revisions of the source code, shall be placed in an approved Document Control Facility.

\subsection{Configuration Identification}

\subsubsection{Identifying Configuration Items}

The configuration index provides a comprehensive list of all software configuration items (SCIs). The configuration index is maintained as a plain text electronic file within the Configuration Management System (CMS). The configuration index will support the identification of the current baseline. Configuration items controlled within CMS will be assigned unique generation / revision numbers used for baseline identification.

The MCU-GRM configuration items are the LabVIEW (.vi) files, developed by SRNL. These are the files that comprise of the User Interface, data acquisition and manipulation algorithms, configuration files, and any other user file that is required for proper MCU-GRM software functionality that can be maintained in the CMS.

COTS software supplied by the vendor on a media such as CD-ROM required for a system build / recovery will be tracked on the configuration index.

\subsubsection{Naming Configuration Items}

All SCIs shall be named within the constraints of the operating system. Duplicate names shall not be allowed and the design agency is responsible for ensuring uniqueness.

\subsubsection{Removable Media Requirements}

All SCIs controlled in the media library must be labeled in a consistent format to identify the product and generation / revision. COTS products supplied on vendor media should be labeled with the product name / title, copyright notice, and version. Custom products stored on media from either vendor, or developed by SRNL that are not uniquely labeled will be assigned a unique number from the media library log and labeled accordingly. If software on media is subject to modification by SRNL two copies of each generation / revision of the media shall be maintained, one as "Baseline" and one as "Working Copy". All software maintained in media control shall be tracked through the master configuration index stored electronically in the CMS system.

\subsection{Configuration Control}

The MCU-GRM Production software source code is not a part of the facility technical baseline. However, the software requirements used to produce the software and certain key software design documents are part of the facility 
technical baseline. There are two methods for changes to be made to baseline software:

\subsubsection{Non-Technical Modifications}

Non-Technical Modifications are modifications to the baseline software that are not driven by a technical baseline document (e.g. graphic changes). Non-Technical Modifications may be performed using a Computer Modification Tracker (CMT).

7.1.5. Technical Modifications

Technical modifications are modifications to baseline software that are driven by changes to one of the software technical baseline documents (SQAP, STP, etc). These changes require a DCP / DCF in addition to a CMT.

\section{Problem Reporting and Corrective Action}

The software owner is responsible for notifying the design authority of problems, design enhancements, and reporting instances of operational nonconformance during the operation of the MCU-GRM software. The design authority shall determine the appropriate level of documentation necessary for this process. Corrective actions shall be controlled as specified in section 7.2 of this procedure. Additionally, operational software problems and programmatic deficiencies shall be reported as specified in QAP 15-1, "control of nonconforming items", and MRP 4.23, "Site Tracking Analysis and Report (STAR) System” as required.

\section{Roles and Responsibilities}

\subsection{Customer and Software Owner: HTF Operations}

The Software Owner has the following responsibilities:

- Initiates request for software support.

- Communicates requirements and constraints to organization developing, designing, maintaining or acquiring the software.

- May initiate change requests to modify the baseline software.

- Approves change requests (CMTs) for the proposed modifications to software products.

- Review and approve changes to the software.

- Confirms testing is performed on the software.

- Final authority for installation and removal of software.

- Accept the tested software.

- Ensure that software configuration control is maintained. 
- Review and approve software quality documentation as indicated in the task matrix.

\subsection{Design Authority: MCU \& HTF Engineering}

The Design Authority has the following responsibilities:

- Perform functional classification for the software in accordance with the E7 manual procedures 5.05 and 2.25 .

- Produce the Requirements Specification for Software (RSS) for the system. The software requirements shall be included as part of the SQAP, (See Attachment 1).

- May initiate change requests to modify the baseline software.

- Review change requests for possible impact on the facility technical baseline.

- Approves change requests to modify the baseline software.

- Review and approve the software design and software design changes for items in the technical baseline.

- Develops the Software Acceptance Test plan for the production system.

- Perform Software Acceptance Testing for the production system.

- Provides independent verification of modifications to the software.

\subsection{Design Agency: SRNL-Engineered Equipment \& Systems (EES)}

The Design Agency has the following responsibilities:

- Review the technical software requirements for the system.

- Develop the Software Quality Assurance Plan (SQAP).

- Complies with the software requirements of the E7 Manual and site standards.

- Ensures that software products are in compliance with site standards.

- May initiate change requests to modify baseline software.

- Develop Design Document for Software (DDS).

- Develop Software Test Plan (STP) for offline software testing.

- Verifies changes to software.

- Develops user documents and technical documents.

- Loads the software to the target system.

- Participates in Software Acceptance Testing as required.

- Manages the configuration control process for the software products.

- Maintains the software design documentation during the product life cycle.

The role of Design Agency, relative to software, is guided by the E7 Manual Section 5 "Software Engineering \& Control" and does not involve development or modifications to the facility technical baseline. 


\subsection{Software Cognizant Quality Function: SRNL-Quality Engineering}

The Cognizant Quality Function has the following responsibilities:

- Review and approve the software quality documentation per task matrix.

\section{5 $\underline{\text { Tasks }}$}

The following table presents the organizational roles for software quality assurance tasks pertaining to MCU-GRM software development.

\begin{tabular}{|l|l|l|l|l|}
\hline \multicolumn{1}{|c|}{ Task } & $\begin{array}{c}\text { Design } \\
\text { Authorit } \\
\text { y }\end{array}$ & $\begin{array}{c}\text { Design } \\
\text { Agency }\end{array}$ & $\begin{array}{c}\text { Quality } \\
\text { Assuran } \\
\text { ce }\end{array}$ & $\begin{array}{c}\text { Software } \\
\text { Owner }\end{array}$ \\
\hline $\begin{array}{l}\text { Functional Classification } \\
\text { Document }\end{array}$ & W,A & & & \\
\hline $\begin{array}{l}\text { Software Requirements Document. } \\
\text { Included in SQAP. }\end{array}$ & W,R,A & R,A & & R,A \\
\hline SQAP (Software QA Plan) & R,A & W,R,A & R,A & R,A \\
\hline $\begin{array}{l}\text { DDS (Design Description for } \\
\text { Software) }\end{array}$ & R,A & W,R,A & & \\
\hline STP (Software Test Plans) & R,A & W,R,A & & R,A \\
\hline Test Cases & R,A & W,R,A & & \\
\hline Test Results & R,A & W,R,A & & R,A \\
\hline User Manual & R,A & W,R,A & & R,A \\
\hline Job Folder (EES \#23075) & & W & & \\
\hline Software Acceptance Test & W,R,A,P & R,A & & R,A \\
\hline Software Modifications & W,R,A & R,A,P & & W,R,A \\
\hline
\end{tabular}

Legend: $\quad \mathrm{P}=$ Perform, $\mathrm{R}=$ Review, $\mathrm{A}=$ Approve, $\mathrm{W}=$ Write

\section{Tools, Techniques, Methods, Standards, Practices, and Conventions}

Tools for troubleshooting, modifying, and maintaining software products for the MCUGRM will be those provided by or approved for use by the vendor of the COTS software. If it is deemed that any of these tools are inadequate or additional tools are required such as those for process simulation, modeling, advanced control algorithms, system backup / recovery or products necessary to maintain configuration control "Third Party" applications may be used after sufficient product testing and concurrence from all effected agencies. 


\section{Quality Assurance Records / Documentation}

All record documentation for software given a controlled number shall be managed in accordance with Manual E7 Procedure 1.20, 1Q QAP 17-1, and the Retention Schedule Matrix. All other software documentation shall be filed in Job Folder \#23075 in the 730-A Document Control facility.

This document shall be maintained as a QA record until the systems are retired or the facility is removed from service.

\section{Training}

The software owner shall determine the level of training required for operation of the MCUGRM software. Operator training, if required, is outside the scope of this document.

\section{Reference Documents}

- U-FCD-H-00008, Rev. 0, "Modular CSSX Unit (MCU) Software Classification - a portion of the DISTRIBUTED CONTROL SYSTEM (DCS) network"

- WSRC-RP-2004-00875, Rev 0, “Task Technical and Quality Assurance Plan for Caustic Side Solvent Extraction Gamma-Ray Monitors”

- U-MT-H-00085, Rev 0, “Cesium Removal Implementation Using Caustic Side Solvent Extraction Technology”

- G-TC-H-00041, Rev 3, “Task Requirements and Criteria - Modular Caustic Side Solvent Extraction Unit (MCU)"

- Technical Task Request, SP-TTR-2004-00013

- WSRC 1Q Manual QAP 20-1, "Software Quality Assurance"

- WSRC 1Q Manual QAP 17-1, "Quality Assurance Records Management"

- WSRC E7 Manual Procedure 1.20, "Engineering Document Numbering System"

- WSRC E7 Manual Procedure 2.25, "Functional Classifications"

- $\quad$ WSRC E7 Manual Procedure 5.01 "Software Engineering \& Control"

- WSRC E7 Manual Procedure 5.03 "Software Quality Assurance Plan"

- WSRC E7 Manual Procedure 5.05 "Software Classification”

- WSRC E7 Manual Procedure 5.07 "Evaluation of Existing and Acquired Software”

- WSRC E7 Manual Procedure 5.10 “Software Requirements”

- WSRC E7 Manual Procedure 5.20 "Software Design and Implementation”

- WSRC E7 Manual Procedure 5.40 "Software Testing, Acceptance, and Turnover”

- WSRC E7 Manual Procedure 5.62 "Computer Program Modification Tracker"

- IEEE Standard 730-1998, “Software Quality Assurance Plans” 


\title{
ATTACHMENT 1: MCU-GRM SOFTWARE REQUIREMENTS
}

\author{
Requirement \#__ $1 \_$Priority: High
}

Function: The MCU-GRM software shall provide the user with the ability to select between either of the two Sodium Iodide detectors, NaI1 or NaI2. Only 1 detector will be functional at any given time. Selection between the two detectors will be accomplished via user selectable switches on the MCU-GRM User Interface.

Performance: None.

User Interface: Detector selection shall be through a means clearly identified on the User Interface.

Acceptance Criteria: The software will successfully switch between the outputs of both NaI detectors.

Requirement \#_____ Priority: High

Function: The MCU-GRM software shall contain a graphical data display of the measured parameters vs time for both Geiger-Mueller (GM1 \& GM2) detectors as well as for the selected Sodium Iodide detector (NaI1 or NaI2).

Performance: A graphical display on the MCU-GRM User Interface shall be used to perform the graphical data representation for both systems. As a minimum, each display shall present the 50 most recent data points for each of the monitored detectors. Data points shall be updated whenever new values are acquired.

User Interface: The user interface shall contain an appropriate number of graphical data windows to display the data points versus time for both GM1 and GM2, and for either NaI1 or NaI2.

Acceptance Criteria: The MCU-GRM software graphical displays will faithfully display the most recent data points and maintain the 50 most recent points in the individual plots.

Requirement \#__ 3_ Priority: High

Function: The MCU-GRM software shall allow the user to perform background measurement and subtraction for the two Sodium Iodide detectors, NaI1 and NaI2, 
independently of the other. Proper valve alignment and flushing and filling the system piping will be procedurally controlled by the facility and are outside the scope of the MCUGRM software.

Performance: The MCU-GRM software shall allow the user to periodically perform a background measurement with either detector, NaI1 or NaI2. The MCU-GRM software will automatically update the background readings for the selected detector and record the date when the reading was performed. The MCU-GRM software will use only the new background reading to perform a background subtraction during the normal measurement cycle.

External Interface: Preparation of the system piping for the background measurement is outside the scope of the MCU-GRM software and will not be performed as part of this requirement. It is the responsibility of the user of the software to properly prepare the system for background measurement.

User Interface: The user interface shall provide a mechanism for performing a background measurement using either NaI1 or NaI2. The user interface shall also include a means for manually entering or reviewing the background values for the NaI1 and NaI2 detectors independent of the other setting.

Acceptance Criteria: When in background counting mode, the background count shall be successfully performed and the new background value and date recorded to reflect the latest measured data. In measurement mode, the new values shall be used to compensate for the most recent measured background levels.

Requirement \#___ P__ Priority: High

Function: The MCU-GRM software shall provide a means for calibration of all four detectors GM1, GM2, NaI1, and NaI2 through the manual entry of a detector efficiency factor. The efficiency setting of each detector shall be independent of the other detectors.

Performance: Initial calibration of each detector shall be performed during off-line testing of the MCU-GRM software. The calibration will produce an efficiency factor for each of the four detectors. These values shall be manually recorded in the MCU-GRM software along with the date when the reading was performed. The MCU-GRM software will use only the latest efficiency values during the normal measurement cycle.

External Interface: After the system is installed calibration shall be controlled by the facility. It is the responsibility of the Facility to obtain the proper calibration standards and to properly prepare the system for calibration. Proper valve alignment and flushing and filling the system piping will be procedurally controlled by the facility and is outside the scope of the MCU-GRM software. 
User Interface: The user interface shall provide a mechanism for manually entering or reviewing the detector efficiency values for detectors GM1, GM2, NaI1, and NaI2.

Acceptance Criteria: In measurement mode, the MCU-GRM software shall provide correction of the raw output of each detector for its own measured efficiency.

Requirement \#__ 5 ___ Priority: High

Function: The MCU-GRM software shall contain provisions for communicating the most recently acquired activity levels obtained from GM1 and GM2, as well as the concentration data from either NaI1 or NaI2 to the MCU Distributed Control (DCS) System. There are no DCS controllable features in the MCU-GRM software.

Performance: The MCU-GRM software will take the most recent data points from the GM1 and GM2 detectors and from either NaI1 or NaI2, perform the necessary conversions, and report this data to the MCU-DCS through the interface hardware.

User Interface: The user interface will display the last data points sent to the MCU-DCS system.

External Interface: A Foundation Field Bus Card shall be provided in the MCU-GRM computer for connection to the MCU-DCS. The external interface shall be coordinated between the Design Agency and Design Engineering in accordance with J-J8-H-07866, MM6-H-02422, M-M6-H-02424.

Acceptance Criteria: The MCU-GRM software will send the most recent data points through the Foundation Field Bus Module. 


\section{Distribution:}

The standard ITS distribution of all technical reports is:

E. W. Holtzscheiter, 773-A

D. A. Crowley, 999-W

S. L. Marra, 999-W

T. B. Calloway, 999-W

N. E. Bibler, 773-A

C.M. Jantzen, 773-A

J. R. Harbour, 773-42A

G. C. Wicks, 773-A

Add this DWPF distribution for DWPF reports:

M. S. Miller, 704-S

J. E. Occhipinti, 704-S

R. M. Hoeppel, 704-27S

H. H. Elder, 703-H

J. F. Iaukea, 704-30S

J. W. Ray, 704-S

M. A. Rios-Armstrong, 704-27S

A. B. Sanders, 704-27S

W. B. Van-Pelt, 704-S

Others depending on subject area

Additional distribution may be added at author's discretion 
Modular Caustic Side Solvent Extraction Unit Gamma Ray Monil ors (MCU-GRM)

Software Test Plan

(U)

Document Number: J-STP-H-00236

Rev. 0

Prepared by:

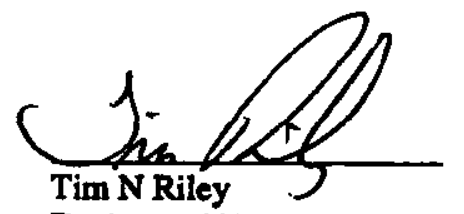

Engineered Equipment \& Systems

Savannah River National Laboratory

Date:

August 11, 2005 
$12 / 08 / 05$

THU 15:41 FAX

정 003

Modular Caustic Side Solvent Extraction Unit Gamma Ray Monitors Software Test Plan
J-STP. H-00236

$\mathbf{R}$ :vision 0

Page $=2$ of 19

WSRC-RP-2005-01902

Revision \#0

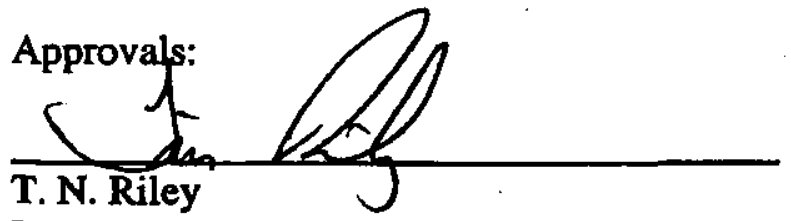

Design Agency

Var lassa

V.R. Canella

IR-1 Independent Reviewer

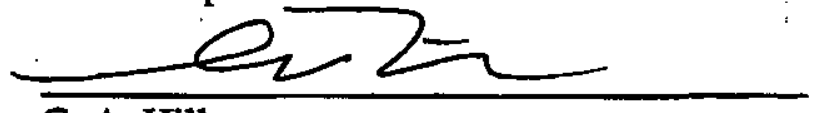

G. A. Hill

Software HT F OPERaTions girts

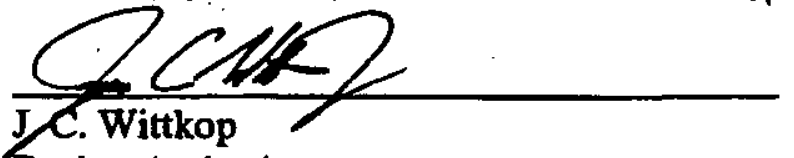

Design Authority

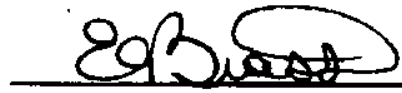

E. A. Brass

MCU Design Authority Manager $\frac{8 / 11 / 2005}{\text { Date }}$

$\frac{8 / 11 / 2005}{\text { Date }}$

$\frac{8 / 16 / 05}{\text { Date }}$

$8 / 15 / 2005$

Date

$8|15| 2005$

Date

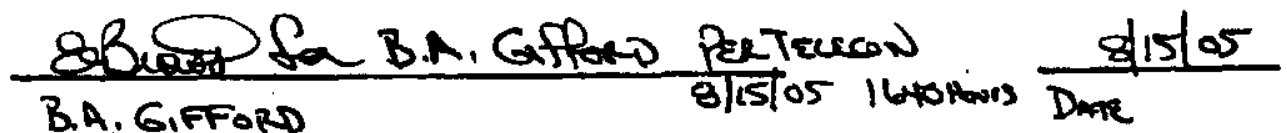
Eiliplos MaN Project owner/Sopt ware Contr

74 
WSRC-RP-2005-01902

Revision \#0

Summary of Changes

\begin{tabular}{|l|l|l|}
\hline Revision: & Date: & Description: \\
\hline A & $7 / 22 / 05$ & Initial routing for review and comments \\
\hline 0 & $8 / 11 / 05$ & Approval \\
\hline & & \\
\hline
\end{tabular}




\section{TABLE OF CONTENTS}

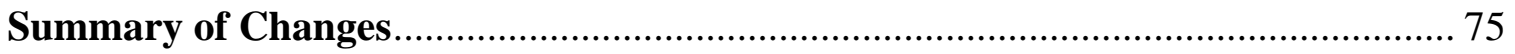

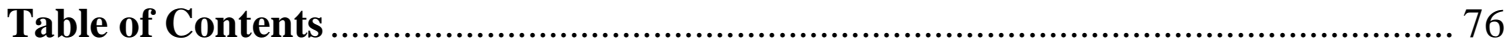

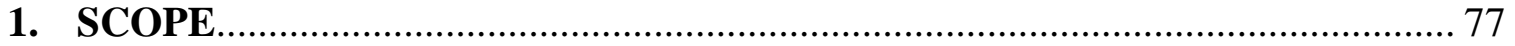

2. SOFTWARE PRODUCT IDENTIFICATION ……………………………........ 77

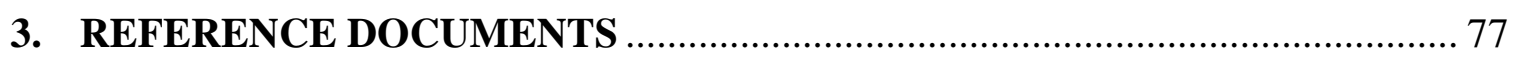

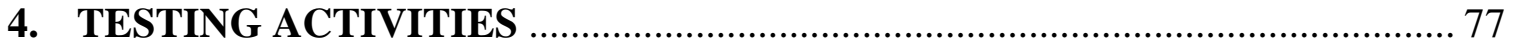

3.1. Software Operating Environment ………………............................................ 77

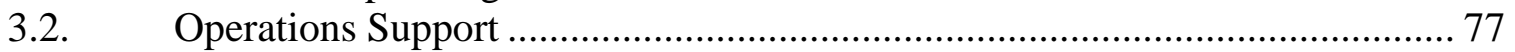

3.3. System Configuration ............................................................................... 78

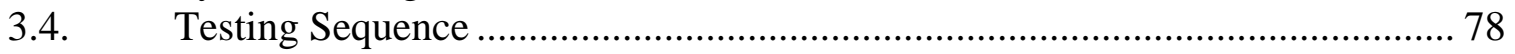

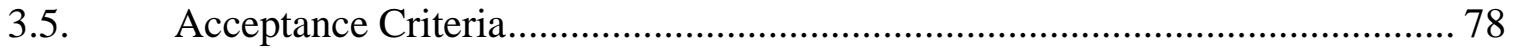

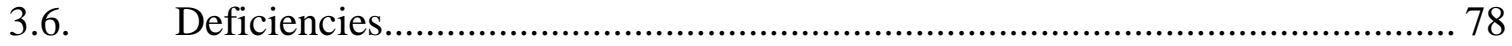

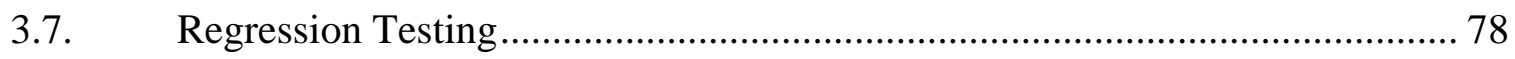

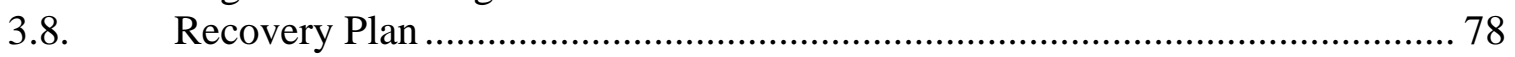

5. TEST RESULTS REVIEW AND APPROVAL .............................................. 79

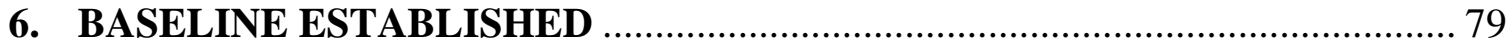

Attachment 1: MCU-GRM Test Cases ……………….............................................. 92 


\section{SCOPE}

This Software Test Plan (STP) is intended to cover the initial offline testing for the Modular Caustic Side Solvent Extraction Unit Gamma Ray Monitors (MCU-GRM) software. Integrated testing of this software with the Modular Caustic Side Solvent Extraction Unit (MCU) DCS system is not covered in this document.

NOTE: The Test Lead Engineer as identified in J-SQP-H-00013 shall develop a Software Acceptance Test Plan for integrated testing of MCU-GRM and MCUDCS software.

\section{SOFTWARE PRODUCT IDENTIFICATION}

\author{
Project Name: \\ Software Product Name: \\ Operating Division: \\ Facility: \\ Location of Target System: \\ Software Lead Engineer:
}

Modular Caustic Side Solvent Extraction Unit (MCU)

Modular Caustic Side Solvent Extraction Unit Gamma Ray

Monitors (MCU-GRM)

HTF Operations

Modular Caustic Side Solvent Extraction Unit (MCU)

H-Area (241-278H)

Tim N. Riley

Building 730-A

725-4801, B17314

\section{Reference Documents}

- J-SQP-H-00013, Rev 0, "Modular Caustic Side Solvent Extraction Unit GammaRay Monitors Software Quality Assurance Plan"

- Attachment 1, "MCU-GRM Software Offline Test Cases”

\section{Testing Activities}

\subsection{Software Operating Environment}

The software was developed using National Instruments LabVIEW ${ }^{\mathrm{tm}} 7.1$ and is operated under the Microsoft Windows $\mathrm{XP}^{\mathrm{tm}}$ operating system. For the purposes of this test, the MCU-GRM software shall be installed and operated on the actual MCU-GRM hardware to be installed in the facility.

\subsection{Operations Support}

No operations support is required during the performance of activities addressed under this test plan. 


\subsection{System Configuration}

Offline testing of the MCU-GRM production software shall be performed in building 773-A Laboratory B154. Testing shall be performed after fabrication of the system is complete, but prior to installation of the equipment in the field. Detectors shall be installed in their shields for the performance of the testing activities.

\subsection{Testing Sequence}

The software lead engineer shall perform off-line testing of the Mcu-Grm production software per this test plan. The testing is to be conducted on an offline system with a successful demonstration of software functionality to be demonstrated to the design authority and software owner prior to deployment to the field.

\subsection{Acceptance Criteria}

Acceptance criteria for each activity are listed within each test case under the Expected Result column.

\subsection{Deficiencies}

Deficiencies encountered during testing shall be recorded using the Computer Modification Tracking process outlined in Manual E7 Procedure 5.62, and tested / accepted by an approved STP per Manual E7 Procedure 5.40.

\subsection{Regression Testing}

The design authority shall determine the extent regression testing of the software required for any of the following cases: deficiencies found; software patch or equivalent is installed; operating system is upgraded or modified; computer problems experienced. Regression testing shall be documented through the use of a test log.

\subsection{Recovery Plan}

At the completion of testing, the Software Test Engineer will ensure that all components are returned to a safe configuration. 


\section{TEST RESULTS REVIEW AND APPROVAL}

\begin{tabular}{llc}
\hline Print & Signature & Date \\
Software Test Engineer & &
\end{tabular}

Print Signature $\quad$ Date

Design Authority

Print Signature Date

IR-1

Print

Signature

Date

Software Owner

\section{BASELINE ESTABLISHED}

\begin{tabular}{|c|c|}
\hline Prin & Signature \\
\hline
\end{tabular}

Print Signature Date

Design Authority

Print Signature Date

IR-1

Print

Signature

Date

Software Owner 


\section{ATTACHMENT 1: MCU-GRM TEST CASES}

Date Executed:

Tester (Print Name):

Tester (initials):

STP \# J-STP-H-00236 Rev 0

Test Case:

Page 1 of 3

Requirements Tested Per Software Test Documentation: Document J-SQP-H-00013 Requirement 1

\begin{tabular}{|c|c|c|c|c|}
\hline Step & Tester Action & Expected Result & Comments & Initial \\
\hline & $\begin{array}{l}\text { Purpose } \\
\text { Methodology } \\
\text { Hardware/ Tools } \\
\text { Personnel } \\
\text { Setup }\end{array}$ & $\begin{array}{l}\text { The purpose of this test is to } \\
\text { ensure that the user is able } \\
\text { to switch detectors from the user } \\
\text { interface. } \\
\text { Bring system to a steady-state } \\
\text { test condition. } \\
\text { NA } \\
\text { NA } \\
\text { The MCU-GRM software should } \\
\text { be operational. }\end{array}$ & & \\
\hline 1.1 & Start the MCU-GRM program & $\begin{array}{l}\text { The Main screen for the program } \\
\text { should appear. }\end{array}$ & & \\
\hline 1.2 & $\begin{array}{l}\text { Verify that the system is } \\
\text { operational by observing the } \\
\text { clock in the upper corner of } \\
\text { the user interface. }\end{array}$ & The time will be incrementing. & & \\
\hline
\end{tabular}


WSRC-RP-2005-01902

Revision \#0

Date Executed:

Tester (Print Name):

STP \# J-STP-H-00236 Rev 0

Test Case:

1

Tester (initials):

Page

2 of 3

Requirements Tested Per Software Test Documentation: Document J-SQP-H-00013 Requirement 1

\begin{tabular}{|c|c|c|c|c|}
\hline Step & Tester Action & Expected Result & Comments & Initial \\
\hline $\begin{array}{l}1.3 \\
1.4\end{array}$ & $\begin{array}{l}\text { Observe the Nal Tube selection } \\
\text { from the screen. Write appropriate } \\
\text { detector in comments column } \\
\text { Observe the GM Tube selection } \\
\text { from the screen. Write appropriate } \\
\text { detector in comments column }\end{array}$ & $\begin{array}{l}\text { Either Nal1 or Nal2 } \\
\text { Either GM1 or } \\
\text { GM2 }\end{array}$ & & \\
\hline 1.5 & $\begin{array}{l}\text { Select the "Count Background" } \\
\text { option from the Main screen and } \\
\text { observe the detectors listed } \\
\text { in the "Start Background" popup } \\
\text { window. Record in comments. }\end{array}$ & $\begin{array}{l}\text { Either Nal1 or Nal2 } \\
\text { and } \\
\text { Either GM1 or GM2 }\end{array}$ & & \\
\hline 1.6 & $\begin{array}{l}\text { Click the cancel button on the } \\
\text { Start Background popup window }\end{array}$ & $\begin{array}{l}\text { The Main screen should be } \\
\text { displayed }\end{array}$ & & \\
\hline 1.7 & $\begin{array}{l}\text { Change tube selections for the } \mathrm{Nal} \\
\text { and GM detectors by selecting } \\
\text { the other remaining detector from } \\
\text { each detector selection menu. }\end{array}$ & & & \\
\hline 1.8 & $\begin{array}{l}\text { Observe the Nal Tube selection } \\
\text { from the screen. Write appropriate } \\
\text { detector in comments column. } \\
\text { This should NOT be the same } \\
\text { selected in step } 1.3\end{array}$ & Either Nal1 or Nal2 & & \\
\hline
\end{tabular}


WSRC-RP-2005-01902

Revision \#0

Date Executed:

Tester (Print Name):

Tester (initials):

STP \# J-STP-H-00236 Rev 0

Test Case:

Page $\quad 3$ of 3

Requirements Tested Per Software Test Documentation: Document J-SQP-H-00013 Requirement 1

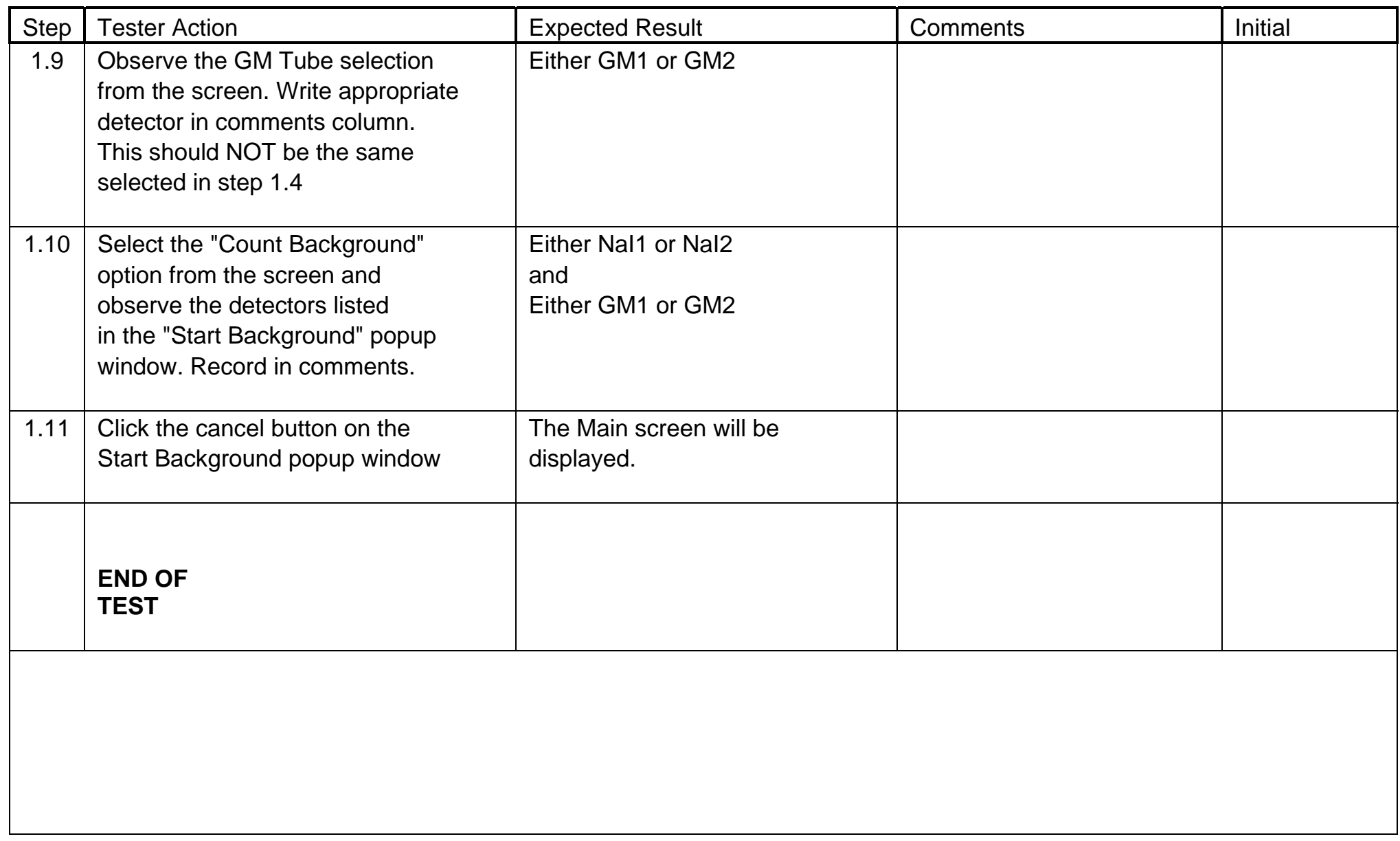


WSRC-RP-2005-01902

Revision \#0

Date Executed:

Tester (Print Name):

STP \# J-STP-H-00236 Rev 0

Tester (initials):

Requirements Tested Per Software Test Documentation: Document J-SQP-H-00013 Requirement 2

\begin{tabular}{|c|c|c|c|c|}
\hline Step & Tester Action & Expected Result & Comments & Initial \\
\hline & $\begin{array}{l}\text { Purpose } \\
\text { Methodology } \\
\text { Hardware/ Tools } \\
\text { Setup }\end{array}$ & $\begin{array}{l}\text { The purpose of this test is to } \\
\text { ensure that the software will } \\
\text { faithfully display the most recent } \\
\text { data point for the selected detector. } \\
\text { Bring system to a steady-state } \\
\text { test condition. } \\
\text { Radioactive Source } \\
\text { The MCU-GRM software should } \\
\text { be operational. } \\
\text { Maestro should be operational. }\end{array}$ & & \\
\hline 2.1 & Start the MCU-GRM program. & $\begin{array}{l}\text { The Main screen for the program } \\
\text { should appear. }\end{array}$ & & \\
\hline 2.2 & Start the Maestro program. & The Maestro screen will appear. & & \\
\hline 2.3 & $\begin{array}{l}\text { Select the "Detector Settings" } \\
\text { option from the Main screen. }\end{array}$ & $\begin{array}{l}\text { The "Detector Configuration" screen } \\
\text { will be displayed. }\end{array}$ & & \\
\hline 2.4 & $\begin{array}{l}\text { Change the Nal \& GM cycle } \\
\text { times to } 10 \text { seconds and change } \\
\text { change all Efficiency values to } 1 \\
\text { and all Background values to } 0 . \\
\text { Click "Apply Changes" on the } \\
\text { configuration screen. }\end{array}$ & $\begin{array}{l}\text { The "Detector Configuration" screen } \\
\text { will close and the Main screen will } \\
\text { appear. }\end{array}$ & & \\
\hline
\end{tabular}


WSRC-RP-2005-01902

Revision \#0

Date Executed:

Tester (Print Name):

Tester (initials):

Requirements Tested Per Software Test Documentation: Document J-SQP-H-00013 Requirement 2

\begin{tabular}{|c|c|c|c|c|}
\hline Step & Tester Action & Expected Result & Comments & Initial \\
\hline 2.5 & $\begin{array}{l}\text { Place the source in front of the } \\
\text { collimator window on the shield. }\end{array}$ & & & \\
\hline 2.6 & $\begin{array}{l}\text { Record the detector selections } \\
\text { in the Comments column. }\end{array}$ & $\begin{array}{l}\text { Either Nal1 or Nal2 } \\
\text { and } \\
\text { Either GM1 or GM2 }\end{array}$ & & \\
\hline 2.7 & $\begin{array}{l}\text { Select the "Start" option from the } \\
\text { Main screen and allow the system } \\
\text { to run through several cycles. }\end{array}$ & $\begin{array}{l}\text { The system should start running } \\
\text { and acquiring data. }\end{array}$ & & \\
\hline
\end{tabular}

\section{FOR EACH CYCLE VERIFY THE FOLLOWING}

2.8 Switch between Maestro and the MCU-GRM software to verify that each new Nal data point is being faithfully represented.

2.9 Check that the GM data is being updated and the data is consistent with the source activity.

2.10 $\quad$ Select the "Stop" option from the

Main screen.

The most recent data point should appear on the digital display after each cycle. This data should also be added to the strip chart display.

The most recent data point should appear on the digital display after each cycle. This data should also be added to the strip chart display.

Data acquisition should stop. STP\#JSTPH00236Rev0

Test Case:

2 of

Page 3 
WSRC-RP-2005-01902

Revision \#0

Date Executed:

Tester (Print Name):

Tester (initials):
STP \# J-STP-H-00236 Rev 0

Test Case:

Page

3 of 3

Requirements Tested Per Software Test Documentation: Document J-SQP-H-00013 Requirement 2

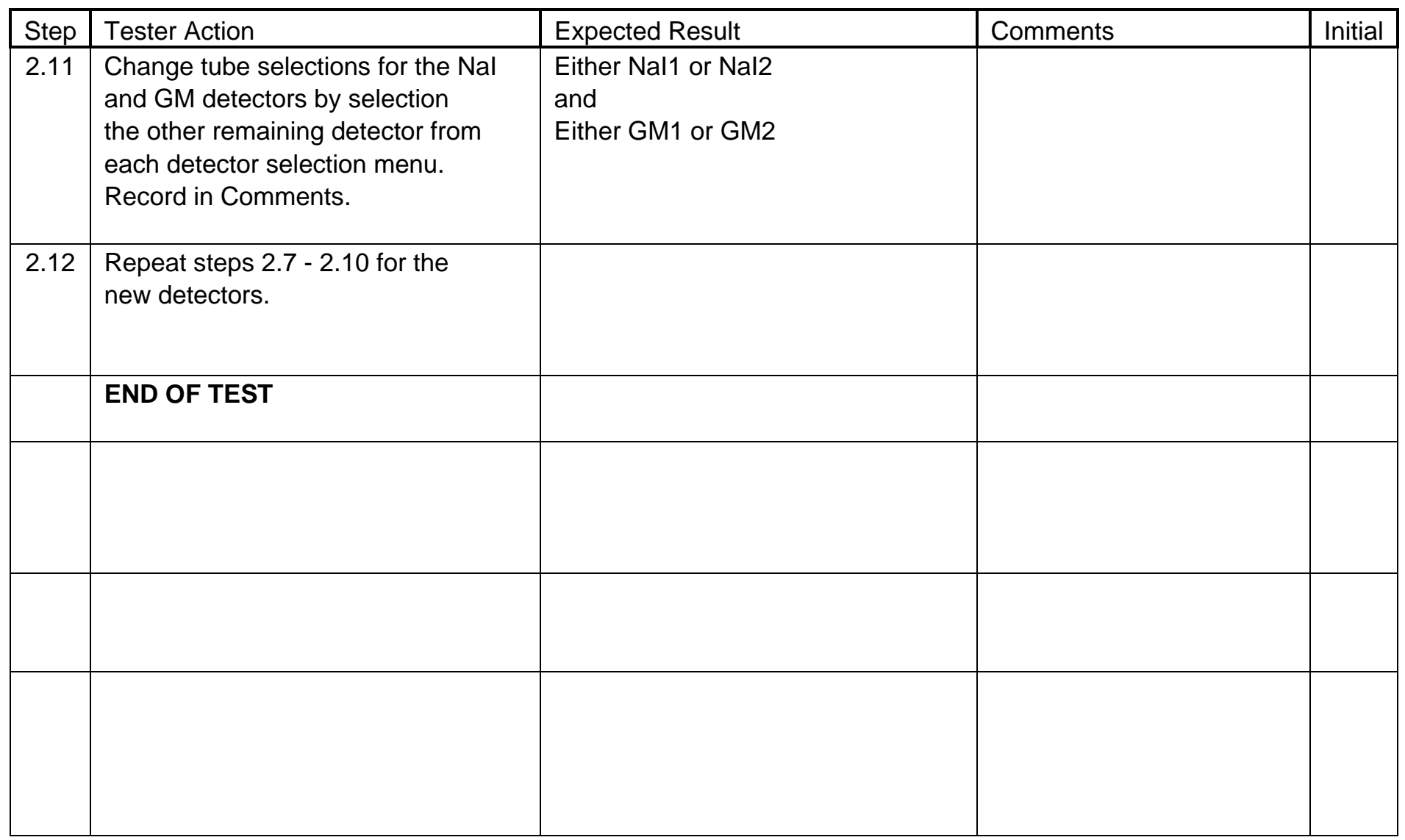


WSRC-RP-2005-01902

Revision \#0

Date Executed:

Tester (Print Name):

Tester (initials):

STP \#J-STP-H00236Rev0

Test Case:

Page 3

Requirements Tested Per Software Test Documentation: Document J-SOP-H-00013 Requirement 3

\begin{tabular}{|c|c|c|c|c|}
\hline Step & Tester Action & Expected Result & Comments & Initial \\
\hline & $\begin{array}{l}\text { Purpose } \\
\text { Methodology } \\
\text { Hardware/ Tools } \\
\text { Setup }\end{array}$ & $\begin{array}{l}\text { The purpose of this test is to } \\
\text { verify that the software will perform a } \\
\text { background count and save the new } \\
\text { background value and date. } \\
\text { Verify that background subtraction } \\
\text { is properly performed. } \\
\text { Bring system to a steady-state } \\
\text { test condition. } \\
\text { Radioactive Source } \\
\text { Insert Radioactive source in front } \\
\text { of collimator window on the shield. } \\
\text { The MCU-GRM software should } \\
\text { be operational. } \\
\text { Maestro should be operational. }\end{array}$ & & \\
\hline 3.1 & Start the MCU-GRM program & $\begin{array}{l}\text { The Main screen for the program } \\
\text { should appear. }\end{array}$ & & \\
\hline 3.2 & $\begin{array}{l}\text { Select the "Detector Settings" } \\
\text { option from the Main screen. }\end{array}$ & $\begin{array}{l}\text { The "Detector Configuration" screen } \\
\text { will be displayed. }\end{array}$ & & \\
\hline 3.3 & $\begin{array}{l}\text { Record the Background value } \\
\text { and Last Update value for each } \\
\text { detector in the comments } \\
\text { section. Click Cancel to close. }\end{array}$ & & $\begin{array}{l}\text { Nal1 background: } \\
\text { Nal1 Last Update: } \\
\text { Nal2 Background: } \\
\text { Nal2 Last Update }\end{array}$ & \\
\hline
\end{tabular}


WSRC-RP-2005-01902

Revision \#0

Date Executed:

STP\# J-STP-H00236Rev0

Tester (Print Name):

Tester (initials):

Test Case:

Page

Requirements Tested Per Software Test Documentation: Document J-SQP-H-00013 Requirement 3

\begin{tabular}{|c|c|c|c|c|}
\hline Step & Tester Action & Expected Result & Comments & Initial \\
\hline $\begin{array}{l}3.3 \\
\text { cont }\end{array}$ & & & $\begin{array}{l}\text { GM1 Background: } \\
\text { GM1 Last Update: } \\
\text { GM2 Background: } \\
\text { GM2 Last Update: }\end{array}$ & \\
\hline 3.4 & $\begin{array}{l}\text { Observe the Nal Tube selection } \\
\text { from the screen. Write appropriate } \\
\text { detector in comments column. }\end{array}$ & Either Nal1 or Nal2 & & \\
\hline 3.5 & $\begin{array}{l}\text { Observe the GM Tube selection } \\
\text { from the screen. Write appropriate } \\
\text { detector in comments column. }\end{array}$ & Either GM1 or GM2 & & \\
\hline 3.6 & $\begin{array}{l}\text { Select the "Count Background" } \\
\text { option from the Main screen and } \\
\text { then click "OK" in the "Start } \\
\text { Background" popup to initiate } \\
\text { the background count. }\end{array}$ & The Background count will start. & & \\
\hline 3.7 & $\begin{array}{l}\text { When the count has completed } \\
\text { record the background counts } \\
\text { value for each detector and click } \\
\text { OK to close each "Background } \\
\text { Complete" window and log the } \\
\text { new values. }\end{array}$ & The Main screen will be displayed. & $\begin{array}{l}\text { Nal counts: } \\
\text { GM counts: }\end{array}$ & \\
\hline 3.8 & $\begin{array}{l}\text { Change tube selections for the Nal } \\
\text { and GM detectors by selection } \\
\text { the other remaining detector from } \\
\text { each detector selection menu. } \\
\text { Record new selections in comments. }\end{array}$ & $\begin{array}{l}\text { Either Nal1 or Nal2 } \\
\text { AND } \\
\text { Either GM1 or GM2 }\end{array}$ & & \\
\hline
\end{tabular}


Date Executed:

STP\#JSTPH00236Rev0

Tester (Print Name):

Test Case:

Tester (initials):

Page

Requirements Tested Per Software Test Documentation: Document J-SQP-H-00013 Requirement 3

\begin{tabular}{|c|c|c|c|c|}
\hline Step & Tester Action & Expected Result & Comments & Initial \\
\hline 3.9 & $\begin{array}{l}\text { Repeat steps } 3.6-3.7 \text { for the } \\
\text { new detectors }\end{array}$ & same as 3.6 and 3.7 & $\begin{array}{l}\text { Nal counts: } \\
\text { GM counts: }\end{array}$ & \\
\hline 3.10 & $\begin{array}{l}\text { Select the "Detector Settings" } \\
\text { option from the Main screen. }\end{array}$ & $\begin{array}{l}\text { The "Detector Configuration" screen } \\
\text { will be displayed. }\end{array}$ & & \\
\hline 3.11 & $\begin{array}{l}\text { Verify that the values and dates } \\
\text { recorded in steps } 3.7 \& 3.9 \\
\text { are displayed in the appropriate } \\
\text { fields. Click cancel to close. }\end{array}$ & $\begin{array}{l}\text { The Main screen will be } \\
\text { displayed. }\end{array}$ & & \\
\hline 3.12 & $\begin{array}{l}\text { Select the "Start" option from the } \\
\text { Main screen and allow the system } \\
\text { to run through one cycle. }\end{array}$ & $\begin{array}{l}\text { The system should start running } \\
\text { and acquiring data. }\end{array}$ & & \\
\hline 3.13 & $\begin{array}{l}\text { Switch between Maestro and the } \\
\text { MCU-GRM software to verify that } \\
\text { background subtraction is done } \\
\text { for the new Nal data point. }\end{array}$ & $\begin{array}{l}\text { The data point should be equal to } \\
\text { the net counts from Maestro } \\
\text { minus the background value for } \\
\text { the selected detector. }\end{array}$ & & \\
\hline 3.14 & $\begin{array}{l}\text { Check that GM data is being } \\
\text { corrected accordingly. }\end{array}$ & & & \\
\hline 3.15 & $\begin{array}{l}\text { Change tube selections for the Nal } \\
\text { and GM detectors by selecting } \\
\text { the other remaining detector from } \\
\text { each detector selection menu. }\end{array}$ & $\begin{array}{l}\text { Either Nal1 or Nal2 } \\
\quad \text { AND } \\
\text { Either GM1 or GM2 }\end{array}$ & & \\
\hline
\end{tabular}


WSRC-RP-2005-01902

Revision \#0

Date Executed:

STP\#JSTPH00236Rev0

Tester (Print Name):

Tester (initials):

Test Case:

Page $\quad 4$ of 4

Requirements Tested Per Software Test Documentation: Document J-SQP-H-00013 Requirement 3

\begin{tabular}{|c|c|c|c|c|}
\hline \multirow{2}{*}{$\begin{array}{l}\text { Step } \\
3.16\end{array}$} & Tester Action & Expected Result & Comments & Initial \\
\hline & $\begin{array}{l}\text { Repeat steps } 3.12-3.14 \text { for the } \\
\text { new detectors. }\end{array}$ & same as $3.12,3.13$, and 3.14 & & \\
\hline & $\begin{array}{l}\text { END OF } \\
\text { TEST }\end{array}$ & & & \\
\hline & & & & \\
\hline & & & & \\
\hline & & & & \\
\hline & & & & \\
\hline & & & & \\
\hline & & & & \\
\hline & & & & \\
\hline & & & & \\
\hline & & & & \\
\hline
\end{tabular}


WSRC-RP-2005-01902

Revision \#0

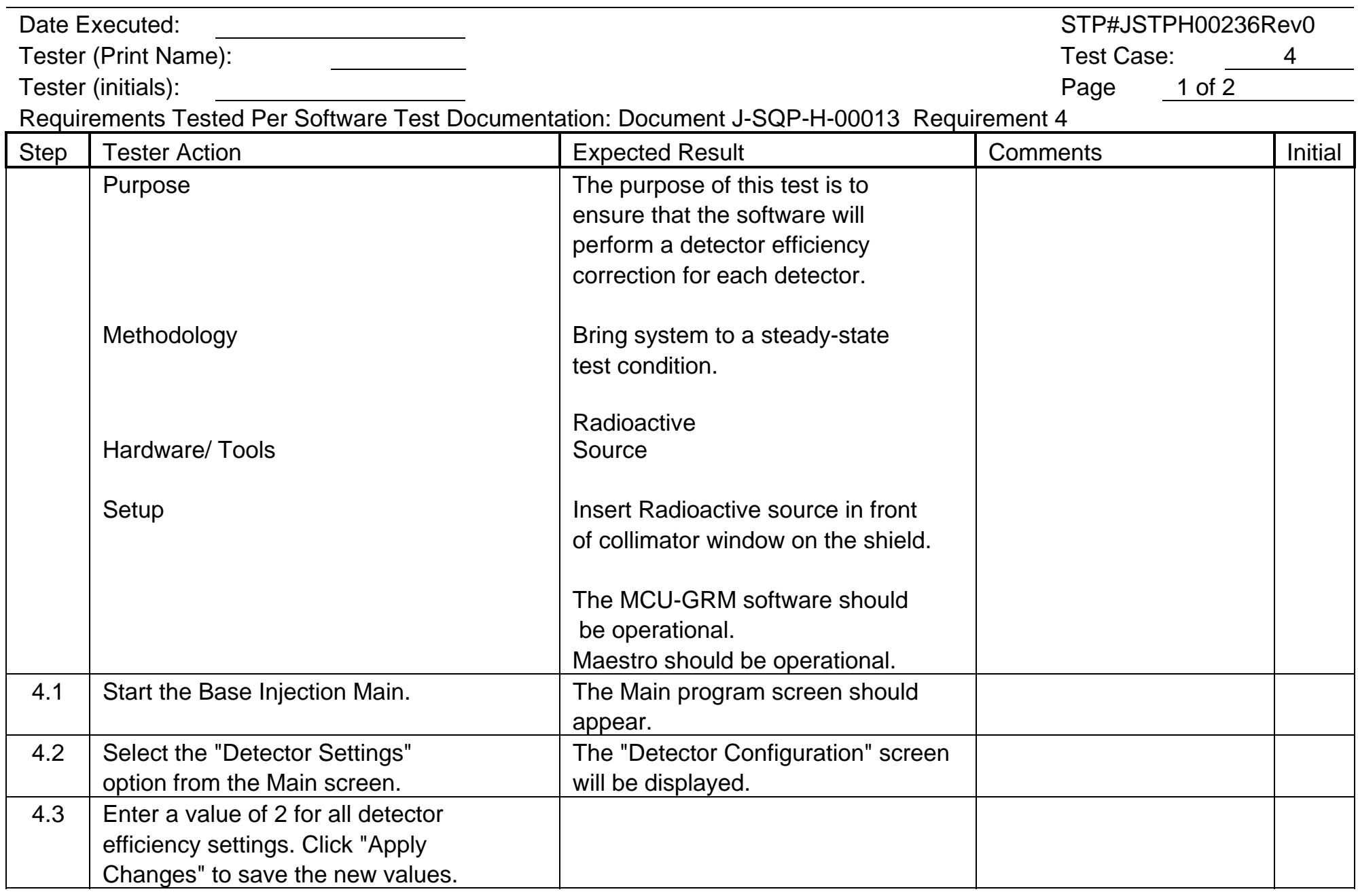


Date Executed:

STP\#JSTPH00236Rev0

Tester (Print Name):

Tester (initials):

Test Case:

Page

Requirements Tested Per Software Test Documentation: Document J-SQP-H-00013 Requirement 4

\begin{tabular}{|c|c|c|c|c|}
\hline Step & Tester Action & Expected Result & Comments & Initial \\
\hline 4.4 & $\begin{array}{l}\text { Record the tube selections } \\
\text { from the main screen. }\end{array}$ & $\begin{array}{l}\text { Either Nal1 or Nal2 } \\
\quad \text { AND } \\
\text { Either GM1 or GM2 }\end{array}$ & & \\
\hline 4.5 & $\begin{array}{l}\text { Select the "Start" option from the } \\
\text { Main screen and allow the system } \\
\text { to run through one cycle. }\end{array}$ & $\begin{array}{l}\text { The system should start running } \\
\text { and acquiring data. }\end{array}$ & & \\
\hline 4.6 & $\begin{array}{l}\text { Switch between Maestro and the } \\
\text { MCU-GRM software to verify that } \\
\text { background subtraction is done } \\
\text { for the new Nal data point. }\end{array}$ & $\begin{array}{l}\text { The data point should be equal to } \\
\text { the half net counts from Maestro. }\end{array}$ & & \\
\hline 4.8 & $\begin{array}{l}\text { Change tube selections for the Nal } \\
\text { and GM detectors by selection } \\
\text { the other remaining detector from } \\
\text { each detector selection menu. }\end{array}$ & $\begin{array}{l}\text { Either Nal1 or Nal2 } \\
\quad \text { AND } \\
\text { Either GM1 or GM2 }\end{array}$ & & \\
\hline 4.9 & $\begin{array}{l}\text { Repeat steps } 4.5-4.7 \text { for the } \\
\text { new detectors. }\end{array}$ & & & \\
\hline & END OF TEST & & & \\
\hline
\end{tabular}




\section{Modular Caustic Side Solvent Extraction Unit - Gamma Ray Monitors MCU-GRM}

L814-J-002v Version 1.0.

\section{Software User's Manual, Rev 0}

\section{INFORMATION ONLY}

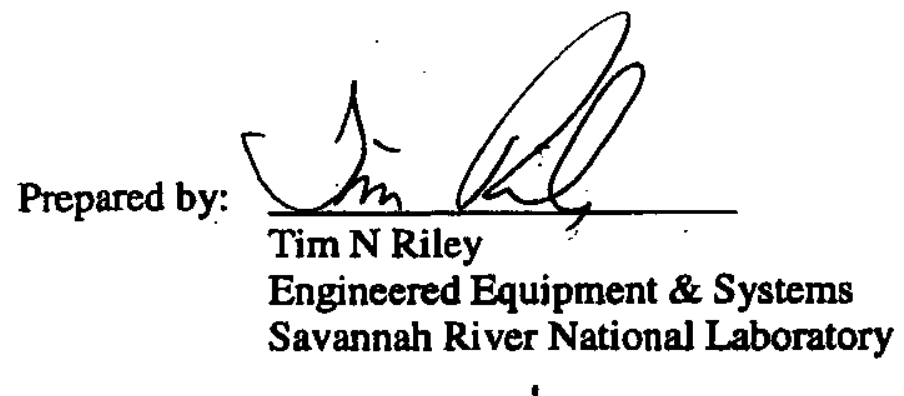

Date: $\quad$ October 3, 2005 
$12 / 08 / 05$ THU 15:42 FAX

005

\begin{tabular}{|l|r|}
\hline Modular Caustic Side Solvent Extraction Unit Gamma Ray Monitors & \\
\hline Software User's Manual & Revision 0 \\
\hline & F age 2 of 21 \\
\hline
\end{tabular}

WSRC-RP-2005-01902

Revision \#0

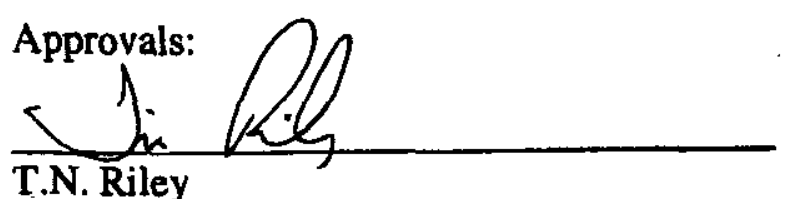

T.N. Riley

Design Agency

Vito. Danielle

V.R. Canella

IR-1 Independent Reviewer

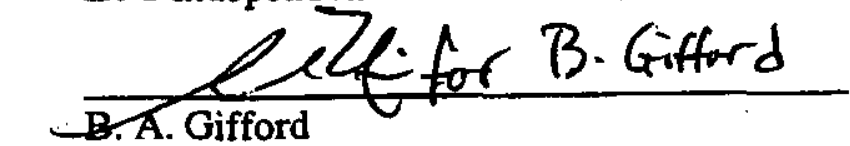

Software Owner

Tate Now r for I.W. Reval per token

Design Authority

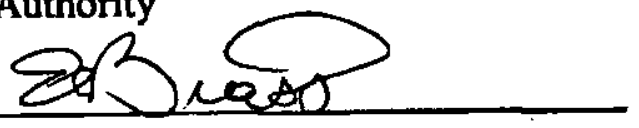

E. A. Brass

MCU Design Authority Manager
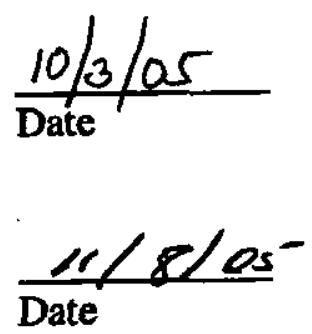

$\frac{1015105}{\text { Date }}$
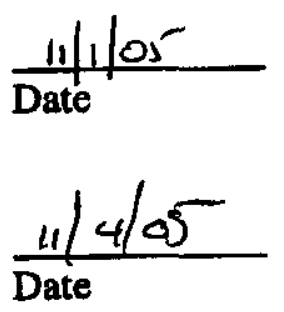

93 
WSRC-RP-2005-01902

Revision \#0

\section{SUMMARY OF CHANGES}

\begin{tabular}{|l|l|l|}
\hline Revision: & Date: & Description: \\
\hline A & $9 / 2 / 05$ & Initial routing for review and comments \\
\hline 0 & $10 / 3 / 05$ & Approval \\
\hline & & \\
\hline
\end{tabular}




\section{TABLE OF CONTENTS}

$\begin{array}{lr}\text { Summary of Changes } & 94\end{array}$

Table of Contents
Table of Figures

\begin{tabular}{l} 
Table of Figures \\
\hline.
\end{tabular}

1. Introduction 96

$\begin{array}{ll}\text { 1.1. Purpose } & 96\end{array}$

1.2. Scope 96

1.3. Definitions and Acronyms 96

2. References 96

3. MCU-GRM System Description 97

4. MCU-GRM Hardware Description 97

5. MCU-GRM Software Description 99

5.1. MCU-GRM Application Window $\quad 99$

5.2. Detector Selection $r$

5.3. Detector Configuration Settings 100

5.4. Routine Data Acquisition 102

5.5. Background Counting 104

6. Startup and Operation of the MCU-GRM System 106

6.1. MCU-GRM Hardware Configuration 106

6.2. MCU-GRM Application Startup and Initialization 106

6.3. Detector Selection 106

6.4. Detector Configuration Settings 107

$\begin{array}{lr}\text { 6.5. Start Routine Data Acquisition } & 107\end{array}$

$\begin{array}{lr}\text { 6.6. Start Background Count } & 107\end{array}$

Appendix A - MCU-GRM Material \& Equipment Listing 109

Appendix B - Configuration File Format $\quad 110$

Appendix C - Error Recovery Procedures $\quad 111$

Appendix D - NaI and GM DataLog file Format 112

$\begin{array}{lr}\text { Appendix E - Manufacturer’s Literature } & 113\end{array}$

\section{TABLE OF FIGURES}

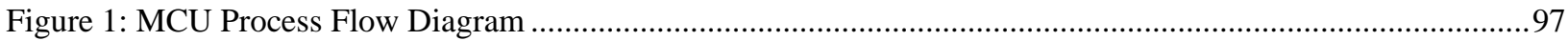

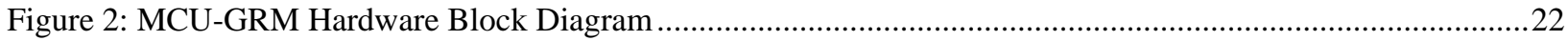

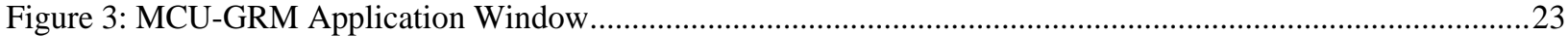

Figure 4: Detector Configuration Settings Password Screen ...................................................................24

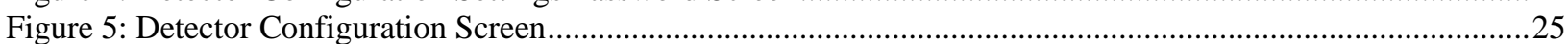

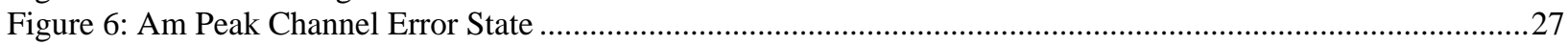

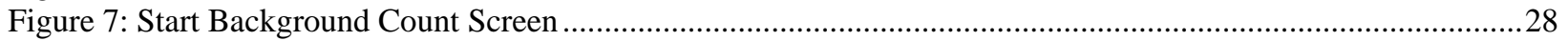

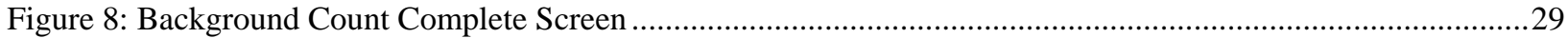




\section{INTRODUCTION}

\section{Purpose}

This document describes the software developed for operation of the Modular Caustic Side Solvent Extraction Unit - Gamma Ray Monitors (MCU-GRM). A brief description of the system hardware is included as necessary for clarification of its interaction with the MCU-GRM software.

\section{Scope}

Provisions of this document apply to software developed by SRNL for the Modular Caustic Side Solvent Extraction Unit Gamma Ray Monitors (MCU-GRM). This document does not cover the design or development of the supervisory distributed control system (DCS).

\section{Definitions and Acronyms}

$\begin{array}{ll}\text { MCU-GRM } & \text { Modular Caustic Side Solvent Extraction Unit - Gamma Ray Monitor } \\ \text { SRNL } & \text { Savannah River National Laboratory } \\ \text { DCS } & \text { Distributed Control System } \\ \text { NIM } & \text { Nuclear Instrumentation Module } \\ \text { MCA } & \text { Multi-Channel Analyzer } \\ \text { GM } & \text { Geiger-Mueller } \\ \text { NaI } & \text { Sodium Iodide } \\ \text { FFB } & \text { Foundation FieldBus }\end{array}$

\section{REFERENCES}

- J-SQP-H-00013, Rev. 0, "Modular Caustic Side Solvent Extraction Unit Gamma Ray Monitors Software Quality Assurance Plan”

- U-FCD-H-00008, Rev. 0, "Modular CSSX Unit (MCU) Software Classification - a portion of the DISTRIBUTED CONTROL SYSTEM (DCS) network"

- WSRC-RP-2004-00875, Rev 0, “Task Technical and Quality Assurance Plan for Caustic Side Solvent Extraction Gamma-Ray Monitors"

- U-MT-H-00085, Rev 1, “Cesium Removal Implementation Using Caustic Side Solvent Extraction Technology"

- G-TC-H-00041, Rev 4, "Task Requirements and Criteria - Modular Caustic Side Solvent Extraction Unit (MCU)”

- G-ESR-H-00072, Rev 0, "Interface Control Document Modular Caustic Side Solvent Extraction (CSSX) Unit (MCU)"

- Technical Task Request, Rev.1, Gamma Monitor for MCU

- WSRC 1Q Manual QAP 20-1, "Software Quality Assurance"

- WSRC E7 Manual Procedure 5.20 "Software Design and Implementation"

- IEEE Standard 1016-1998, "IEEE Recommended Practice for Software Design Descriptions”.

- J-DD-H-00001, Rev.0, Modular Caustic Side Solvent Extraction Unit Gamma Ray Monitors (MCU-GRM), Design Document for Software 


\section{MCU-GRM SYSTEM DESCRIPTION}

The Modular Caustic Side Solvent Extraction Unit Gamma Ray Monitor (MCU-GRM) is an integrated hardware/software platform designed specifically for continuous monitoring of the Cesium removal process of the Modular Caustic Side Solvent Extraction Unit (MCU). A simplified MCU process flow diagram is shown in Figure 5. The MCU employs the CSSX process, a continuous process that uses a novel solvent to extract cesium from waste and concentrate it in dilute nitric acid. For a more detailed discussion of the CSSX process see WSRC-RP-2004-00875 "Task Technical and Quality Assurance Plan for Caustic Side Solvent Extraction Gamma-Ray Monitors”.

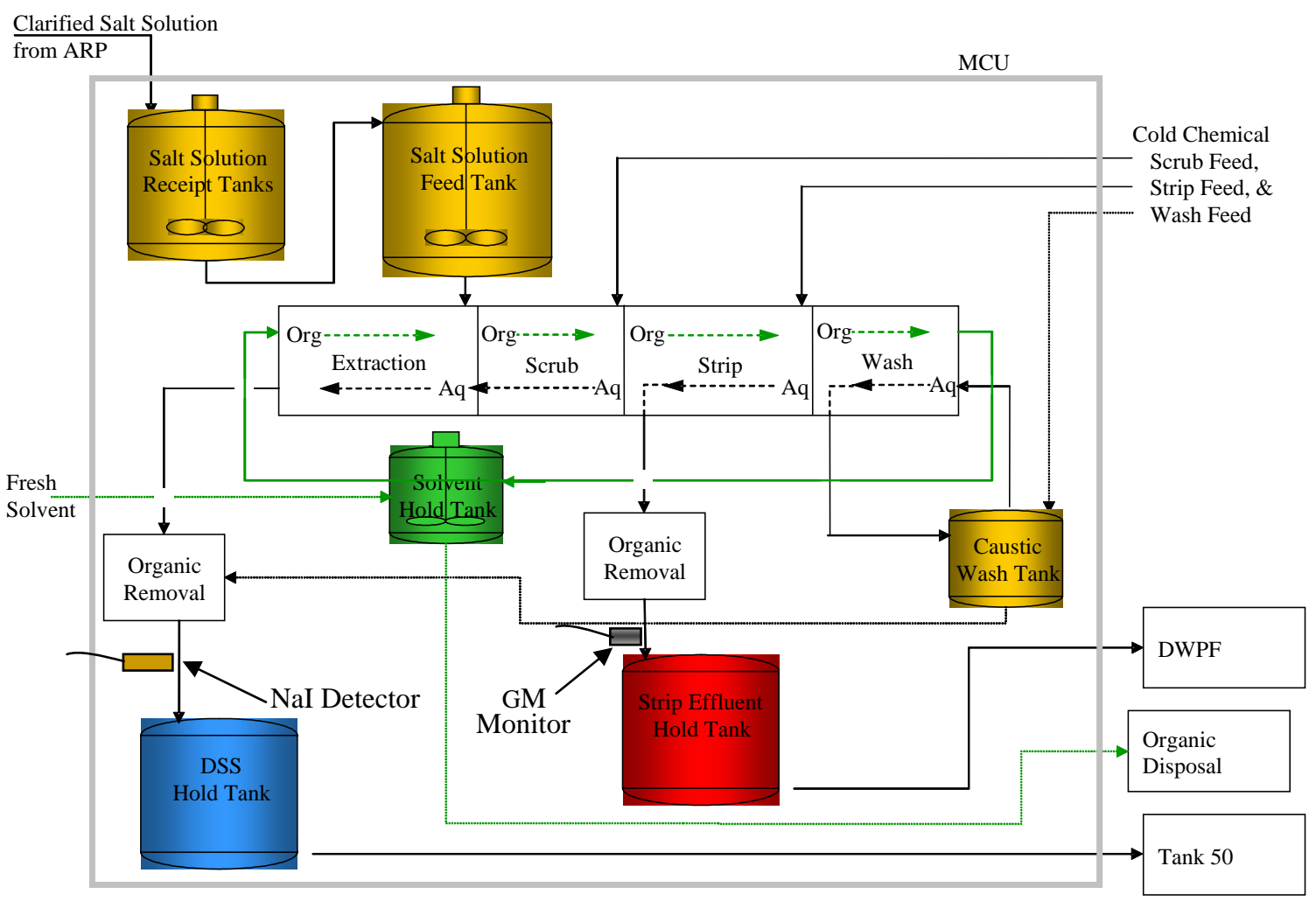

Figure 5: MCU Process Flow Diagram

\section{MCU-GRM HARDWARE DESCRIPTION}

The MCU-GRM hardware consists of two - Sodium Iodide (NaI) photomultiplier tubes, two - Geiger Mueller tubes, two - spectroscopy amplifiers, two - high voltage power supplies, two radiation detection modules, one - modular Nuclear Instrumentation Module (NIM) bin and power supply, one computer, one - keyboard, one - pulse counter card and associated connection hardware, two - multichannel analyzer cards, and one - Foundation FieldBus card. A materials and equipment listing for the MCU-GRM hardware is included in Appendix A - MCU-GRM Material \& Equipment Listing.

Two NaI spectrometers (one online and one backup) are used for measuring the Cs-137 concentration in the decontaminated salt solution entering the DSS Hold Tank. High voltage and preamp power are provided to the detectors through Nuclear Instrumentation Module (NIM) based modular electronics. The amplified and scaled output signals from each detector are connected to an ORTEC Trump-PCI 
card located inside the MCU-GRM computer housing. The Trump-PCI card is a computer controlled Multi-Channel Analyzer (MCA) geared specifically towards nuclear spectroscopy applications.

Two GM tubes (one online and one backup) are used for measuring the Cs-137 concentration in the strip effluent before entering the Strip Effluent Hold Tank. These detectors are connected by a single coax cable to an Aware Electronics PMI30 instrument module. The Aware module is a self contained radiation detection system that provides detector High Voltage, as well as pulse scaling and amplification. The Aware modules are mounted inside a blank double width NIM module along with a custom circuit board designed to convert the Aware module pulse output to TTL compatible signal levels. This scaled output signal is applied to a National Instruments 6602 counter/scalar card for gross activity counting.

The two Trump-PCI cards and the NI 6602 counter card are installed in spare PCI slots in the MCUGRM computer, along with a National Instruments PCI-FBUS/2 Foundation FieldBus card which is required for communication between the MCU-GRM and the Distributed Control System (DCS). A block diagram of the MCU-GRM hardware is shown in Figure 3-1 below.

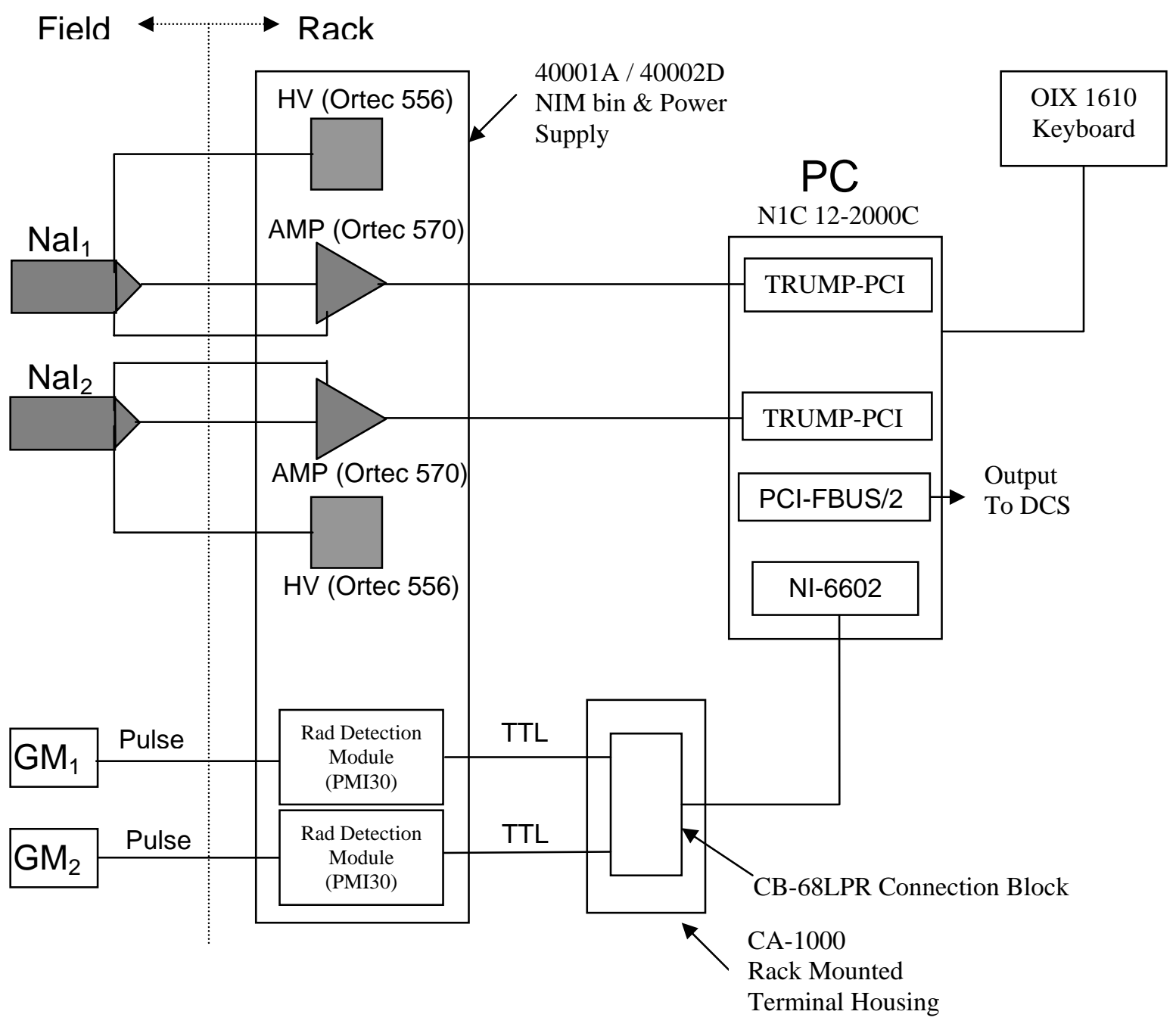


WSRC-RP-2005-01902

Revision \#0

\section{Figure 6: MCU-GRM Hardware Block Diagram}

\section{MCU-GRM SOFTWARE DESCRIPTION}

The MCU-GRM production software is a LabView based application that serves as a unified interface for controlling the MCU-GRM hardware and communicating with the host DCS. These activities are accomplished through five basic software modules that are described in detail in J-DD-H-00001

"MCU-GRM Design Document for Software". The MCU-GRM software source code number is L814$\mathrm{J}-002 \mathrm{v}$ Version 1.0.

From the User's point of view, the MCU-GRM software can be broken down into just a few software modules that will be described in this section. These software modules are the MCU-GRM Application Window, Detector Selection, Detector Configuration Settings, Background Counting, and Routine Data Acquisition.

\section{MCU-GRM Application Window}

The major component of the MCU-GRM software is the application window, shown in Figure . Besides serving as the primary user interface, this window provides a means for selecting the appropriate NaI or GM detector, performing routine MCU-GRM measurement activities, performing a background measurement, or gaining access to the detector configuration settings screen. All actions associated with the MCU-GRM software originate from this screen. The system time is displayed in the upper right hand corner of the screen and is updated every second to indicate that the system is active. 


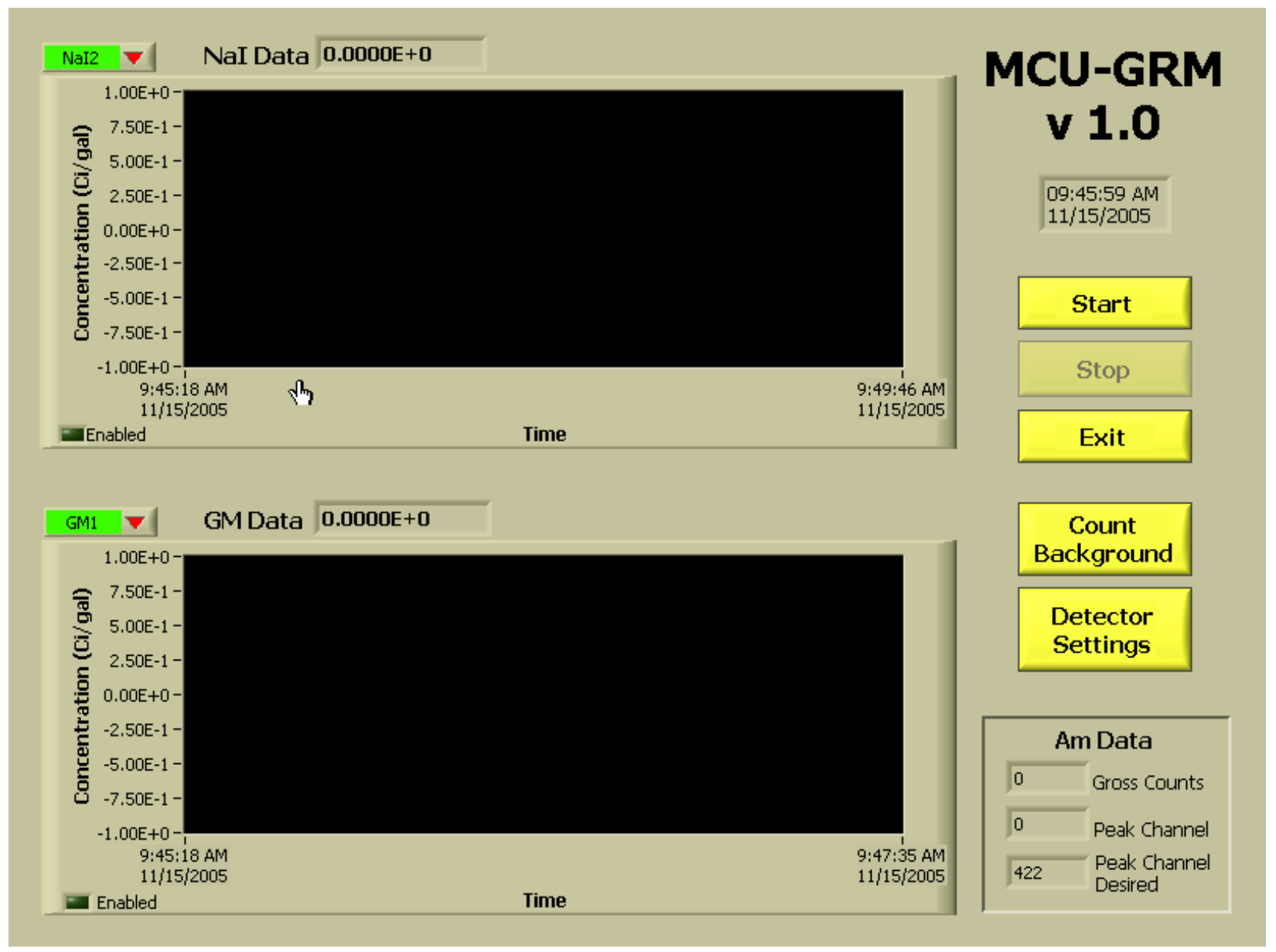

Figure 7: MCU-GRM Application Window

The most prominent features on the application window are the measurement history graphs. The two graphs display the 50 most recent data points collected during routine measurement activities. This serves as a visual reference of the measurement trend over the past 50 cycles. Additionally, the data display at the top center of each graph shows the most recently acquired data point for the selected detector.

\section{Detector Selection}

Selection of the desired NaI or GM detector is performed from the MCU-GRM Main screen, as shown in Figure, by clicking on the red arrow selector located beside both detector selection menus. This action brings up a pull-down menu from which the user can select the desired detector. Only one detector of each type may be selected at any given time. When NaI1 is on, $\mathrm{NaI} 2$ is off and vice versa. The same rules apply to the GM detectors. The detector selection function is disabled if either the MCU-GRM routine data collection or background counting options have been started.

\section{Detector Configuration Settings}

As is the case with any gamma monitoring system, the user must know certain detector operating parameters such as the detector efficiency and measured background count in order to make compensations to the measured activity for variations in the detector internals and for the 
WSRC-RP-2005-01902

Revision \#0

amount of activity entrained within the system. Without these values, accurate determination of the solution activity is impossible. The MCU-GRM stores these values in a configuration file (MCU_GRM_CONFIG.ini). The format of this file is shown in Appendix B - Configuration File Format

The user is granted access to these parameters only through the detector configuration utility. The user can access this utility, by clicking the Detector Settings button on the MCU-GRM main screen (Figure ). Because these values are crucial to the operation of the system and its ability to produce reliable output data, a password is required for access. The Password Utility Screen is shown in Figure .

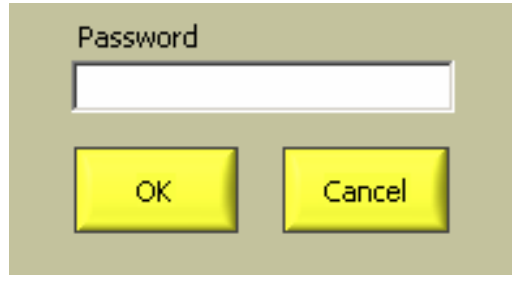

\section{Figure 8: Detector Configuration Settings Password Screen}

The password utility is case sensitive. Upon entering the correct password, the user will be able to access data on the Detector Configuration screen as illustrated in Figure . The user can change the password by changing the password character string in the password file. The filename is not included in this document. NOTE: The password will be changed by the User after the project turnover.

The Detector Configuration Screen is divided into 5 sections. Four identical sections, two for the NaI detectors and two for the GM detectors, are used for setting the detector operating parameters. This allows for independent parameter settings that are specific to each detector in the system. The single section at the bottom of the screen is used for setting the cycle times for routine data collection.

Within each of the detector sections, the user can set values for the detector Efficiency, measured Background, and Background Count Time. Changes can be made by either clicking the yellow up or down arrows next to each of the fields, or by typing a value directly into the text box. Each field performs automatic range checking on the entered data to allow only numerical entries within a predetermined range of values. The final range will be determined empirically when the system functional testing is performed.

If changes are made to either the detector Efficiency or measured Background settings, the associated Last Update fields are automatically imprinted with the current date. This is to help keep track of the last entries made for the critical detector operating parameters. Changes to the Last Update fields are done programmatically and are not accessible to the user. The user can select the Background Count Time for each detector. Optimal values will be determined empirically during system functional testing. Once changed, the new values are stored in the configuration file (MCU_GRM_CONFIG.ini) and are used for all future computations. 
WSRC-RP-2005-01902

Revision \#0

MCU-GRM Detector Configuration

NaI1

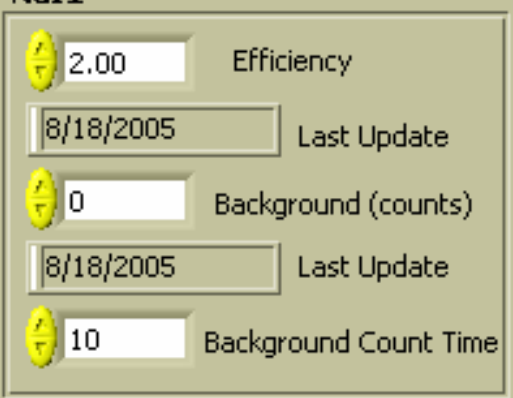

$\mathrm{NaI2}$
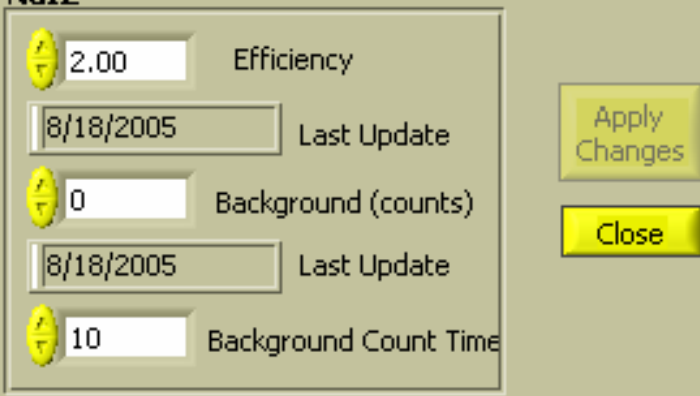

GM1

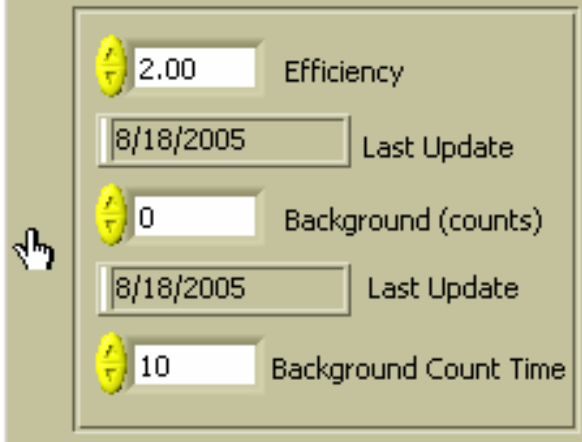

GM2

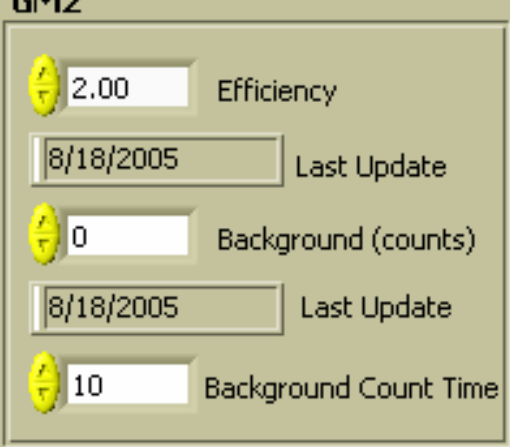

09:46:54 AM $09 / 27 / 2005$

Cycle Times (seconds)

t) $10 \quad$ NaI $\sqrt[5]{10}$ GM

Figure 9: Detector Configuration Screen

\section{Routine Data Acquisition}

The Routine Data Acquisition mode is the primary mode of operation for the MCU-GRM software. In order to start the routine monitoring application, the user should verify that the desired detector pair has been selected (one GM and one NaI detector) and then click the Start button on the MCU-GRM application window (Figure ).

At this point, the application changes to the running state as indicated on the screen. In the running mode, the time remaining for each detector's acquisition cycle is displayed in the corresponding Next Update counter along the top of each graph. The Next Update counter is updated once a second to show the time remaining until the end of the current acquisition cycle. By default, the data acquisition cycle for both detectors is set for 60 seconds.

At the start of Run cycle, the program reads the GM and NaI detector configuration data as set previously using the Detector Configuration Utility. The system starts the first count by writing the live time preset to the Trump Card to start the spectrum collection. The Trump card performs all the required spectrum collection functions as instructed without further interaction from the MCU-GRM software. The system also initializes and starts the NI-6602 counter to monitor the pulse output of the GM signal train. 
After the NaI time interval has elapsed, the program polls the Trump card to determine if the required live time spectrum collection has completed. If the live time interval has not completed the program waits for its completion. (NOTE: These two times should be about equal, unless a significant amount of dead time is encountered.) At completion of the counting cycle, the program queries the Trump card to get the raw counts in the Cesium photo-peak, along with other Cesium Region-of-Interest (ROI) statistical information. The program also reads the raw counts from the Americium photo-peak as well as the Am peak centroid channel number within the Am peak ROI. The ROIs in question are those established by the user during the initial system setup and calibration and should be the one containing the Cs and Am photo-peaks respectively. The program then issues commands to the Trump card to clear the current spectrum and restart the NaI data acquisition cycle. After the Trump card is restarted, the MCUGRM software calculates the net counts in the Cesium photo-peak. At this point, the program has enough information to calculate the Cesium Concentration (Ci/gal) in the clarified salt solution. This is done by subtracting the measured background value from the net counts and dividing the result by the detector efficiency.

To wrap up the processing of the NaI data, the program calculates the net counts in the Americium peak as well as the location (spectrum channel number) of the Am peak centroid. The actual Am peak centroid channel number is compared against its desired location to determine if adjustments need to be made in the detector HV supply or the amplifier gain. If the Am peak channel is outside of an acceptable band, the system will flag the user with an error message similar to that shown in Figure. The NaI detector system will not perform its monitoring function until this condition is corrected. These adjustments are covered in Appendix C - Error Recovery Procedures.

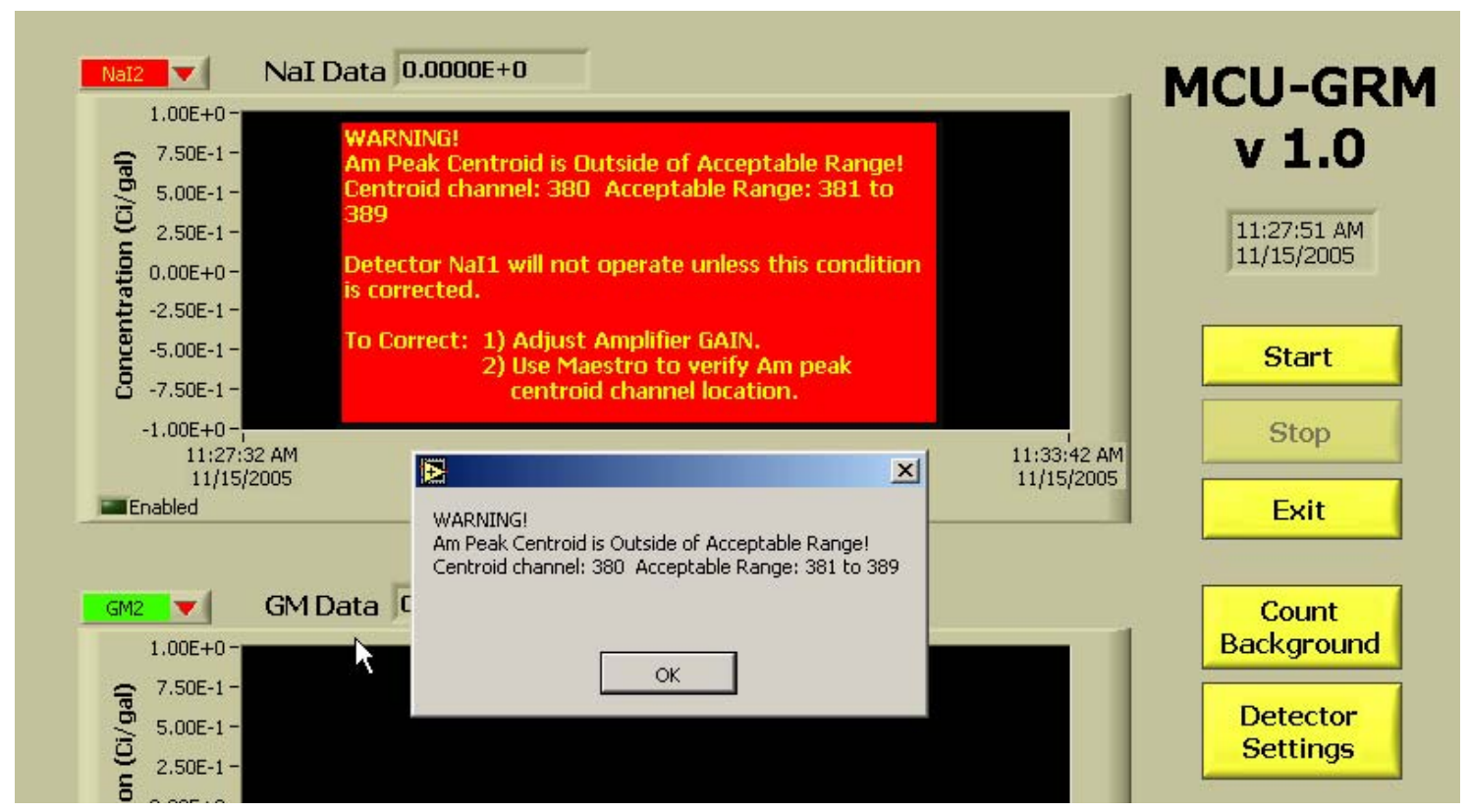

Figure 10: Am Peak Channel Error State

Like the NaI detector cycle, the MCU-GRM software issues commands to stop the NI-6602 counter and to read the total count collected during the GM data acquisition cycle. When this is 
completed, the program issues commands to clear and restart the count for the next cycle. Similar to the NaI data, the GM net counts are calculated using the GM detector measured background and the detector efficiency.

At the completion of the acquisition cycle, the two new data points are written to their corresponding graphs and any linked digital displays. Each new data point is also passed along to the DCS through the Foundation FieldBus interface. The new data and a selected subset of system and detector parameters are written to a log file (See APPENDIX D - NAI AND GM DATALOG FILE FORMAT). Both acquisition cycles continue until the user clicks the Stop button on the application window.

\section{Background Counting}

In order to gain an accurate picture of the activity of the solution moving through the system the system must be able to separate out that portion of the measured activity that is contributed by the salt solution from the portion that is due to the entrained particles within the system and its surroundings. In order to do this, the software must be able to null out the contribution of the system components to the overall measured activity. The MCU-GRM software accomplishes this through background subtraction. In order to perform the background subtraction and report only the activity of the solution moving through the system, periodic background measurements must be performed. This task must necessarily be performed in-situ, as this is the only method for accurate determination of the ambient activity levels.

The performance of this measurement requires coordination between the MCU-GRM and the DCS because a thorough flushing is required for all components within the detectors field of view. The system setup for this operation will be procedurally controlled within the facility and is outside the scope of this document. What is covered here is the performance of a background measurement as related to the MCU-GRM.

From the MCU-GRM point of view, the user will initiate a background count by first selecting the desired detector pair (one GM and one NaI detector) and then clicking the Count

Background button on the MCU-GRM application window (Figure ). The Start Background dialog box will be displayed as shown in Figure .

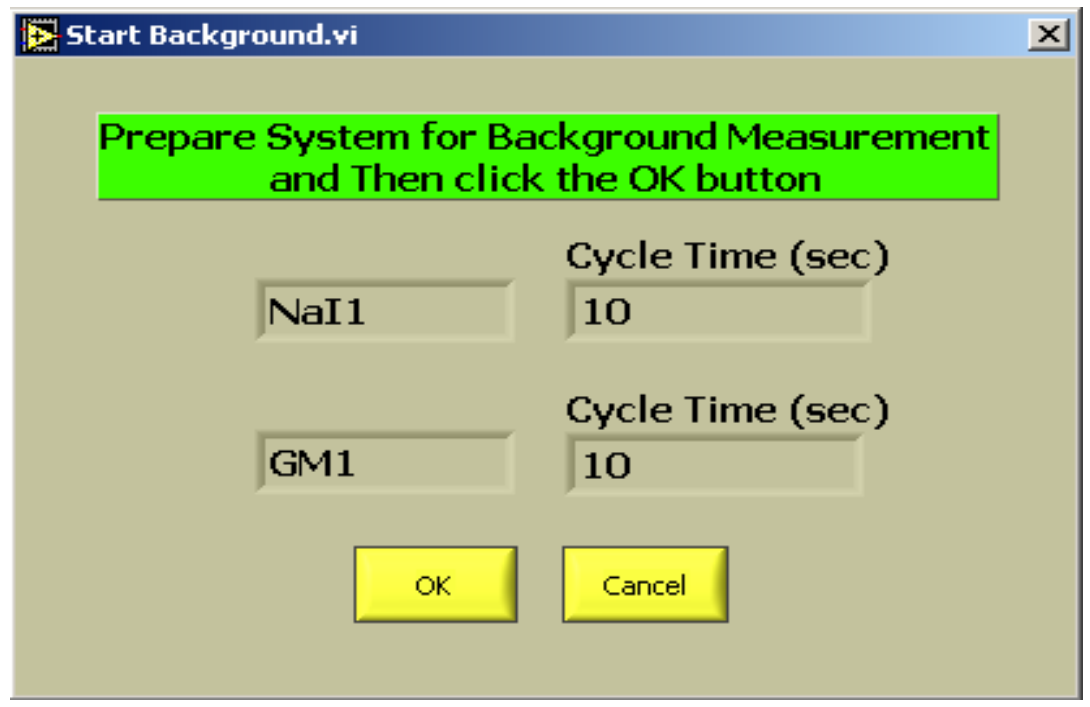

Figure 11: Start Background Count Screen 
The Start Background screen shows the detectors currently selected for the background counting operation, as well as the background count time for each detector. The screen also contains a message to remind the user the system preparation should be completed prior to performing the background measurement. The MCU-GRM software only reminds the user that these activities should be performed, but has no method to enforce the requirement. Inadequate system preparation may result in inaccurate readings for the measured background values.

To proceed beyond the initial screen, the user must either accept or cancel the activity. If cancelled, the Start Background screen will disappear and the MCU-GRM application window will be displayed. If accepted, the Background count will commence. The count will be performed for the length of time specified in the window for each detector. During the count, the Next Update field on the MCU-GRM main screen (Figure ) will count down to indicate the time remaining in the current counting cycle. At the completion of the background counting cycle for each detector a Background Count Complete dialog box will appear. This screen is shown in Figure .

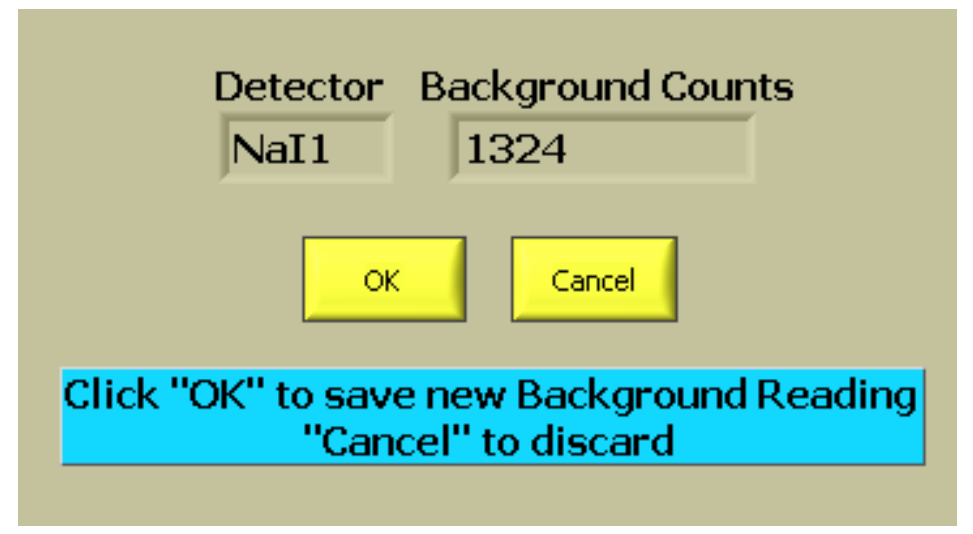

\section{Figure 12: Background Count Complete Screen}

The Background Complete screen displays the newly acquired background data point for the indicated detector and prompts the user to decide whether to keep or discard the new data. If the user decides to keep the new data point, the data is written to the detector configuration file (MCU_GRM_CONFIG.ini) and used for all subsequent calculations requiring background correction. This would also cause the Last Update field to be changed to reflect the new data point change. (Refer to Figure .) Otherwise the data is discarded and the current settings retained. When the background counts for both detectors have completed, the system returns to the standby mode awaiting further instructions from the user.

To summarize, the Background Counting mode performs a count for the two detectors that are currently selected, one GM and one NaI detector. Each count is performed for a preset period of time as determined by the setting in the Detector Configuration Window for the specified detector. At the completion of the count the new measured background data point may either be discarded, or written to the detector configuration settings file to be used on all subsequent calculations. Neither of the data points are written to the graph or to the digital display on the MCU-GRM application window. 
WSRC-RP-2005-01902

Revision \#0

\section{STARTUP AND OPERATION OF THE MCU-GRM SYSTEM}

\section{MCU-GRM Hardware Configuration}

There are four configuration programs that must be run to set up the MCU-GRM hardware before starting the MCU-GRM application software for the first time. This operation is only required to be performed prior to the initial startup.

1. Run the ORTEC "MCB Config” program to setup the communication channels with MCA1 and MCA2.

2. Run the ORTEC "Maestro" program to properly establish the two regions of interest (ROIs) needed for the data collection process.

3. Run the NI-FBUS Interface Configuration Utility to set up the Foundation FieldBus card.

4. Run the NI Measurement and Automation Explorer to set up the NI-6602 Counter/Timer card.

The MCU-GRM initialization sequence verifies that these operations have been completed. The MCU-GRM application program will be unable to initialize or communicate with the hardware devices and will generate an appropriate error should any of these steps fail to be performed. The procedures for performing all the above actions are listed in the appropriate manufacturer's literature for each device and will not be included in the MCU-GRM documentation. A complete listing of the manufacturer's literature is included in Appendix E - Manufacturer's Literature. A copy of each document will also be placed in the EES Job Folder \#23075 for the project.

\section{MCU-GRM Application Startup and Initialization}

1. The MCU-GRM software is started by [double-clicking] the MCU-GRM icon from the Windows desktop.

At startup, the software performs the following checks: it verifies that the NI-6602 card is installed and functional; it verifies that both Trump-PCI cards are installed and functional and that two ROIs have been established for each device; and it verifies that the Foundation FieldBus card is installed and functional. The program then runs an initialization loop to setup the MCU-GRM user interface for operation. After these checks have completed, the MCU-GRM main screen is displayed as illustrated in Error! Reference source not found.. The program remains in an IDLE state until one of the program actions is requested by the user.

\section{Detector Selection}

1. To switch between detectors NaI1 and NaI2, [CLICK] on the red arrow button located beside the detector selection pull-down menu on the MCU-GRM application window.

The Detector Selection option is only active when the MCU-GRM application is in the IDLE mode.

2. When the menu pops up, [CLICK] on the desired detector.

3. GM tube selection may be performed in the same manner as described above. 
WSRC-RP-2005-01902

Revision \#0

\section{Detector Configuration Settings}

1. To gain access to the Detector Configuration Utility, [CLICK] on the yellow DETECTOR SETTINGS button on the MCU-GRM application window.

The Password Screen will appear. The Detector Configuration Settings option is only active when the MCU-GRM application is in the IDLE mode.

2. On the Password Screen, Type 'CSSX' and [CLICK] the $\mathbf{O K}$ button. The password is case sensitive.

The Detector Configuration Screen will appear. If the user [CLICKS] the CANCEL button from the Password Screen, the application will divert execution back the MCU-GRM application window.

3. Once the Detector Configuration Screen is up, the user may change any of the parameters by [CLICK]ing the yellow ARROW BUTTONS beside any of the parameter fields, or by Typing the desired value directly into the text box.

Fields that have been changed are indicated by a flashing marker to remind the user to save changes if desired. If changes have been made the APPLY CHANGES button becomes active to allow the user to save the changes.

4. In order to save the changes to the configuration file, the user must [CLICK] the APPLY CHANGES button on the Detector Configuration Window.

This will cause the new values to be written to the detector configuration file for use on all subsequent calculations. Similarly, [CLICK]ing the CLOSE button will cause any changes to be discarded. In either case, the Detector Configuration Screen will close and control will divert back to the MCU-GRM application window.

\section{Start Routine Data Acquisition}

1. To start the MCU-GRM routine monitoring application, [CLICK] on the yellow START button on the MCU-GRM application window.

The program will switch to RUNNING mode, as evident from the change in state of the START button. In RUNNING mode, the program will continue to cycle through a continuous series of GM and NaI monitoring cycles. At the completion of each cycle, the new data point will be written to the graph and its associated digital display. Each new data point is also passed to the DCS. The program remains in the RUNNING state until the STOP action is requested by the user.

2. To stop the MCU-GRM routine monitoring application, [CLICK] on the yellow STOP button.

Control will divert back to the MCU-GRM application window.

\section{Start Background Count}

1. To start a background count, [CLICK] on the yellow COUNT BACKGROUND button on the MCU-GRM application window.

The Start Background Count Screen will appear. The Count Background option is only active when the MCU-GRM application is in the IDLE mode. 
WSRC-RP-2005-01902

Revision \#0

2. On the Start Background Count Screen, [CLICK] the OK button to start the background count.

The MCU-GRM application window will appear. The Next-Update field at the top of each graph will count down the time remaining for each detectors counting cycle. The background counting function can be interrupted if the user [CLICKS] the STOP button from the MCUGRM application window. As the background counting cycle is completed for each detector, the Background Complete screen will appear with the selected detector identifier and the physical count for the background counting cycle.

3. The user can accept the new background activity values by [CLICK]ing the OK button on the Background Complete Window.

The Background setting in the configuration file will be overwritten with the new data. The Background Complete Screen will close and control will divert back to the MCU-GRM application window. The new values are discarded if the user [CLICKS] the CANCEL button from the Background Complete screen. 
WSRC-RP-2005-01902

Revision \#0

\section{APPENDIX A - MCU-GRM MATERIAL \& EQUIPMENT LISTING}

\begin{tabular}{|c|l|l|}
\hline Qty & Manufacturer Part \# & Description \\
\hline 2 & Scionix 25BS25/2-E2-Am-X & Americium seeded NaI(TI) detector assembly \\
\hline 2 & Ludlum 133-6-1 & Geiger Mueller tubes \\
\hline 2 & Ortec 570 & Spectroscopy amplifiers \\
\hline 2 & Ortec 556 & High voltage power supplies \\
\hline 2 & Aware PMI30 & Radiation detection modules \\
\hline 1 & Ortec 4001A/4002D & Modular NIM bin and power supply \\
\hline 1 & CyberResearch N1C 12-2000C & Rack mounted computer \\
\hline 1 & CyberResearch OIX 1610 & Rack mounted keyboard \\
\hline 1 & National Inst NI-PCI-6602 & Pulse counter card, NI\# 777531-01 \\
\hline 2 & Ortec Trump-PCI-2K & Multi-Channel analyzer cards \\
\hline 1 & National Inst NI PCI-FBUS/2 & PCI based Foundation FieldBus card, NI\# 778573-01 \\
\hline 1 & National Inst CA-1000 & Configurable Connector Assembly Enclosure, NI\# 777664-01 \\
\hline 1 & National Inst CB-68LPR & Connection Block, NI\# 777145-02 \\
\hline 1 & National Inst SH68-68-D1 & Shielded 68 pin cable assembly, 1 meter long, NI\# 183432-01 \\
\hline 8 & National Inst Blank Panelette & Blank Panelette for CA-1000 NI\# 184483-01 \\
\hline 1 & National Inst BNC Panelette & BNC Panelette for CA-1000 NI\# 184737-01 \\
\hline 1 & National Inst CA-1000 hardware & CA-1000 Rack Mount Kit (1U), NI\# 777665-01 \\
\hline
\end{tabular}


WSRC-RP-2005-01902

Revision \#0

\section{APPENDIX B - CONFIGURATION FILE FORMAT}

The format for the Configuration File is shown below. At startup, the MCU-GRM software reads the detector configuration values from the configuration file (MCU_GRM_CONFIG.INI). DATA IN THIS FILE CAN ONLY BE CHANGED FROM THE DETECTOR CONFIGURATION WINDOW OR AFTER COMPLETION OF A BACKGROUND MEASUREMENT.

$\begin{array}{ll}\text { [NaI1] } & \text { Section Header } \\ \text { Eff: } & \text { NaI1 Detector Efficiency. } \\ \text { Eff Date: } & \text { Date that the NaI1 detector efficiency setting was last changed. } \\ \text { Bckgnd: } & \text { Measured Background value for detector NaI1. } \\ \text { Bckgnd Date: } & \text { Date that the NaI1 measured background setting was last changed. } \\ \text { Bckgnd Count Time: } & \text { Duration of time (seconds) for NaI1 background counting. } \\ \text { [NaI2] } & \text { Section Header } \\ \text { Eff: } & \text { NaI2 Detector Efficiency. } \\ \text { Eff Date: } & \text { Date that the NaI2 detector efficiency setting was last changed. } \\ \text { Bckgnd: } & \text { Measured Background value for detector NaI2. } \\ \text { Bckgnd Date: } & \text { Date that the NaI2 measured background setting was last changed. } \\ \text { Bckgnd Count Time: } & \text { Duration of time (seconds) for NaI2 background counting. } \\ \text { [GM1] } & \text { Section Header } \\ \text { Eff: } & \text { GM1 Detector Efficiency. } \\ \text { Eff Date: } & \text { Date that the GM1 detector efficiency setting was last changed. } \\ \text { Bckgnd: } & \text { Measured Background value for detector GM1. } \\ \text { Bckgnd Date: } & \text { Date that the GM1 measured background setting was last changed. } \\ \text { Bckgnd Count Time: } & \text { Duration of time (seconds) for GM1 background counting. } \\ \text { [GM2] } & \text { Section Header } \\ \text { Eff: } & \text { GM2 Detector Efficiency. } \\ \text { Eff Date: } & \text { Date that the GM2 detector efficiency setting was last changed. } \\ \text { Bckgnd: } & \text { Measured Background value for detector GM2. } \\ \text { Bckgnd Date: } & \text { Date that the GM2 measured background setting was last changed. } \\ \text { Bckgnd Count Time: } & \text { Duration of time (seconds) for GM2 background counting. } \\ \text { [Cycle Times] } & \text { Section Header } \\ \text { NaI Cycle Time: } & \text { Duration of time (seconds) for NaI normal measurement cycle. } \\ \text { GM Cycle Time: } & \text { Duration of time (seconds) for GM normal measurement cycle. } \\ & \end{array}$


WSRC-RP-2005-01902

Revision \#0

\section{APPENDIX C - ERROR RECOVERY PROCEDURES}

\section{Am Peak Channel Adjustment}

1. Note the NaI detector to be calibrated from the MCU-GRM application window.

2. Start the Maestro program and collect a spectrum. Collection time should be long enough to determine where the Cs and Am peaks are located. (To start the Maestro program Double-Click the Maestro Icon on the desktop or go to C:IProgram Files\Maestro\Mca32.exe).

3. Right click on the Am peak and select "Peak Info" from the pop up menu.

4. Note the channel number of the Am peak centroid.

5. Adjust the detector HV supply or the Amplifier gain to bring the Am peak centroid back to the approximate center of the Am peak ROI.

6. Close Maestro.

7. Select the appropriate NaI detector from the MCU-GRM software main screen.

8. Click the START button and let the program go through one acquisition cycle. Verify that the error has cleared. 


\section{APPENDIX D - NAI AND GM DATALOG FILE FORMAT}

The format for the DataLog files for both the NaI and GM detectors is shown in Tables D-1 and D-2 below. At the end of each analysis cycle, the new data stream is appended to the end of the appropriate file for each detector. A new file is created at the beginning of each month to keep the log file to a manageable size. The month and year are embedded within each file name as shown in each table below. ( $\mathrm{mm}$ is the 2 digit month and yyyy is the 4 digit year for the month in which the file was first created.)

\section{Table D-1 -DataLog File Format (C:IMCU_GRM NaI Data_mmyyyy.txt)}

[Date/Time]
Date/Time String
[Live Time]
Live Time:
[True Time]
True Time:
[Cs Data]
Cs Peak Channel:
Cs Net Counts:
[Am Data]
Am Peak Channel:
Am Net Counts:
[Concentration (Ci/gal)]
Concentration:

[NaI Detector] Detector Selected: [Background] Measured Background: [Efficiency] Detector Efficiency: End of Data Marker: (Repeat Data for each loop)

\author{
Section Header \\ Date and time that analysis was completed \\ Section Header \\ The live time setting for each iteration. (The number of $20 \mathrm{msec}$ intervals) \\ Section Header \\ The true time elapsed for the iteration, as read from the Trump Card. (The \\ number of 20 msec intervals) \\ Section Header \\ The channel number of the Cs photo-peak centroid. \\ The net Counts in the Cesium photopeak. \\ Section Header \\ The channel number of the Am photo-peak centroid. \\ The net Counts in the Americium photopeak. \\ Section Header \\ The Cs-137 concentration calculated using the measured background and \\ detector efficiency settings. \\ Section Header \\ The detector used in the analysis \#1-NaI1, \#2-NaI2 \\ Section Header \\ Measured background data as set in the Configuration Utility. \\ Section Header \\ Efficiency data as set in the Configuration Utility. \\ $(* * * * * * * * * * * * * * * * * *)$ A flag to signal the end of data for the current analysis.
}

\section{Table D-2 -DataLog File Format (C:IMCU_GRM GM Data_mmyyyy.txt)}

\section{[Date/Time] \\ Date/Time String \\ [Cycle Time] \\ Cycle Time: \\ [Activity (Ci/gal)] \\ Activity:}

[GM Detector] Detector Selected:

[Background]

Measured Background:

[Efficiency]

Detector Efficiency:

End of Data Marker:

(Repeat Data for each loop)
Section Header

Date and time that analysis was completed

Section Header

The acquisition time setting for each iteration.

Section Header

The calculated activity using the measured background and detector efficiency settings.

Section Header

The detector used in the analysis \#1-GM1, \#2-GM2

Section Header

Measured background data as set in the Configuration Utility.

Section Header

Efficiency data as set in the Configuration Utility.

$(* * * * * * * * * * * * * * * * * *)$ A flag to signal the end of data for the current analysis. 
WSRC-RP-2005-01902

Revision \#0

\section{APPENDIX E - MANUFACTURER'S LITERATURE}

\begin{tabular}{|c|c|c|}
\hline Manufacturer Part \# & Description & Revision \\
\hline Scionix 25BS25/2-E2-Am-X & Specifications and Technical Data Sheets & $1 / 4 / 2005$ \\
\hline Ludlum 133-8-1 & Instruction Manual & 9/30/2003 \\
\hline Ortec 570 & Spectroscopy Amplifier Operating and Service Manual & Rev E, \\
\hline Ortec 556 & Model 556 High Voltage Power Supply Operating and Service Manual & Rev H \\
\hline Aware PMI30 & $\begin{array}{l}\text { PMI-30 Pre-Amp - Amp High Voltage Computer Interface User } \\
\text { Manual }\end{array}$ & N/A \\
\hline Ortec $4001 \mathrm{~A} / 4002 \mathrm{D}$ & $\begin{array}{l}\text { 1. Model 4001A Modular System Bin Operating and Service Manual } \\
\text { 2. Model 4002D NIM Bin Power Supply Operating and Service } \\
\text { Manual }\end{array}$ & $\begin{array}{l}\text { Rev D } \\
\text { Rev J }\end{array}$ \\
\hline CyberResearch N1C 12-2000C & $\begin{array}{ll}\text { 1. } & \text { SUPER P4SPA+ SUPER P4SPE User’s Manual } \\
\text { 2. } & \text { CyberResearch N1C-12-200C Detailed Specification } \\
\text { 3. } & \text { MXSK CEL-2000 Motherboard Detailed Specification } \\
\end{array}$ & $\begin{array}{l}\text { Rev 1.1a } \\
\text { N/A } \\
\text { N/A }\end{array}$ \\
\hline CyberResearch OIX 1610 & CyberResearch OIX 1610 Rack-Mount Keyboard Detailed Specification & N/A \\
\hline National Inst. NI-PCI-6602 & 6601 / 6602 User Manual & $1 / 99$ \\
\hline Ortec Trump-PCI-2K & $\begin{array}{l}\text { TRUMP-PCI-8K TRUMP PCI-2K Multichannel Buffer Card Hardware } \\
\text { Manual }\end{array}$ & Rev E \\
\hline National Inst. NI PCI-FBUS/2 & $\begin{array}{ll}\text { 1. } & \text { Getting Started with Your PCI-FBUS and the NI-FBUS Software } \\
\text { 2. } & \text { NI-FBUS Communications Manager User Manual } \\
\text { 3. NI-FBUS Communications Manager Function Reference Manual } \\
\text { 4. } & \text { Foundation FieldBus Overview } \\
\text { 5. } & \text { Foundation FieldBus Hardware and NI-FBUS Software for } \\
& \text { Windows 2000/XP }\end{array}$ & $\begin{array}{l}5 / 2003 \\
2 / 2004 \\
5 / 2003 \\
5 / 2003 \\
5 / 2003\end{array}$ \\
\hline National Inst. CA-1000 & CA-1000 Configurable Connector Accessory Enclosure & $12 / 2000$ \\
\hline National Inst. CB-68LPR & SCB-68 68 Pin Connector Block User Manual & $12 / 2002$ \\
\hline
\end{tabular}


WSRC-RP-2005-01902

Revision \#0

\section{APPENDIX E. CALIBRATION CERTIFICATES FOR CS-137} STANDARDS 


\title{
Certificate of Calibration
}

\section{Standard Radionuclide Source}

\author{
$68709-147$ \\ Cs-137 Solid in 2 Inch Schedule 40 Pipe
}

This standard radionuclide source was prepared gravimetrically from a calibrated master solution. The master solution was calibrated in an ionization chamber that was calibrated by the National physical Laboratory, Teddington, U.K., and is directly traceable to national standards.

Radionuclide purity and calibration were checked using a germanium gamma spectrometer system. The nuclear decay rate and assay date for this source are given below.

ANALYTICS maintains traceability to the National Institute of Standards and Technology through Measurements Assurance Programs as described in USNRC Reg. Guide 4.15, Revision 1.

U.S. Patent 4,430,258; U.K. Patent GB2,149,194B; CA. Patent $1,196,776$. Density of solid matrix $1.15 \mathrm{~g} / \mathrm{cc}$.

ISOTOPE :

ACTIVITY (dps):

HALF - LIFE :

CALIBRATION DATE:

RELATIVE EXPANDED

UNCERTAINTY $(k=2)$ :
Cs -137

1.889 E7

3.007 El years

July 14, 2004 12:00 EST

$3.3 \%$

Impurities: $\quad \gamma$-impurities $<0.1 \%$

P O NUMBER AC37844G, Item 1

SOURCE PREPARED

BY :

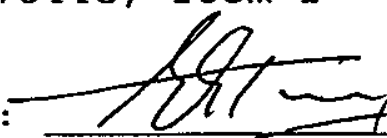

M. Taskaeva, Radiochemist

Q A APPROVED:

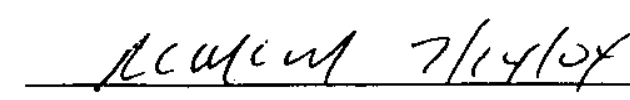

$$
404-352-287
$$




\title{
Certificate of Calibration Standard Radionuclide Source
}

\author{
$70803-147$
}

Cs-137 Solid in 2 Inch Long $x 1$ Inch Diameter Schedule 40 Pipe This standard radionuclide source was prepared gravimetrically from a calibrated master solution. The master solution was calibrated with an ionization chamber that was calibrated by the National Physical Laboratory, Teddington, U.K., and is directly traceable to national standards.

Radionuclide purity and calibration were checked with a germanium gamma spectrometer system. The nuclear decay rate and assay date for this source are given below.

ANALYTICS maintains traceability to the National Institute of Standards and Technology through Measurements Assurance Programs as described in USNRC Reg. Guide 4.15, Revision 1.

U.S. Patent 4,430,258; U.K. Patent GB2,149,194B; CA. Patent $1,196,776$. Density of solid matrix $1.15 \mathrm{~g} / \mathrm{cc}$.

$\begin{array}{ll}\text { ISOTOPE: } & \text { Cs-137 } \\ \text { ACTIVITY (dps): } & 8.377 \text { E6 } \\ \text { HALF-LIFE: } & 3.007 \text { E1 years } \\ \text { CALIBRATION DATE: } & \text { June 24, 2005 12:00 EST } \\ \begin{array}{l}\text { RELATIVE EXPANDED } \\ \text { UNCERTAINTY (k=2): }\end{array} & 3.3 \%\end{array}$

Impurities: $\quad \gamma$-impurities $<0.1 \%$

$28 \mathrm{~mL}$ solid in customer supplied pipe.

P O NUMBER AC43806G, Item 1

SOURCE PREPARED BY: NTasxaeva

M. Taskaeva, Radiochemist

Q A APPROVED:

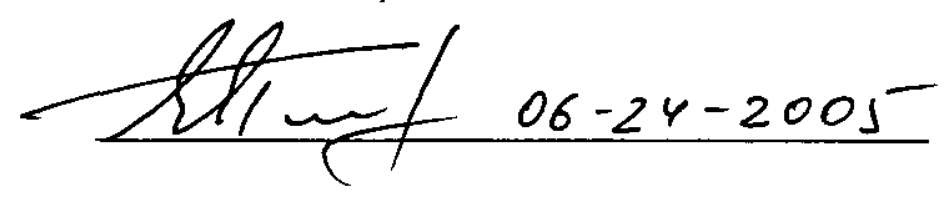




\title{
Certificate of Calibration Standard Radionuclide Source
}

\author{
$70804-147$
}

Cs-137 Solid in 4 Inch Long $x \quad 0.5$ Inch Diameter Schedule 40 Pipe

This standard radionuclide source was prepared gravimetrically from a calibrated master solution. The master solution was calibrated with an ionization chamber that was calibrated by the National Physical Laboratory, Teddington, U.K., and is directly traceable to national standards.

Radionuclide purity and calibration were checked with a germanium gamma spectrometer system. The nuclear decay rate and assay date for this source are given below.

ANALYTICS maintains traceability to the National Institute of Standards and Technology through Measurements Assurance Programs as described in USNRC Reg. Guide 4.15, Revision 1.

U.S. Patent 4,430,258; U.K. Patent GB2,149,194B; CA. Patent $1,196,776$. Density of solid matrix $1.15 \mathrm{~g} / \mathrm{cC}$.

$\begin{array}{ll}\text { ISOTOPE: } & \text { Cs-137 } \\ \text { ACTIVITY (dps): } & 8.783 \mathrm{E6} \\ \text { HALF-LIFE: } & 3.007 \text { E1 years } \\ \text { CALIBRATION DATE : } & \text { June 24, 2005 12:00 EST } \\ \begin{array}{l}\text { RELATIVE EXPANDED } \\ \text { UNCERTAINTY (k=2): }\end{array} & 3.38\end{array}$

Impurities: $\quad \gamma$-impurities $<0.1 \%$

$20 \mathrm{~mL}$ solid in customer supplied pipe.

P O.NUMBER AC43806G, Item 2

SOURCE PRERARED BY: $\frac{\text { lltasyaeva }}{M \text { Taskaeva Radiochemist }}$

Q A APPROVED:

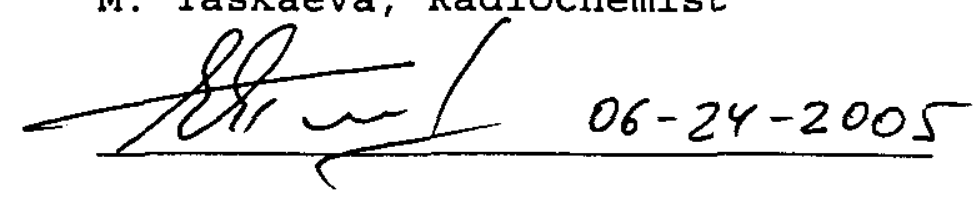




\section{Certificate of Calibration Standard Radionuclide Source}

70805-147

Cs-137 Solid in 4 Inch Long $x \quad 0.5$ Inch Diameter Schedule 40 Pipe

This standard radionuclide source was prepared gravimetrically from a calibrated master solution. The master solution was calibrated with an ionization chamber that was calibrated by the National Physical Laboratory, Teddington, U.K., and is directly traceable to national standards.

Radionuclide purity and calibration were checked with a germanium gamma spectrometer system. The nuclear decay rate and assay date for this source are given below.

ANALYTICS maintains traceability to the National Institute of Standards and Technology through Measurements Assurance Programs as described in USNRC Reg. Guide 4.15, Revision 1.

U.S. Patent 4,430,258; U.K. Patent GB2,149,194B; CA. Patent $1,196,776$. Density of solid matrix $1.15 \mathrm{~g} / \mathrm{CC}$.
ISOTOPE :
Cs -137
ACTIVITY (dps) :
4.375 E6
HALF-LIFE :
3.007 E1 years
CALIBRATION DATE:
June 24, 2005 12:00 EST
RELATIVE EXPANDED
UNCERTAINTY $(\mathrm{k}=2)$ :
$3.3 \%$

Impurities: $\quad \gamma$-impurities $<0.1 \%$

$20 \mathrm{~mL}$ solid in customer supplied pipe.

P O NUMBER AC43806G, Item 3

SOURCE PREPARED BY: Cltarkaeva

M. Taskaeva, Radiochemist

Q A APPROVED:

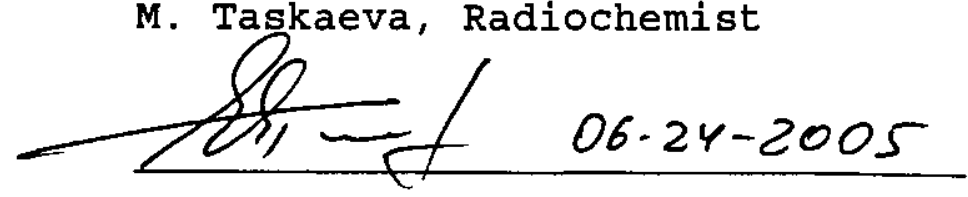

